Illinois State University

ISU ReD: Research and eData

Theses and Dissertations

4-27-2021

\title{
Assessing the Impact of Regional Climate on the Sudd Wetland
}

Geno Salvatore Persico

Illinois State University, gpersic@ilstu.edu

Follow this and additional works at: https://ir.library.illinoisstate.edu/etd

\section{Recommended Citation}

Persico, Geno Salvatore, "Assessing the Impact of Regional Climate on the Sudd Wetland" (2021). Theses and Dissertations. 1462.

https://ir.library.illinoisstate.edu/etd/1462

This Thesis is brought to you for free and open access by ISU ReD: Research and eData. It has been accepted for inclusion in Theses and Dissertations by an authorized administrator of ISU ReD: Research and eData. For more information, please contact ISUReD@ilstu.edu. 


\section{ASSESSING THE IMPACT OF REGIONAL CLIMATE ON THE SUDD WETLAND}

\section{GENO SALVATORE PERSICO}

\section{Pages}

The Sudd is the largest wetland system in Africa and one of the largest tropical wetlands in the world. Climate and human impact in this region potentially affect the influx to the Sudd and the wetland. The objective of this project was to understand the impact climate could have on the Sudd Wetland. Climate data, temperature and rainfall, were analyzed from regions upstream from the Sudd to observe how the wetland responds to variation in the climate. The Normalized Difference Vegetation Index (NDVI) data was used to project the changes in vegetation of the wetland to see its response to upstream influence by climate parameters. Spatial and temporal trends show increasing trends in rainfall and temperature that were compared with NDVI data to assess the impact climate has on the Sudd. When focusing on drought-like conditions, it is apparent the Sudd responds to changes in its freshwater supplies. Conclusive evidence from this paper could be used to assess water policy and management in the region while protecting key parts of the hydrologic cycle.

KEYWORDS: GIS, remote sensing, climate, hydrologic cycle 
GENO SALVATORE PERSICO

A Thesis Submitted in Partial Fulfillment of the Requirements for the Degree of

MASTER OF SCIENCE

Department of Geography, Geology, and the Environment

ILLINOIS STATE UNIVERSITY 
(C) 2021 Geno Salvatore Persico 
ASSESSING THE IMPACT OF REGIONAL CLIMATE ON THE SUDD WETLAND

GENO SALVATORE PERSICO

COMMITTEE MEMBERS:

Wondwosen Seyoum, Chair

Eric Peterson

Dagmar Budikova 


\section{ACKNOWLEDGMENTS}

I would like to express extensive amounts of gratitude and praise to my committee members. To Dr. Wondwosen Seyoum, thank you for serving as my thesis chair. The insurmountable amount of work you helped me through when formalizing and working through my thesis helps emulates the patience, enthusiasm, and passion you show towards myself, other students and colleagues, and towards the field of science. Dr. Seyoum truly made this project and my experience here at ISU memorable and I could not thank him enough for knowledge and skill sets I have acquired through him. To Dr. Dagmar Budikova, thank you for serving as a member on my committee and for your expertise in the field of climatology! Your knowledge and helpful wisdom of this field allowed me to mold and shape my thesis into what it is today. To Dr.

Peterson, thank you for serving as my final member of my committee chair! Thank you for your consistent guidance and insight to my thesis and my entire curriculum these past two years here at ISU! You are the backbone of the Hydrogeology department and always assisted me throughout this process! Thank you to all my thesis committee members!

To the rest of the Illinois State University's Department of Geography, Geology, and the Environment, thank you for your unending support and motivation to pursue and complete my thesis! Dr. Catherine O’Reilly, thank you for your guidance and passion of teaching GEO 410; your course helped build the foundations for this project!

Thank you to my cohort, especially Ethan Conley and Eli Schukow! Your consistent motivation and words of encouragement helped push through some of the tougher aspects of this process. To Giavanna Desai, thank you for being my rock! I always had you here to give me strength, positivity, and support as I progressed through graduate school. Finally, thank you to my family! Being a first-generation graduate school student within my immediate family, I am 
happy to represent them with dignity, pride, and honor as one chapter of my life comes to a close and a new one will begin.

G.S.P 


\section{CONTENTS}

Page

ACKNOWLEDGMENTS

TABLES Di

FIGURES vii

CHAPTER I: INTRODUCTION 1

CHAPTER II: HYPOTHESES \& QUESTIONS 8

CHAPTER III: STUDY AREA 99

$\begin{array}{ll}\text { The Bahr al-Jabal sub-basin (BAJs) } & 12\end{array}$

Lake Albert and Lake Kyoga sub-basin (LALKs) 13

Lake Victoria sub-basin (LVs) 13

CHAPTER IV: DATA \& METHODOLOGY 15

$\begin{array}{ll}\text { Data } & 15\end{array}$

$\begin{array}{ll}\text { Temperature } & 17\end{array}$

Rainfall 17

$\begin{array}{ll}\text { Vegetation } & 18\end{array}$

Surface Water Height and Surface Area of Open Water Bodies 19

$\begin{array}{ll}\text { Methodology } & 19\end{array}$

Seasonal and Long-term Trend Analysis $\quad 21$

$\begin{array}{ll}\text { Data Processing and Analysis } & 22\end{array}$

$\begin{array}{ll}\text { Correlation and Interpretation } & 23\end{array}$

CHAPTER V: RESULTS 24

$\begin{array}{ll}\text { Climate } & 24\end{array}$ 
$\begin{array}{ll}\text { Temperature } & 24\end{array}$

$\begin{array}{ll}\text { Bahr al-Jabal sub-basin } & 26\end{array}$

Lake Albert and Lake Kyoga sub-basin 28

Lake Victoria sub-basin 31

Spatial Temperature Trend Analysis $\quad 34$

$\begin{array}{ll}\text { Rainfall } & 39\end{array}$

$\begin{array}{ll}\text { Bahr al-Jabal sub-basin } & 40\end{array}$

Lake Albert and Lake Kyoga sub-basin 43

Lake Victoria sub-basin $\quad 46$

Spatial Rainfall Trend Analysis $\quad 49$

$\begin{array}{ll}\text { Sudd Wetland } & 54\end{array}$

The Normalized Difference Vegetation Index (NDVI) 54

Spatial NDVI Trend Analysis $\quad 59$

Water Level/Surface Area of Water Bodies $\quad 64$

CHAPTER VI: DISCUSSION

$\begin{array}{ll}\text { Climate } & 68\end{array}$

Sudd Wetland in Relation to Climate $\quad 72$

Interannual Variability (fluctuations) of the Climate $\quad 75$

$\begin{array}{ll}\text { CHAPTER VII: CONCLUSION } & 77\end{array}$

$\begin{array}{ll}\text { WORKS CITED } & 81\end{array}$

APPENDIX A: RAINFALL GRAPHS 86

$\begin{array}{ll}\text { APPENDIX B: NDWI DATA } & 87\end{array}$

APPENDIX C: NDVI P-VALUE DATA 88 


\section{TABLES}

Table

Page

1. Data table highlighting the main hydroclimate variables that are used in this study 


\section{FIGURES}

Figure

1. (Left) The location of the upper White Nile River basin, showing the subbasins and the Sudd Wetland. (Right) Satellite image of East Africa depicting the study area found within boxed area (ESRI, ArcGIS)

2. Conceptual model of a wetland system portraying the high and low extents of a wetland depending on climatic and season trends

3. Topographic profile of the studied region- part of the upper White Nile River basin starting at the headwaters in Lake Victoria and flowing into the Sudd Wetland

4. Climate map of Africa with the study area outlined in the purple box

5. Flow chart displaying the methodology of this project

6. (a) Map showing average temperature from 1983-2016, (b) Mean annual, (c) Mean monthly, and (d) Seasonal mean temperature data for all three subbasins. JF (January, February) (blue), MAM (March, April, May) (orange), JJAS (June, July, August, September) (grey), and OND (October, November, December) (yellow) are the seasons

7. Long-term mean monthly (top - bar graph), monthly temperature (center - heat map), and mean annual temperature (left side - scatter plot) for the Bahr al-Jabal subbasin. In the heat map, the bright yellow color indicates lower temperatures while the bright purple/violet color indicates higher temperatures recorded

8. Mean seasonal temperature variations in the Bahr al-Jabal subbasin: (a) JF, (b) MAM, (c) JJAS, and (d) OND 
9. Long-term mean monthly (top - bar graph), monthly temperature (center - heat map), and mean annual temperature (left side - scatter plot) for the LALK subbasin. In the heat map, the bright yellow color indicates lower temperatures while the bright purple/violet color indicates higher temperatures recorded

10. Mean seasonal variation in temperature for the LALKs

11. Long-term mean monthly (top - bar graph), monthly temperature (center - heat map), and mean annual temperature (left side - scatter plot) for the LV subbasin. In the heat map, the bright yellow color indicates lower temperatures while the bright purple/violet color indicates higher temperatures recorded

13. (a) Map of the entire study region showing the annual Sen's slope of the CHIRTS data. (b) Is the annual p-value map showing the areas and data that are significant. (c-f) Are the four seasonal Sen's slope maps. The Sudd is outlined in black located at the top (north) of the maps. Monthly Sen's slope and P-value maps are found in Figure 1-E

14. (a) A map that illustrates the average total annual rainfall distribution from the 39-year data span for the study area. (b) Shows the long-term mean monthly rainfall measurements. (c) A box-n-whisker graph showing average seasonal rainfall within each sub-basin

15. (Center) The heat map showing temporal variation of the average rainfall during each month of the 39 years of data, long-term mean monthly rainfall (top), and total annual rainfall (left side) for the BAJs

16. Graphs showing the total seasonal variation in rainfall (JF: January, February; MAM: March, April, May; JJAS: June, July, August, September; OND: October, November, December) in each subbasins 
17. (Center) The heat map showing temporal variation of the average rainfall during each month of the 39 years of data, long-term mean monthly rainfall (top), and total annual rainfall (left side) for the LALKs

18. Graphs showing the total seasonal variation in rainfall (JF: January, February; MAM: March, April, May; JJAS: June, July, August, September; OND: October, November, December) in each subbasins

19. (Center) The heat map showing temporal variation of the average rainfall during each month of the 39 years of data, long-term mean monthly rainfall (top), and total annual rainfall (left side) for the LVs

20. Graphs showing the total seasonal variation in rainfall (JF: January, February; MAM: March, April, May; JJAS: June, July, August, September; OND: October, November, December) in each subbasins

21. (a) Map of the entire study region showing the annual Sen's slope of the CHIRPS data. (b) Is the annual P-value map showing the areas and data that are significant. (c-f) Are the four seasonal Sen's slope maps. The Sudd is outlined in black located at the top (north) of the maps. Monthly Sen's slope and P-value maps are found in Figure D-2

22. Heat map generated combining the AVHRR and MODIS data to create a complete dataset showing annual, monthly, and season variation of NDVI

23. Mean monthly NDVI for the Sudd Wetland from 1981-2019

24. Minimum (a) and maximum (b) NDVI recorded in the year from 1981-2019

25. (a-d) Seasonal graphs created to show the change of the NDVI within the four seasons 
26. (a and c) are the monthly Sen's slopes for AVHRR and MODIS and their respected P-Values (b and d). (e-h) show seasonal Sen's slope for NDVI data plotted on the Bahr al-Jabal sub-basin that was recorded by the AVHRR sensor from 1981-2000. (i-1) are seasonal Sen's slope for NDVI in the Bahr al-Jabal taken from the MODIS sensor that mapped from 2000-2020

27. (a) Total surface water area of water bodies in the Sudd Wetland extracted from various Landsat satellites. (b) Lake Albert water height that was collected from ESA's Copernicus climate program. (c and d) Lake level data for Lake Kyoga and Lake Victoria plotted based on distance above sea level (in meters) from 1992-2020. Data was gathered from various satellite missions of TOPEX/Poseidon and Jason's 1-3

28. (a) Cross-correlation between NDVI and rainfall in each of the three sub-basins. (b-d) are the graphs representing the highest correlation for each sub-basin's monthly average rainfall plotted against the Sudd's monthly NDVI data 


\section{CHAPTER I: INTRODUCTION}

The hydrologic cycle is the most important system that supports both natural and anthropogenic biomes on planet Earth. The conveyor belt-like water system is in constant motion interacting in Earth's atmosphere, surface, and subsurface transitioning between solid, liquid, and gaseous states. Both climate and humans are potentially disrupting the very process that supports every system on Earth. Today's society is facing its biggest threat, climate change. If climate change continues at the rate it is occurring, every natural and anthropogenic system will be affected. The results of this would challenge mankind with rising sea levels, increased precipitation, high temperatures, poor air quality, damaged food supplies, diseases, and many other possibilities (NASA, 2020). The current condition of the climate is in a warming period following the most recent ice age. Due to increased populations, expanding urbanization, deforestation, and industrialization, the average temperature on Earth has seen a dramatic rise that has not occurred before in history. Two main constituents used as indicators for climate change are temperature and precipitation. With the rapid increase of carbon emissions into the atmosphere, precipitation and temperature are both being drastically impacted on affecting every region around the world (Parmesan and Yohe, 2003).

Climate change impacts the hydrologic cycle by causing a decrease in glacier masses throughout all latitudes on Earth, increase precipitation in wet regions, which increases flooding, desert regions become hotter, and colder regions will begin to warm (NASA, 2020). Humans impact the hydrologic cycle through irrigation for economic and agricultural needs, contamination of water systems, urbanization, and unbalancing the natural movement of water between lakes, tributaries, rivers, and oceans. As a result, surface water bodies, such as lakes and 
wetlands, are shrinking and disappearing (e.g., Aral Sea, Rift Valley Lakes) (Seyoum, 2015), winter ice cover of lakes is declining (Sharma, et al. 2019), and discharges of rivers are significantly fluctuating (Barnett and Pierce, 2009). Understanding and assessing the change in Earth's hydrologic systems over the span of decades allows for better management of natural and human-based systems in an ever-changing climate. Climate change is affecting major systems in the hydrologic cycle. Work done by Mortsch et al., (2000) and Angel and Kunkel, (2010) show that the net Great Lake basin supplies are drastically changing based on seasonal variation, which in turn affects outflows from the region. Gosain et al., (2006) conducted research on Indian river basins and their response to climate change. They stated that climate change is going to severely impact the developing world due to their little-to-no capacity to adapt to climate variability.

Systems such as wetlands develop a vast biodiversity of flora and fauna. Wetlands cover 4-6\% of Earth's surface and are home to a variety of aquatic and terrestrial animals (World Wildlife Fund, 2019). According to the U.S. Environmental Protection Agency (EPA), wetlands are areas where water covers the soil, or is present either at or near the surface of the soil, all year or for varying periods of time during the year, including during the growing season. Since the time that man acknowledged the existence of wetlands, they have been a source for draining water for agriculture/irrigation. This developed a huge strain on hydrologic systems associated with those wetlands. Anthropogenic processes also cause groundwater reservoirs to disappear as well as the ecosystem that thrive on it. The Everglades, located in the southern portion of Florida, is a wetland system that has been vastly altered by human intervention. U.S. Army Corps of Engineers built levees, canals, pumping stations, and water control structures in 
response to frequent flooding and hurricanes that caused harm to urban areas. The installation of water management systems split the Everglades, which reduced large amounts of water to flow throughout the entire wetland. This has consequently reduced the number of bird populations and a vast array of aquatic species in the Everglades (DeAngelis et al., 1998). In Ramsar, Iran in 1971, 18 nations signed a treaty for Wetlands of International Importance (Matthews, 1993). Not too long before this, the Environmental Protection Agency (EPA) formed in the United States in order to develop and coordinate programs to preserve and sustain the natural environment. Human concern for the natural world shifted focus. As of this year, the Ramsar Convention now has 170 nations contributing to the cause of preserving 2,323 wetlands, which cover around 2.1 million $\mathrm{km}^{2}$ (Matthews, 2019).

This study focuses on the Sudd Wetland, located in a semi-arid and tropical climate in East Africa, just north of the equator. The climate of East Africa is affected by seasonal changes in Hadley circulation, oscillating between a twice-per-year migration of the Intertropical Convergence Zone (ITCZ), El Nino Southern Oscillation (ENSO), and Indian Ocean Dipole (IOD) (Nguvava et al., 2019; Wolff et al., 2011). According to Johnson (2020), the IOD is a recently recognized phenomenon that has a strong impact on climate in East Africa. The shifting of the IOD and the ITCZ circulation throughout the year cause shifts in wind direction, which affect the monsoon systems. The climate in East Africa is located between the African monsoon to the west and the Indian Ocean monsoon to the east. The $20^{\text {th }}$ century saw an increase in temperature by about $0.5^{\circ} \mathrm{C}$ throughout Africa. The rainy months saw an increase in rainfall from 5-20\%; while the dry months saw a 5-10\% decrease in rainfall (Hulme et al., 2001). These direct measurements observed during the $20^{\text {th }}$ century showed the possible consequences of a changing 
climate (Serdeczny et al., 2017). A research article showed significant increasing trends in both maximum temperature $\left(1.9^{\circ} \mathrm{C}\right)$ and minimum temperature $\left(1.2^{\circ} \mathrm{C}\right)$ for the East African region from 1979-2010. The change in temperature varies by regions depending on the regional climate (Gebrechorkos et al. 2019). Regions that are relatively dry have seen an increase in temperature, while regions that are relatively wet have seen an increase in rainfall (Koetse and Rietveld, 2009). The climate in the Sudd region is characterized by two rainy seasons and two dry seasons. The dry seasons occur from January to February and October to December. The wet seasons occur from March to May and June to August. From April to November the wetland receives around $800-900 \mathrm{~mm}$ of rainfall. The average daytime temperature is from $30-33^{\circ} \mathrm{C}$ during the dry season and from $26-28^{\circ} \mathrm{C}$ during the rainy season. Humidity during the rainy season exceeds $80 \%$, while the humidity is below $50 \%$ during the dry season (Mohamed et al., 2005).

Despite being the largest wetland system in all of Africa, the Sudd is the least studied wetland in Africa. Due to lack of accessibility, regional conflicts, and economy, the region has not allowed for many in-situ data collection and research. Currently, the South Sudanese Civil War has been raging since 2013 forcing 4 million people to displace or flee the country. From the years of 1955 to 2005, the First and Second Sudanese Civil Wars raged (Council on Foreign Relations, 2019). The constant threat of civil war in a restless region of the world does not allow for scientific advancements. This has caused one of the largest and most dynamic wetlands systems to become dormant from any scientific research. The development and technological advances of remote sensing and the use of satellites have given scientists better opportunities to study places, like the Sudd, all around the world. 
The rapid development of technology and scientific innovations have allowed for scientists to have the ability to observe it from afar. Using satellites, climate data have been compiled over the decades to develop trends. Satellite remote sensing allows research to be conducted on regions in the world that are hard to access because of terrain or human conflicts. Several remote sensing satellites exist that measure the different components of the terrestrial water cycle. For example, TERRA satellite, which houses the Moderate Resolution Imaging Spectroradiometer (MODIS) instrument, provides land information such as vegetation, water, and land surface temperature (Thome, 2020). The Gravity Recovery and Climate Experiment (GRACE) measures terrestrial water storage. The Tropical Rainfall Measuring Mission (TRMM) measures tropical and subtropical rainfall using microwave and visible infrared sensors (Graham, 1999). The European Space Agency’s (ESA) ENVISAT measured sea surface temperature, temperature, water vapor, and earth radiation around the globe (ESA, 2020). European RemoteSensing Satellite (ESA-ERS-2), TOPEX/Poseidon, and Jason I and II measure water height such as sea level and lake level. Instruments such as spectrophotometers, multispectral bands, altimetry, and LiDAR allow scientist to approach studies in ways humans are not physically equipped to do (Hassan and Jin, 2014; Sosnowski et al., 2015). Using these satellites and others alike, studies can be conducted in order to the understand the trends of the regional climate (e.g., using data from TRMM) in the Sudd Wetlands (e.g., using data from MODIS) and understand the influence climate and human impact has on the wetland and upstream tributaries of the wetlands in order to assess the water management of the region and be able to predict water supplies in the future to possibly create policies. 
The main questions that arise with every hydrologic system on planet Earth: 1) what is causing the negative aspects of a water system (i.e., depleted, contaminated, or not usable)? 2) what can be done to fix these problems? In a time of major climate change, every system becomes imperative to sustain the environment and reduce human impacts on the environment, and it is also important to provide a greener environment for generations to come in order for them to continue where past generations left off. Even though this study is being conducted in East Africa, the methodologies and the problems are universal (as it could potentially relate to wetlands elsewhere). The problems this study is trying to convey are the indirect consequences humans can exert onto a changing climate. Climatological data, as well as information about the landcover and water extent, were collected and analyzed from the past three decades. The two sets of data were then compared and correlated in order to understand the status and changes in the Sudd Wetland. My overall hypothesis is that both anthropogenic factors and climate change impact the Sudd Wetland.

The purpose of this study was to understand not only the human-induced effects on the hydrologic cycle, but also to understand the climate over the past decades to determine the main factor that is affecting the Sudd Wetland in South Sudan in East Africa. Climate factors that impact East Africa are temperature and rainfall. This study focused on four decades worth of climate data to observe if there is a change in climate for this region. It was then compared to the surface area and water levels of the Sudd to calculate the climate's impact of the wetland. The hydrologic cycle in this region, as a result, is affected downstream with less discharge flowing into the wetlands. Exploring potential climate trends in the wetland's data allowed for correlation between the systems to be formulated. Understanding a changing environment will allow for new 
efficient policies, innovations in technology, protection of the natural world, and better data about the hydrologic system. 


\section{CHAPTER II: HYPOTHESES \& QUESTIONS}

The following research questions were addressed:

Q1: What are the annual, monthly, and seasonal variability and trends in rainfall and in temperature in the basin that constitutes the Sudd Wetland?

Hypothesis 1: With continue climate change, trends in the climate data are expected for the study site.

Q2: Is there a change in vegetation and surface water resources in the Sudd Wetland?

Hypothesis 2: Climate variability and trend influences the water and vegetation in the wetland.

Q3: If there is, what is the relationship between the trends observed from the vegetation and the change in regional climate?

Hypothesis 3: Surface water inflow from rainfall from basins upstream of the Sudd, which controlled by regional climate, sustain the Sudd Wetland's vegetation. 


\section{CHAPTER III: STUDY AREA}

The study area, Sudd Wetlands located in South Sudan, East Africa, was the focus of this project (Figures 1 and 2). The Sudd is found in the Nile River drainage basin, which extends from the northern borders of Tanzania, near Lake Victoria, to the mouth of the Nile River in Egypt where it flows into the Mediterranean Sea. The Sudd is also known as Bahr al Jabal, which translates to 'Sea of Mountain' in Arabic. The area of the Sudd Wetland ranges from $23,000 \mathrm{~km}^{2}$ (Rebelo, et al., 2016) to $40,000 \mathrm{~km}^{2}$ (Mohamed et al., 2006) varying due to seasonal variations.

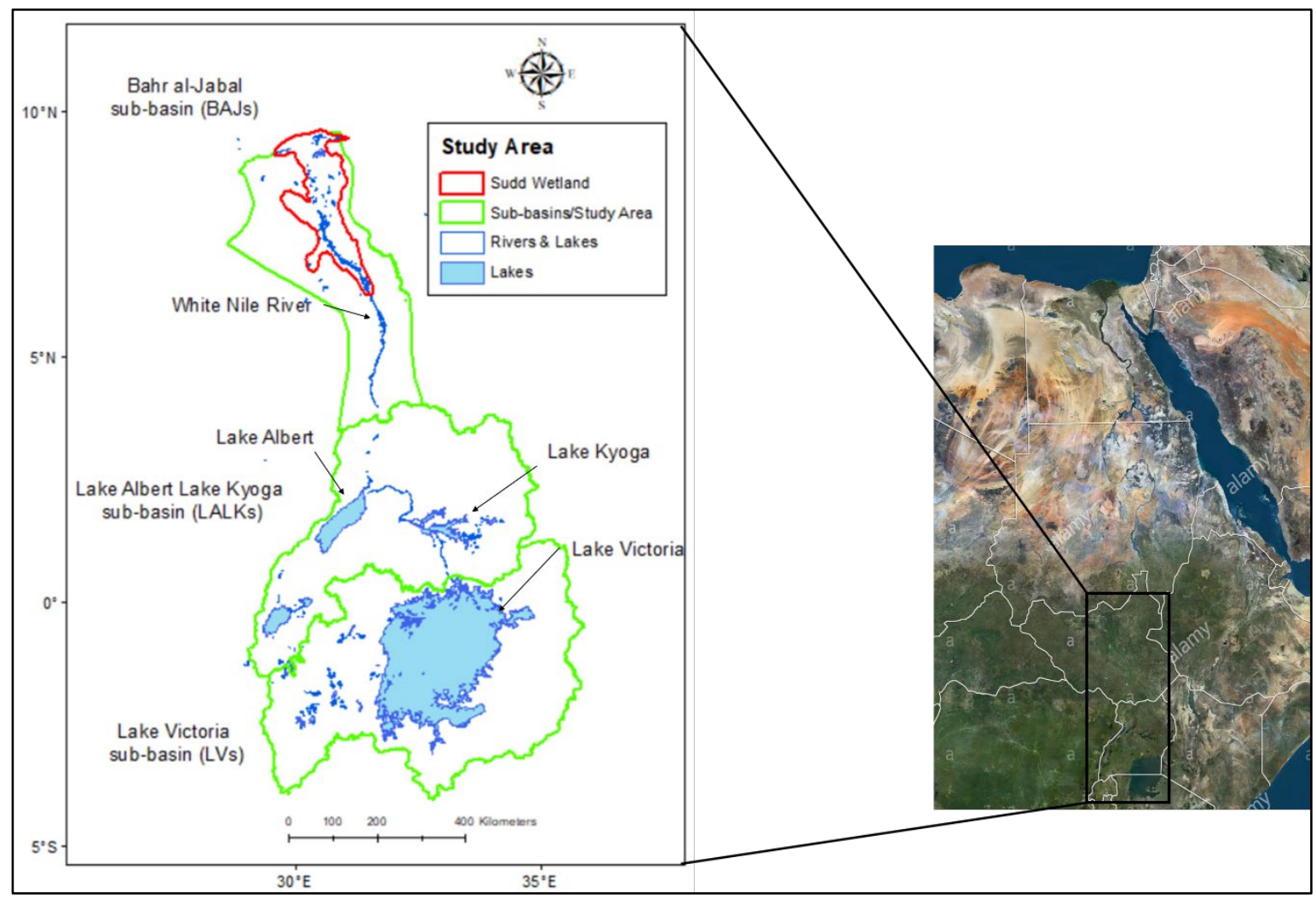

Figure 1. (Left) The location of the upper White Nile River basin, showing the subbasins and the

Sudd Wetland. (Right) Satellite image of East Africa depicting the study area found within boxed area (ESRI, ArcGIS). 
The Sudd is the largest wetland system in Africa and one of the largest tropical wetlands in the world. With it being the largest wetland, it draws the attention of inhabitants, foreign entrepreneurs, and scientists. The preservation of the Sudd gained attention when it was put on the Ramsar Convention on Wetlands of International Importance especially as Waterfowl Habitat. As described by Peterson (2008), the Sudd is dominated by:

1) Open water vegetation such as free-floating leaved plants and submerged plants. Macrophytes, aquatic plants are abundant in little-to-no flowing regions of the channels.

2) Permanent swamps, land that is flooded throughout the year, contain numerous plants and floating vegetation.

3) Seasonal river-flooded grasslands, occurring during rainy seasons, are usually saturated and covered by tall grasses. This is most prominent for grazing livestock and wildlife due to high protein counts of decomposed wild rice grass. Small pools from seasonal flooding allows for more areas for domestic livestock and wildlife as well as fish.

4) Rain-flooded grasslands, seasonal regions flooded by the river or rainfall, are areas that are well-drained by their clayey soils. Low permeability, to an already inundated area, causes sheet flow and a high-mass biomass but nutrient-rich zone.

5) Floodplain woodlands occur at higher altitudes than grassland plains. They are dominated by several species of trees, shrubs, and lust of grasses. A diagram of the different portions of a wetland is shown below in Figure 2. 


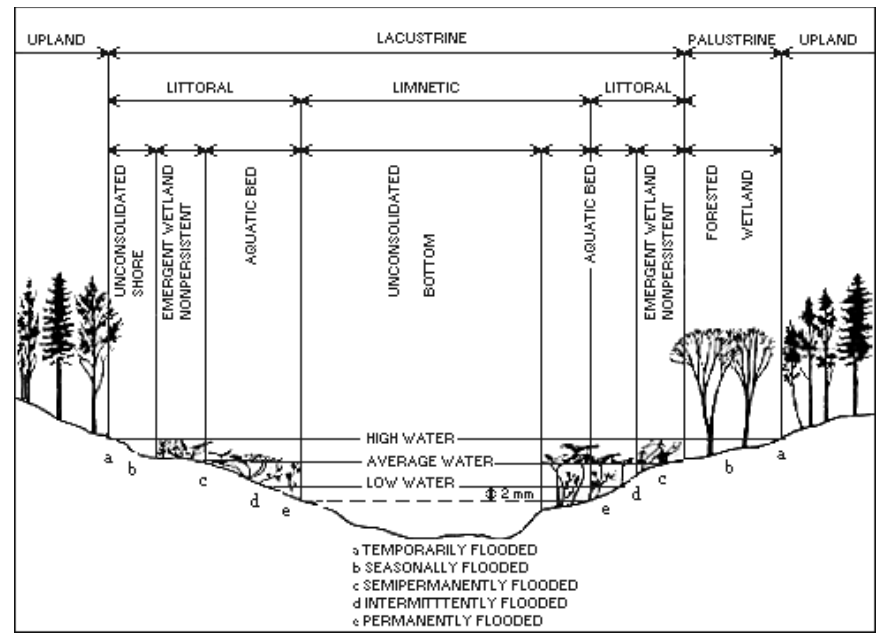

Figure 2. Conceptual model of a wetland system portraying the high and low extents of a wetland depending on climatic and season trends.

(https://www.fws.gov/wetlands/documents/classwet/lacustri.htm, access date March 3, 2021)

Three pastoral/agricultural-based indigenous groups occupy the Sudd regions: Dinka, Nuer, and Shilluk. The Sudd's tribe's economy is characterized by changes of the wetlands through droughts and floods. This impacts pastoralism (movement with herds), production of crops, and a supplement of wild meat and fish. Their way of life is adopted to economic and cultural demands in response to the hydrological cycle (Howell et al., 1988). The uniqueness of the Sudd's hydrologic processes as well as its biodiversity and aquatic systems shrouds the amount of knowledge that is still waiting to be learned from the wetlands.

The Sudd Wetland receives significant amount of surface inflow $\left(\sim 36 \mathrm{~km}^{3}\right)$ of water from Lake Victoria Basin via the White Nile, and approximately 55\% of this water is lost via evapotranspiration in the Sudd Wetland (Sutcliffe and Parks, 1999). Given very high temperature and evapotranspiration, this surface inflow is crucial to sustain the wetland. There are three main 
sub-basins of the White Nile basin that are connected (or contribute) to the Sudd Wetland: the Bahr al-Jabal sub-basin (BAJs), the Lake Albert and Lake Kyoga sub-basin (LAKs), and the Lake Victoria sub-basin (LVs).

\section{The Bahr al-Jabal sub-basin (BAJs)}

The BAJs constitutes the Sudd Wetland and is located in South Sudan, which sits in a semiarid climate region. As shown in Figure 3, its elevation above sea level is around 400m. The sub-basin's northern end is signified by the northern extent of the Sudd Wetland near the border of Sudan and South Sudan. The southern boundary is the border between South Sudan and Uganda, where the LALKs sub-basin begins. The western and easter extent of the BAJs are areas stretching farther than the wetland's extent. The White Nile River runs through the sub-basin and exits in the northeastern portion signifying an endpoint for the wetland. Based on drainage basin principles, areas outside of the Sudd that makeup the BAJs that receive rainfall will drain into the Sudd and river and allow for more accurate results when understanding the sub-basin's climate.

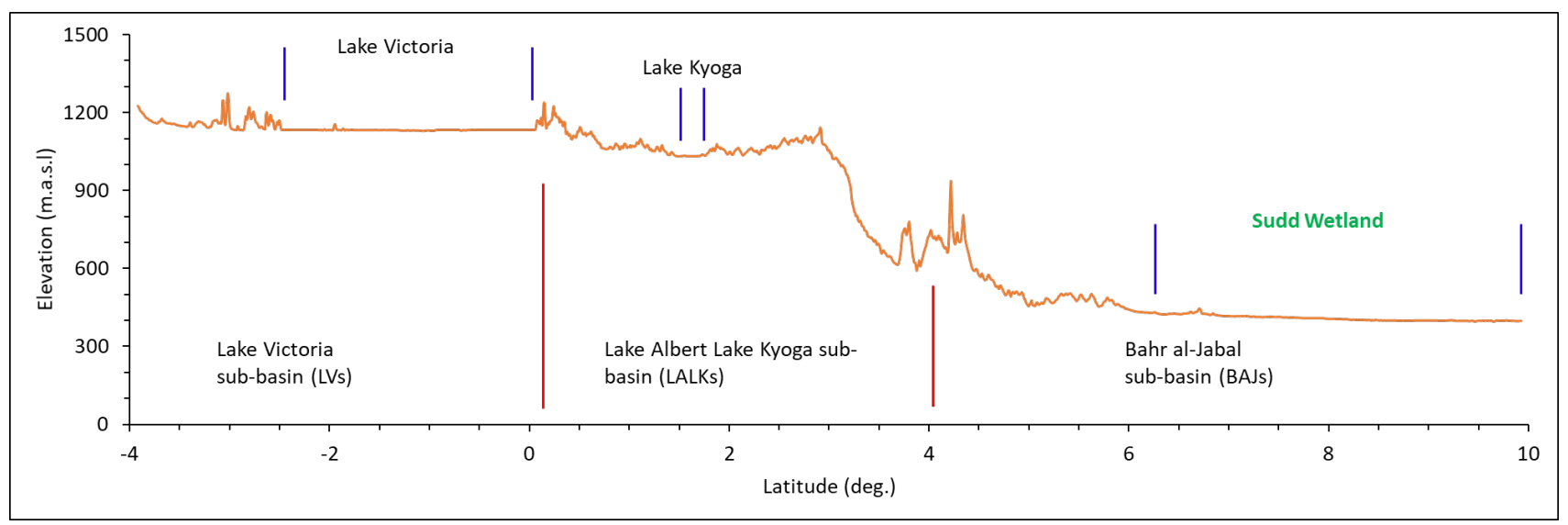

Figure 3. Topographic profile of the studied region- part of the upper White Nile River basin starting at the headwaters in Lake Victoria and flowing into the Sudd Wetland. 


\section{Lake Albert and Lake Kyoga sub-basin (LALKs)}

The Lake Albert Lake Kyoga sub-basin is located just north of the equator in a tropical region but near the fringe of a tropical and semi-arid climate boundary, shown in (Figure 4). It is the sub-basin located between the BAJs to the north and the LVs to the south occupying the western part of Kenya and most of Uganda. The White Nile River connects Lake Victoria with the two lakes located in this sub-basin, Lake Albert and Lake Kyoga. The White Nile River provides freshwater downstream to the Sudd, roughly $650 \mathrm{~km}$ away, from these two lakes. There is also a third lake located in LALKs, Lake Edward, but it is not directly linked to these lakes that are connected via the White Nile River, therefore not important in this study. LALKs sits at an elevation of around 1,100 meters above sea, (Figure 3).

\section{Lake Victoria sub-basin (LVs)}

The Lake Victoria sub-basin, located in Uganda, Kenya, and Tanzania, sits right on the equator making it a tropical region. The sub-basin is the southern-most sub-basin of the three and is located at elevations of around 1,200 meters above sea level as shown in Figure 3. LVs is home to the largest tropical lake and the second largest freshwater lake in the world that provides a constant supply of water to the hydrologic system of East Africa. Lake Victoria, along with Lake Albert and Lake Kyoga, provide water to the Sudd Wetland and the Nile River valley to allow ecosystems, wildlife, and human-based agriculture and urbanization to prosper (Williams et al., 2015). The regional climate of the sub-basins of Lake Albert, Kyoga, and Victoria (LAKA) are still affected by the larger systems that dictate the air and weather patterns over East Africa (Hadley cells circulating the ITCZ, the African and Indian monsoons, and elevation 
changes as described above). However, the main climate factors that vary between them and the Sudd is the elevation change that affects the amount of rainfall and temperature variation as shown in Figure 4. Because of this, the LAKA sub-basins are considered a tropical wet and dry region while the Sudd is considered semi-arid, as shown in Figure 4.

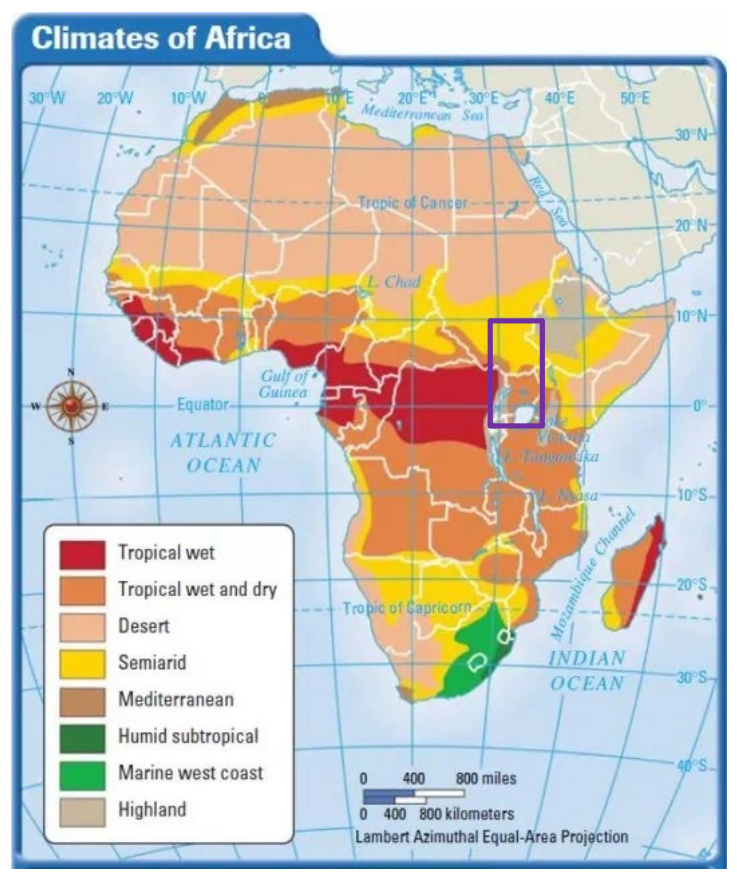

Figure 4. Climate map of Africa with the study area outlined in the purple box.

(https://geography.name/africa-climate-and-vegetation/, access date March 3, 2021) 


\section{CHAPTER IV: DATA \& METHODOLOGY}

\section{Data}

In this study, publicly available remote sensing and model-based data were used. The variables, data sources, and characteristics are summarized in Table 1.

Table 1. Data table highlighting the main hydroclimate variables that are used in this study. (NDVI=Normalized Difference Vegetation Index; MNDWI=Modified Normalized Difference Water Index)

\begin{tabular}{|c|c|c|c|c|c|c|}
\hline Hydrological & Satellite/ & Data & Tempor & Spatial & Locati & Source \\
\hline \multirow[t]{3}{*}{ Variable } & Datasets & Availability & al & Resolutio & on & \\
\hline & & & Resoluti & $\mathbf{n}$ & & \\
\hline & & & on & & & \\
\hline \multirow[t]{4}{*}{ Rainfall } & CHIRPS & $1981-2020$ & Monthly & $0.05^{\circ} \times 0.05$ & Sudd & https://ww \\
\hline & & & & $\circ$ & $\&$ & W.chc.ucsb. \\
\hline & & & & & Upstre & $\underline{\mathrm{edu} / \mathrm{data} / \mathrm{ch}}$ \\
\hline & & & & & $\mathrm{am}$ & $\underline{\operatorname{irps}}$ \\
\hline Average & CHIRTS & $1981-2020$ & Monthly & $0.05^{\circ} \times 0.05$ & Sudd & https://ww \\
\hline \multirow[t]{3}{*}{ Temperature } & & $1979-2020$ & & $\circ$ & $\&$ & w.chc.ucsb. \\
\hline & & & & $0.25^{\circ} \times 0.25$ & Upstre & edu/data/ch \\
\hline & & & & $\circ$ & $\mathrm{am}$ & irtsmonthly \\
\hline
\end{tabular}

(Table Continues) 
Table 1, Continued

\begin{tabular}{|c|c|c|c|c|c|c|}
\hline $\begin{array}{l}\text { Hydrological } \\
\text { Variable }\end{array}$ & $\begin{array}{l}\text { Satellite/ } \\
\text { Datasets }\end{array}$ & $\begin{array}{l}\text { Data } \\
\text { Availability }\end{array}$ & $\begin{array}{l}\text { Temporal } \\
\text { Resolution } \\
\end{array}$ & $\begin{array}{l}\text { Spatial } \\
\text { Resolution }\end{array}$ & Location & Source \\
\hline \multirow[t]{9}{*}{ NDVI } & MODIS & $2000-2020$ & Monthly & $500 \mathrm{mx} 500$ & & https://lpd \\
\hline & & & & $\mathrm{m}$ & Sudd & aac.usgs. \\
\hline & AVHRR & $1981-2020$ & & & & gov/prod \\
\hline & & & & $0.01^{\circ} \times 0.01$ & & ucts/mod \\
\hline & & & & $\circ$ & & $\underline{13 \mathrm{a} 3 \mathrm{v} 006}$ \\
\hline & & & & & & 1 \\
\hline & & & & & & https://sea \\
\hline & & & & & & rch.earthd \\
\hline & & & & & & $\frac{\text { ata.nasa.g }}{\text { ov/ }}$ \\
\hline MNDWI & Landsat, & 1984-2020 & Annual & $30 \mathrm{mx} 30 \mathrm{~m}$ & Sudd \& & $\underline{\text { https://gis }}$ \\
\hline (Surface Area & TM5,7 & & & & Lakes & hub.org/w \\
\hline \multirow[t]{2}{*}{ of Lakes) } & ETM8+, & & & & & ater-app \\
\hline & LOI & & & & & \\
\hline Lake Height & JASON I, & $1992-2020$ & Monthly & NA & Lakes & https://ipa \\
\hline \multirow[t]{5}{*}{ (Altimetry) } & II, and III & & & & upstream & d.fas.usda \\
\hline & TOPEX/ & & & & & .gov/crop \\
\hline & Poseidon & & & & & explorer/ \\
\hline & & & & & & global_re \\
\hline & & & & & & servoir/ \\
\hline
\end{tabular}




\section{Temperature}

Temperature datum was available through the Climate Hazards Center (CHC) of UC Santa Barbara from 1983-2016 known as the Climate Hazards Group Infrared Temperature with Stations (CHIRTS). The CHIRTS is a conglomeration of in-situ observation reports and geostationary satellite thermal infrared (TIR) observations with a spatial resolution of $5 \mathrm{~km}$ by 5 $\mathrm{km}$ with global coverage. The data set aims to provide better and up-to-date resources to regions such as: South America, Africa, and areas north of $50^{\circ}$ where data may not be as readily available.

(URL: https://www.chc.ucsb.edu/data/chirtsmonthly)

\section{Rainfall}

Rainfall data was available through the CHC of UC Santa Barbara from 1981 to present. This dataset is known as the Climate Hazards Group Infrared Precipitation with Stations (CHIRPS), which also has a spatial resolution of $5 \mathrm{~km}$ by $5 \mathrm{~km}$. Funding for the CHC by USAID, NASA, and NOAA allows regions with sparse data to develop and provide resources combining both in-situ observations and satellite observations. The CHIRPS data was created in order to provide accurate and predictive analyses for drought monitoring in collaboration with the United States Geological Survey (USGS) Earth Resources Observation and Science (EROS). With the CHIRPS data providing trend analyses for drought and extreme rainfall events in the study area, CHIRTS data was brought in to build regional climate trends that would then be correlated with vegetation indices to determine how affected the Sudd was to climate.

(URL: https://www.chc.ucsb.edu/data/chirps) 


\section{Vegetation}

The vegetation coverage of the Sudd Wetland was analyzed using the aid of the Moderate Resolution Imaging Spectroradiometer (MODIS) sensor and Advanced Very High Resolution Radiometer (AVHRR). The MODIS instrument is a part of five others in the TERRA and AQUA series, while AVHRR is a part of NOAA's Polar Orbiting Environmental Satellites (POES). AVHRR targeted visible, near-infrared, and thermal infrared portions of the electromagnetic spectrum. The AVHRR data series is available between 1981-2002 while the MODIS data series spans from 2000 and is currently still surveying the Earth's surface. It consists of multi-band spectral imaging sensors. This provided a broad blueprint for the area and size of the wetlands. To provide more accurate measurements and results, NDVI was used to indicate differences in plant pigmentation and vegetation parameters to get a more accurate reading of the vegetation that is within the wetlands based on the equation:

$$
\mathrm{N}=\frac{(N I R-R e d)}{(N I R+R e d)}
$$

NDVI distinguishes measurements between water and vegetation by isolating near infrared and red wavelengths and creating a ratio (between 0 and 1) from the difference and sum of those values. The isolation of these wavelengths allows for NDVI instruments to focus on collecting vegetation and not any water (Palacios-Orueta et al., 2006). (URL:

https://pdaac.usgs.gov/products/mod13a3v006/; https://search.earthdata.nasa.gov/) 


\section{Surface Water Height and Surface Area of Open Water Bodies}

The surface water variation through time in the Sudd wetland was analyzed using two variables, surface water height and surface area of open water bodies in the wetland. The surface water height was collected from United States Department of Agriculture (USDA) sources derived from satellite altimetry data. The open water bodies of the Sudd Wetland were analyzed using data collected from the Normalized Difference Water Index (NDWI). The NDWI measurement, which is also a multi-band spectral imaging sensor aboard the TERRA and AQUA satellite series, is generated using an equation:

$$
\mathrm{N}=\frac{(N I R-S W I R)}{(N I R+S W I R)}
$$

Similar to NDVI, the NDWI isolates a specific part of the electromagnetic spectrum (in this case green) to create a ratio (between 0 and 1) by taking the difference over the sum of measurements in the green wavelengths. This data was made available using a Google Earth Engine code that extracted data from Landsat, TM5+7 (Landsat 5+7), ETM8+(Landsat 8) sensor Operational Land Imager (OLI) (Wang et al., 2018).

(URL: https://www.jpl.nasa.gov/missions/jason-3/; https://sealevel.jpl.nasa.gov/missions/topex/)

\section{Methodology}

The purpose of this project was to understand the climatic trends of the Sudd. Understanding the trend that governs the size of the wetland could allow for a future sensitivity model to be calculated. Trends in East Africa can be determined by using the data gathered from the various satellites and models such as: CHIRPS, CHIRTS, and MODIS and AVHRR. Over the span of around forty years, from 1981-2019, a trend was formulated for temperature and rainfall. 
The overall conceptual model of this project is shown in Figure 5. Two main constituents of climate, rainfall and temperature, were used to represent long-term climate in East Africa. The CHIRPS and CHIRTS datasets provided four decades (1980-2020) to understand climatic effects on wetlands, specifically the Sudd Wetland. To match the four decadal climate data, vegetation indices from 1980-2020 were needed to correlate (AVHRR (1980-2000) and MODIS (20002020)) NDVI datasets were obtained to do so. All four datasets were obtained as monthly files.

Trend analyses (Sen's Slope and Mann-Kendall Method) were generated to provide average, increasing/decreasing slopes, magnitude values, and the data significancy values. Sen's slope, also known as the Theil-Sen estimator, was named and designed by Henri Theil in 1950 and later revised by Pranab K. Sen in 1968. The method is nonparametric, which allows the method to not draw from any probability distribution. Like Sen's slope, the Mann-Kendall Method is also nonparametric. It is used to determine if any time series shows an upward or downward trend. It was created by H.B. Mann (1945), revised by Maurice Kendall (1975), and improved by Hirsch et al. $(1982,1984)$. The four datasets were then organized by their resulting trends and values into annual, monthly, and seasonal variables. From there, preliminary surface water area of the Sudd (NDWI) and lake level data were correlated with the climate data and wetland data to understand the correlation between climate trends and the wetland extent. 


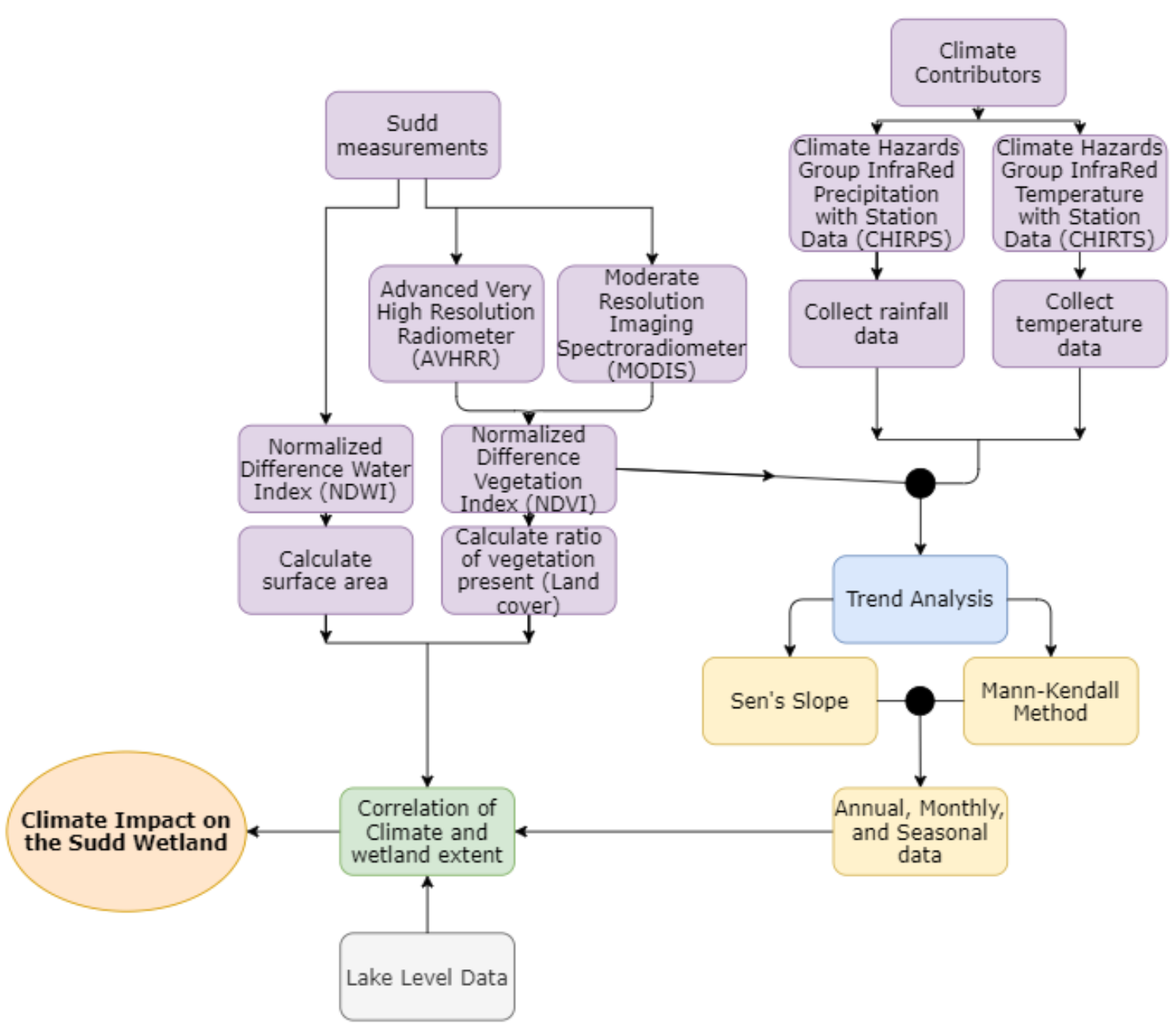

Figure 5. Flow chart displaying the methodology of this project.

\section{Seasonal and Long-term Trend Analysis}

Once the datasets of NDVI, rainfall, and temperature were downloaded and organized, long-term trend analyses were done on them to develop results that would lead to correlation between the climate and wetland data. The two methods used were the Mann-Kendall Method and Sen's slope. The Mann-Kendall Method and Sen's slope were both used three times to process each of the three datasets properly. The Mann-Kendall Method considers the entire monthly dataset and gives a relative value of magnitude - meaning the sum of the data is 
showing either an increasing trend or decreasing trend. This method was performed on each of the dataset's resolution scales throughout the entire study area. The data was also calculated annually, its original monthly temporal resolution, and seasonally. Sen's slope method then took that data and gave these increasing or decreasing trends numerical values - meaning these values came out as negative (decrease) or positive (increase). Sen's slope method was used due to its non-parametrical procedure of being able to estimate these values even in a linear regression (Yu et al., 1993). The confidence level of the data points was also calculated with Sen's slope at a confidence interval of $>95 \%$.

These methods were used to develop trend analyses on the monthly NDVI data, CHIRPS, and CHIRTS data for the entire study area, the Sudd, BAJs, LALKs, and LVs. Using ManKendall and Sen's slope, these monthly temporal resolutions also derived into annual and seasonal (JF, MAM, JJAS, and OND) datasets to increase or decrease the temporal scaling of this data. The sampling size consisted of four decades worth of data from 1981-2019 (CHIRPS being 1983-2016)

\section{Data Processing and Analysis}

Once all the climate data (temperature and rainfall) and NDVI data (AVHRR and MODIS) were gathered from their respected sources, all the data processing went through RStudio and ArcGIS. Various tools were used from both software that allowed for the full integrity and true resolution of the data to be preserved. RStudio was used primarily to create and preserve the temporal resolution of both the climate and Sudd datasets. Using RStudio allowed for the large amounts of data to be processed, especially when calculating Sen's slope and using the Man-Kendall Method. RStudio also allowed for quick and reliable transfer of the data into 
.TIF and .JPEG files from their original RAW source. The transferring into .TIF and .JPEG made the transition of opening those images/datasets in ArcGIS. ArcGIS was used mainly for the spatial resolution aspect of the data. In ArcGIS, data was able to be merged and processed with other data for easy analysis.

\section{Correlation and Interpretation}

Correlation of the wetland and regional climate was analyzed using the climate data, NDVI, and lake level and surface water area data. A key way to understand if the wetland extent was affected by climatic trends in the upper White Nile River basin was by analyzing specific years that saw record lows in rainfall and lake level data. The lag correlation between the NDVI and rainfall would then be seen in the following season or two after noted low events. If these correlations were observed, then a connection between the surficial hydrologic regime upstream from the Sudd truly affects the Sudd Wetland's extent. 


\section{CHAPTER V: RESULTS}

\section{Climate}

The two main constituents of climate, temperature and rainfall, were used in this study to understand the effects of climate on the Sudd Wetland. The climate data was then correlated with NDVI data of the Sudd Wetland to determine if the variation in vegetation within the defined region of the wetland was changing in response to climate variability. Though there exists slight variation in terms of seasonality, for analysis purpose similar months of seasons were used for the three sub-basins of the White Nile River Basin, Bahr al-Jabal, Lake Albert and Lake Kyoga, and Lake Victoria, two dry seasons of January to February (JF) and October to December (OND) and the two wet seasons of March to May (MAM) and June to September (JJAS).

\section{Temperature}

Figure 6 shows the mean annual, monthly, and seasonal temperature for three subbasins BAJ, LALK, and LV. The mean annual temperature showed an increasing pattern (Figure 6a). Mean annual temperature in each sub-basin, in the 34-year span, has increased by around $0.7^{\circ} \mathrm{C}$. The monthly temperature data helps show the variation in the recorded temperature for the entire study area that can then be broken down into seasons throughout the year in response to changing conditions over the year in this region. Based on outliers and the season of JJAS, the seasonal temperatures of the Bahr al-Jabal stay between show high variation in temperatures throughout the year. The LALKs saw the second highest variation in seasonal temperatures with similar average temperatures in each of the four seasons compared to BAJs. However, the Lake 
Victoria sub-basin's seasonal temperatures stay in relatively smaller ranges in temperature based on the size of their boxes and the outliers seen in Figure 6c.

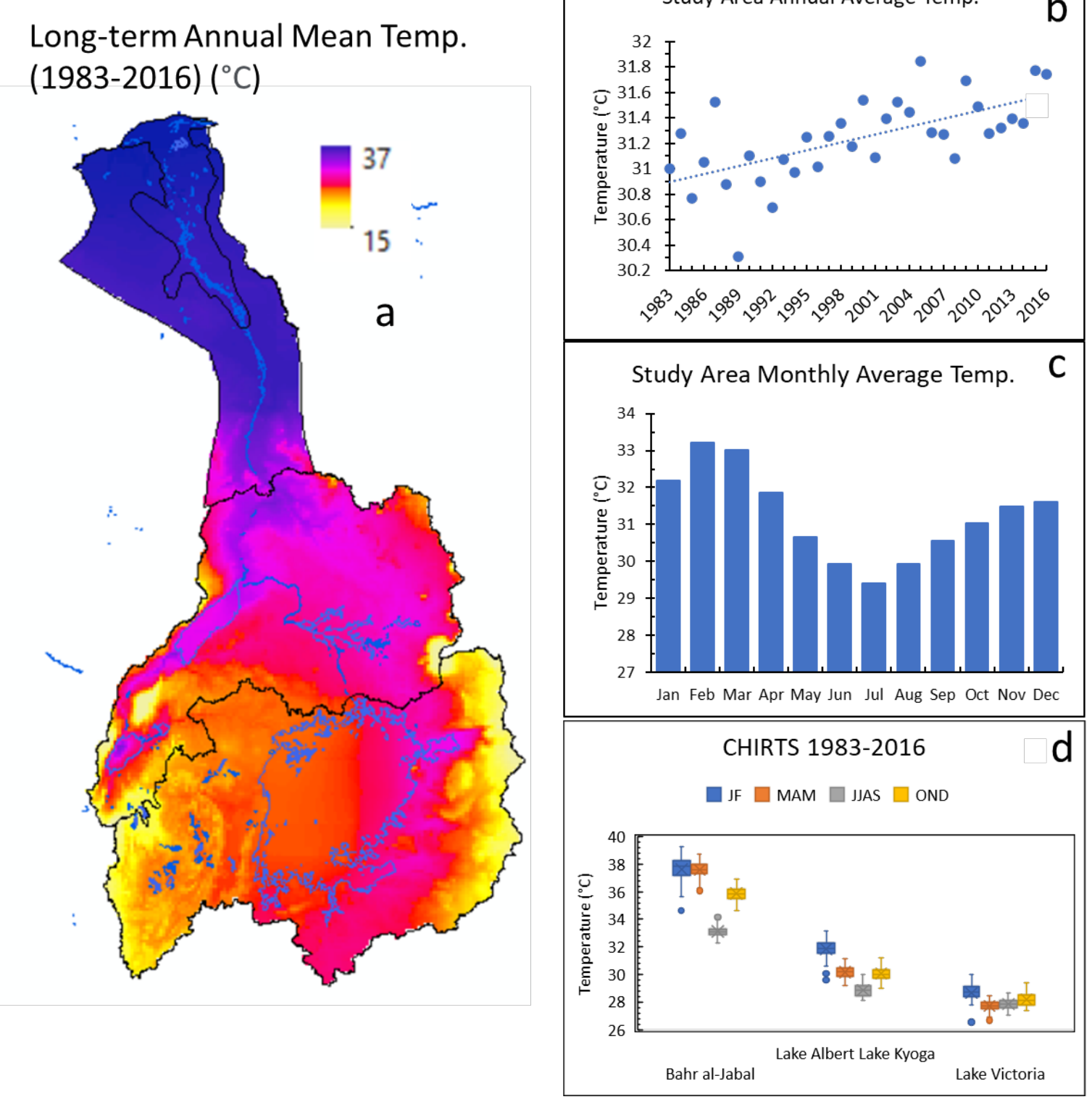

Figure 6. (a) Map showing average temperature from 1983-2016, (b) Mean annual, (c) Mean monthly, and (d) Seasonal mean temperature data for all three subbasins. JF (January, February) (blue), MAM (March, April, May) (orange), JJAS (June, July, August, September) (grey), and OND (October, November, December) (yellow) are the seasons. 


\section{Bahr al-Jabal sub-basin}

The Bahr al-Jabal sub-basin, which comprises the Sudd Wetland, saw an increase in mean annual temperature from data recorded between 1983-2016 (Figure 7 - side graph). The warmest months in the Bahr al-Jabal subbasin occurred between February and April with a longterm mean temperature of more than $38^{\circ} \mathrm{C}$ (Figure 7 - top). The months from October to February show a consistent pattern from 1983-2016 where their temperatures appear the highest, while June, July, August, and September received relatively lower temperatures. In Figure 7, the heat map shows monthly temperature variation in each of the 12 months in the 34 years analyzed. The lowest temperature recorded in 1989, when the temperature throughout the months stayed relatively low (as observed where the color signifying temperature does not go above a deep red). The mean annual temperature of the Bahr al-Jabal saw a high variation spanning from a low of around $34.72^{\circ} \mathrm{C}$ in 1989 to around $36.4{ }^{\circ} \mathrm{C}$ in 2005 shown in Figure $7-$ side graph. As of 2016 , the mean annual temperature registered at $36.2{ }^{\circ} \mathrm{C}$, which is approximately a $0.7^{\circ} \mathrm{C}$ change from the average annual temperatures recorded from 1983 to 2016 . The hottest year is 2005 , with a mean annual temperature value of $36.5^{\circ} \mathrm{C}$. The coolest monthly temperature recorded was in July 1988 at around $31^{\circ} \mathrm{C}$. The highest monthly temperature recorded was on Feb. of 2005 at $40.7^{\circ} \mathrm{C}$.

Figure 8 shows the seasonal trend for the BAJs with all seasons showing an increase in trend except OND. 


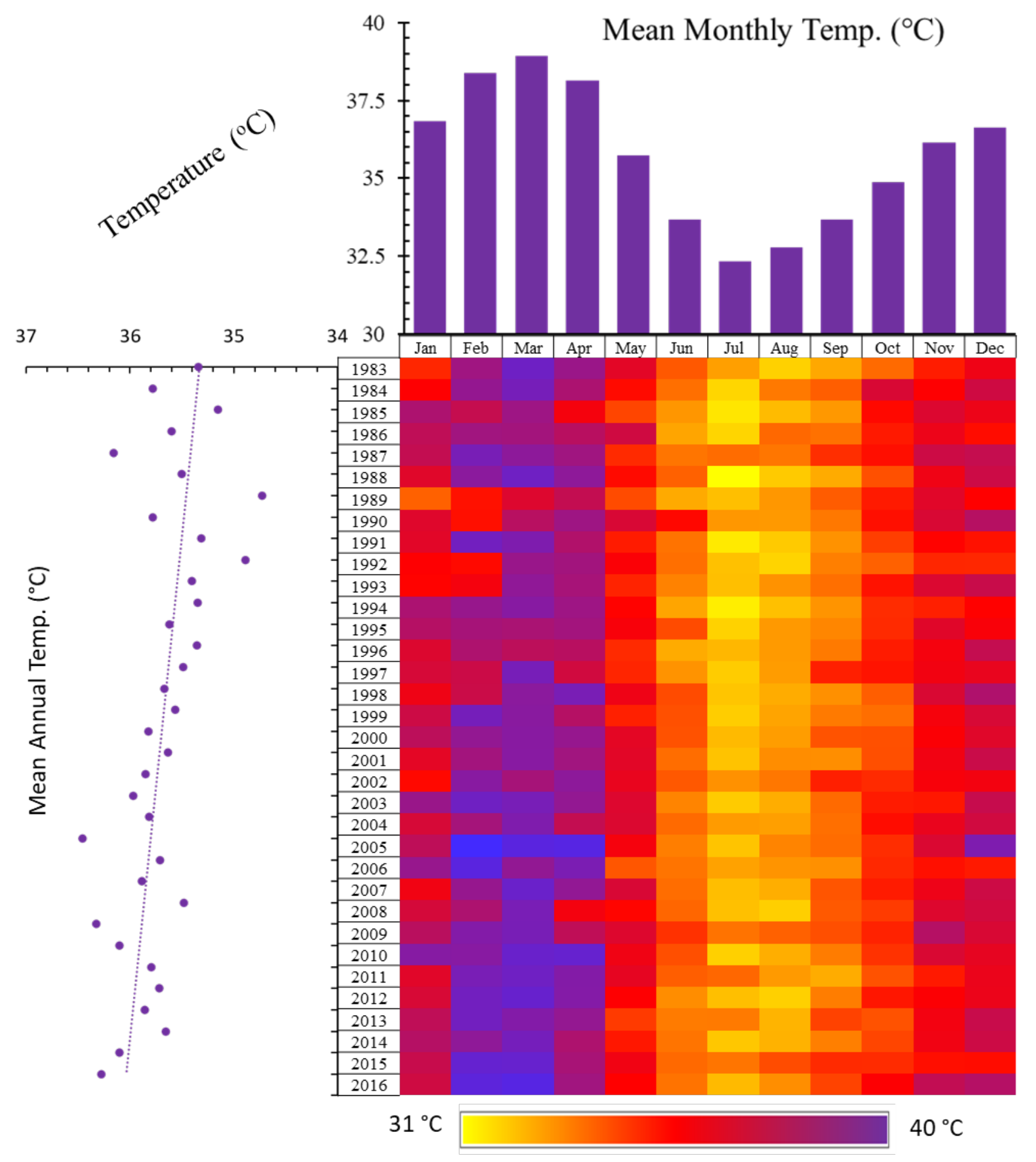

Figure 7. Long-term mean monthly (top - bar graph), monthly temperature (center - heat map), and mean annual temperature (left side - scatter plot) for the Bahr al-Jabal subbasin. In the heat 
map, the bright yellow color indicates lower temperatures while the bright purple/violet color indicates higher temperatures recorded.

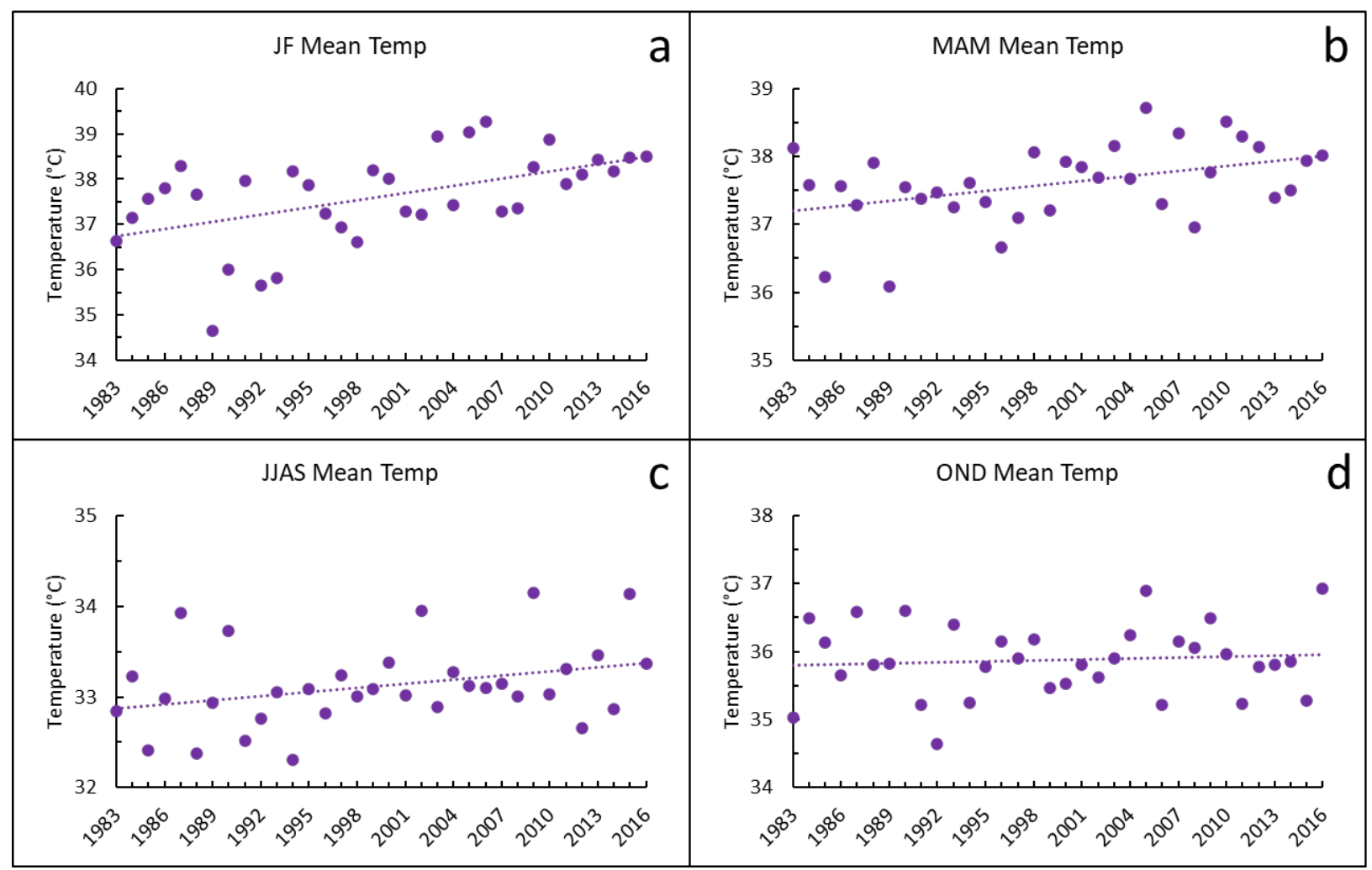

Figure 8. Mean seasonal temperature variations in the Bahr al-Jabal subbasin: (a) JF, (b) MAM, (c) JJAS, and (d) OND.

\section{Lake Albert and Lake Kyoga sub-basin}

The Lake Albert and Lake Kyoga sub-basin (LALKs) saw an increase in temperature, just like the Bahr al-Jabal, between the 1983-2016 study time range. The year of 1989, as described above as the coldest average temperature observed in the Bahr al-Jabal, was also the coldest recorded average temperature observed in the LALKs at mean annual temperature of $29.1^{\circ} \mathrm{C}$. The coolest temperature recorded was on the month of July 1988 at $27.1^{\circ} \mathrm{C}$, and the highest 
temperature observed was in Feb. 1999 at $33.9^{\circ} \mathrm{C}$. The warmest average annual temperature recorded was in 2015 with mean annual temperature of $30.8{ }^{\circ} \mathrm{C}$ (Figure 12 - side graph). The year 2005, which was the Bahr al-Jabal's highest average, was the second warmest year for the LALKs with mean annual temperature of around $30.6{ }^{\circ} \mathrm{C}$. However, when comparing their annual average temperature from 1983-2016 (side graphs of Figures 7 and 9), their variation in temperatures follow almost parallel trends with an increase in the 34-year timespan. Just like the Bahr al-Jabal and Lake Victoria, which will be discussed later, all three sub-basins fall within the same regional climate with dry and wet seasons. These seasons shift slightly regarding their occurrence in a year depending on which sub-basin is being inspected. BAJ and LALKs show similar occurrence of seasons compared to the LVs. The highest temperatures, illustrated with a bright purple color, are found in the dry months of January and February but also into March. The coolest temperatures, light yellow color, were recorded in July (Figure 9 - top). The brighter yellow to orange-colored boxes seen in the months of June, July, and August in 1995 and earlier transition to darker orange and even bright, red-colored boxes from 2000 to more recent years confirm that the rise in average temperatures throughout the sub-basin.

Figures 10 a-d describe the seasonal average temperature in the subbasin. All four seasons show an increase in mean temperature through the 34-year study. 


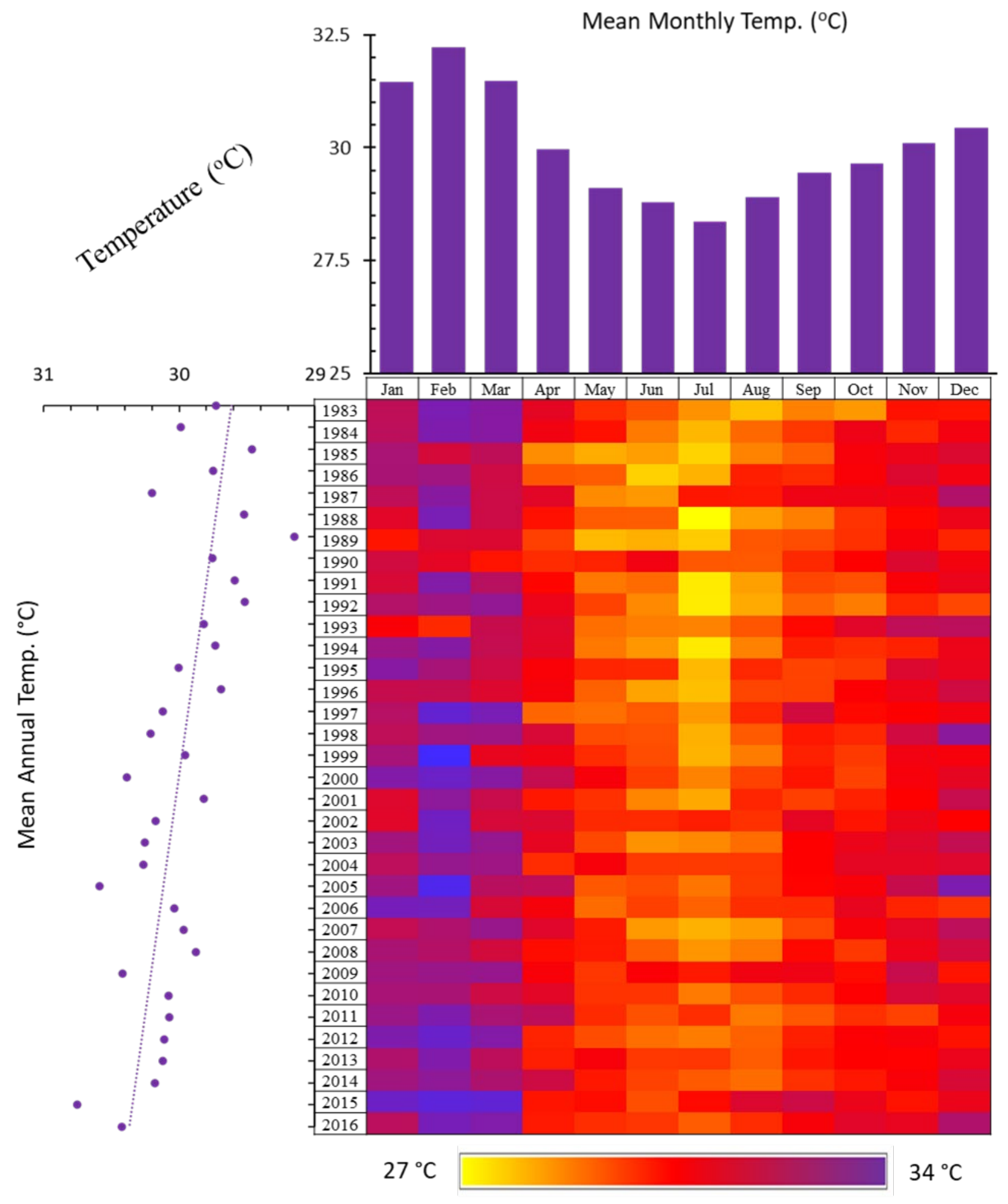


Figure 9. Long-term mean monthly (top - bar graph), monthly temperature (center - heat map), and mean annual temperature (left side - scatter plot) for the LALK subbasin. In the heat map, the bright yellow color indicates lower temperatures while the bright purple/violet color indicates higher temperatures recorded.

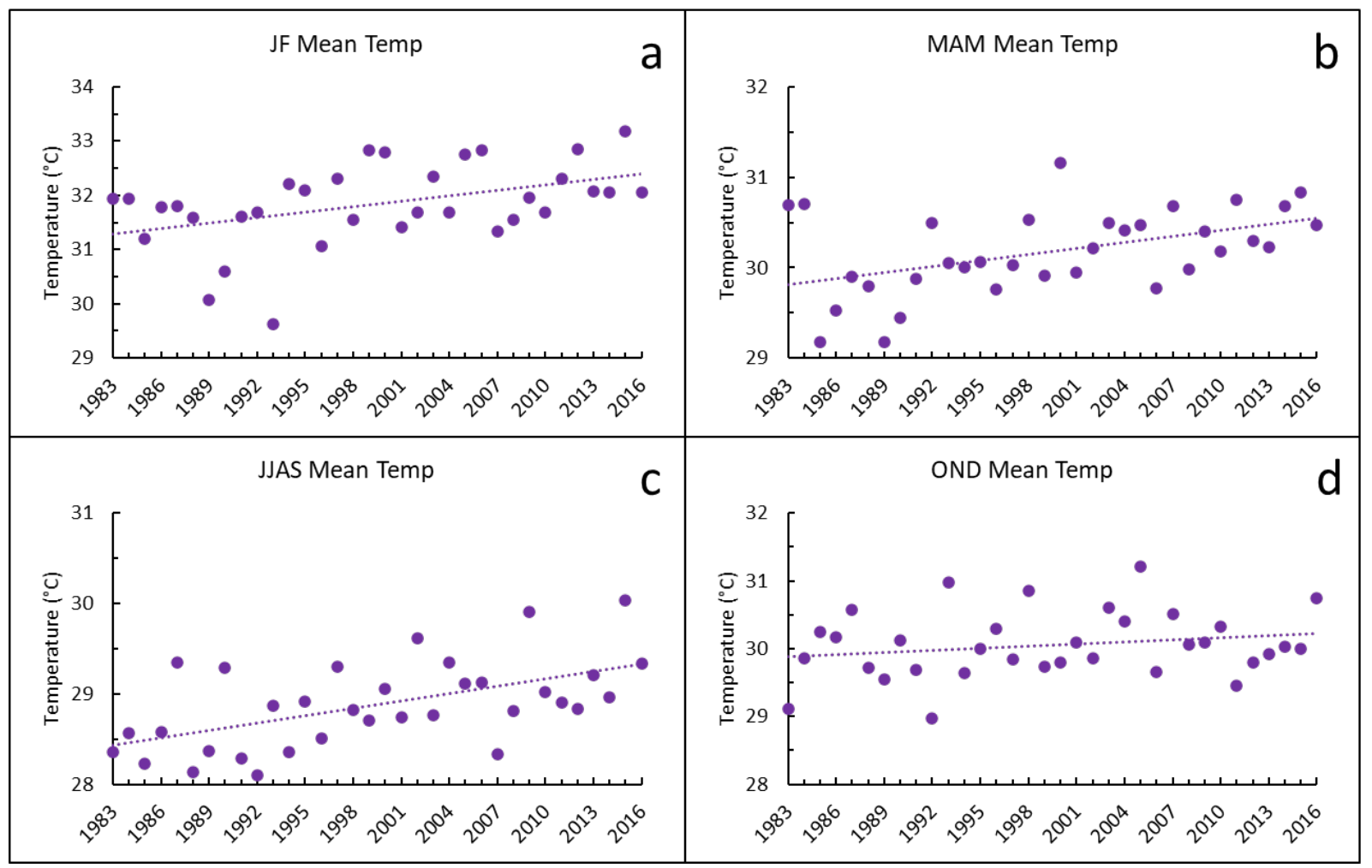

Figure 10. Mean seasonal variation in temperature for the LALKs.

\section{Lake Victoria sub-basin}

The Lake Victoria sub-basin (LVs), the upstream portion of the study area - the source for the White Nile River, also saw an increase in average temperatures from 1983-2016. Just like the other two sub-basins, LVs observed its coolest mean annual temperature in 1989 at $27.1^{\circ} \mathrm{C}$. The highest mean annual temperature recorded was in 2005, like the Bahr al-Jabal, and 2016 at 
around $28.5^{\circ} \mathrm{C}$. Much like the LALKs, the main trend that can be seen is an increase in temperature during the two wet seasons of MAM and JJAS, specifically between the months of April, May, and June. From 1983-1990, there were more yellows and oranges, but the colors change to more orange and red colors into the 2000 s and more recent years. This helps solidify the evidence that not only are dry seasons getting hotter, but the wet seasons are increasing in average temperatures as well. Figure 11 - side shows the average monthly temperature data for the sub-basin. The coolest temperature observed was in 1989 at $25.8^{\circ} \mathrm{C}$. The highest temperature observed in the sub-basin was $31.1^{\circ} \mathrm{C}$ in 1999 . Out of the three sub-basins, LVs showed the smallest in temperature variation using the monthly data. Lake Victoria sub-basin showed only a $5.3^{\circ} \mathrm{C}$ difference in the coolest and highest temperature, while the LALKs difference was $6.9^{\circ} \mathrm{C}$ and the Bahr al-Jabal's was $9.5^{\circ} \mathrm{C}$.

Figures 12 a-d show the seasonal average temperatures for the four seasons, where all four seasons show an increase in temperature. 


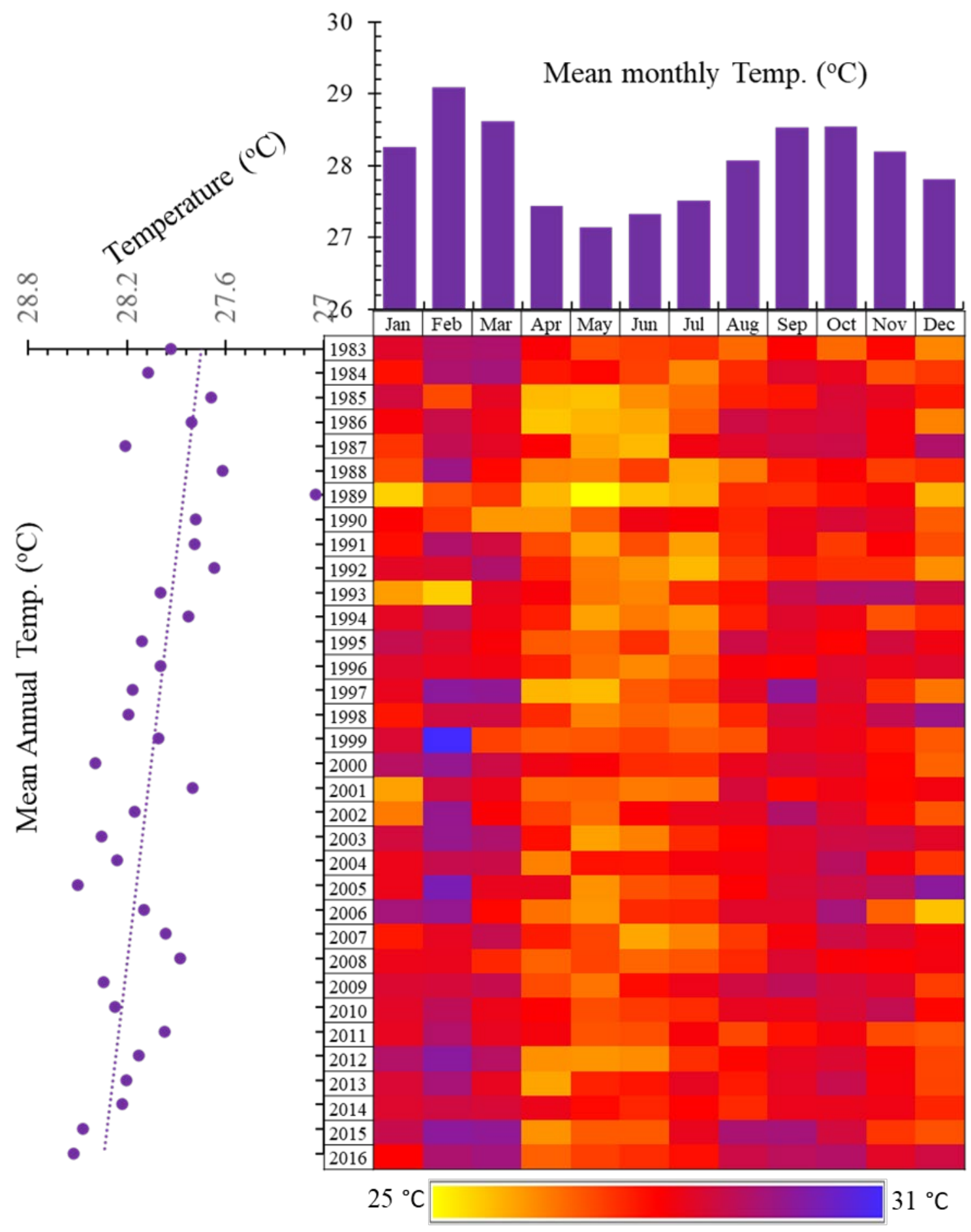

Figure 11. Long-term mean monthly (top - bar graph), monthly temperature (center - heat map), and mean annual temperature (left side - scatter plot) for the LV subbasin. In the heat map, the 
bright yellow color indicates lower temperatures while the bright purple/violet color indicates higher temperatures recorded.

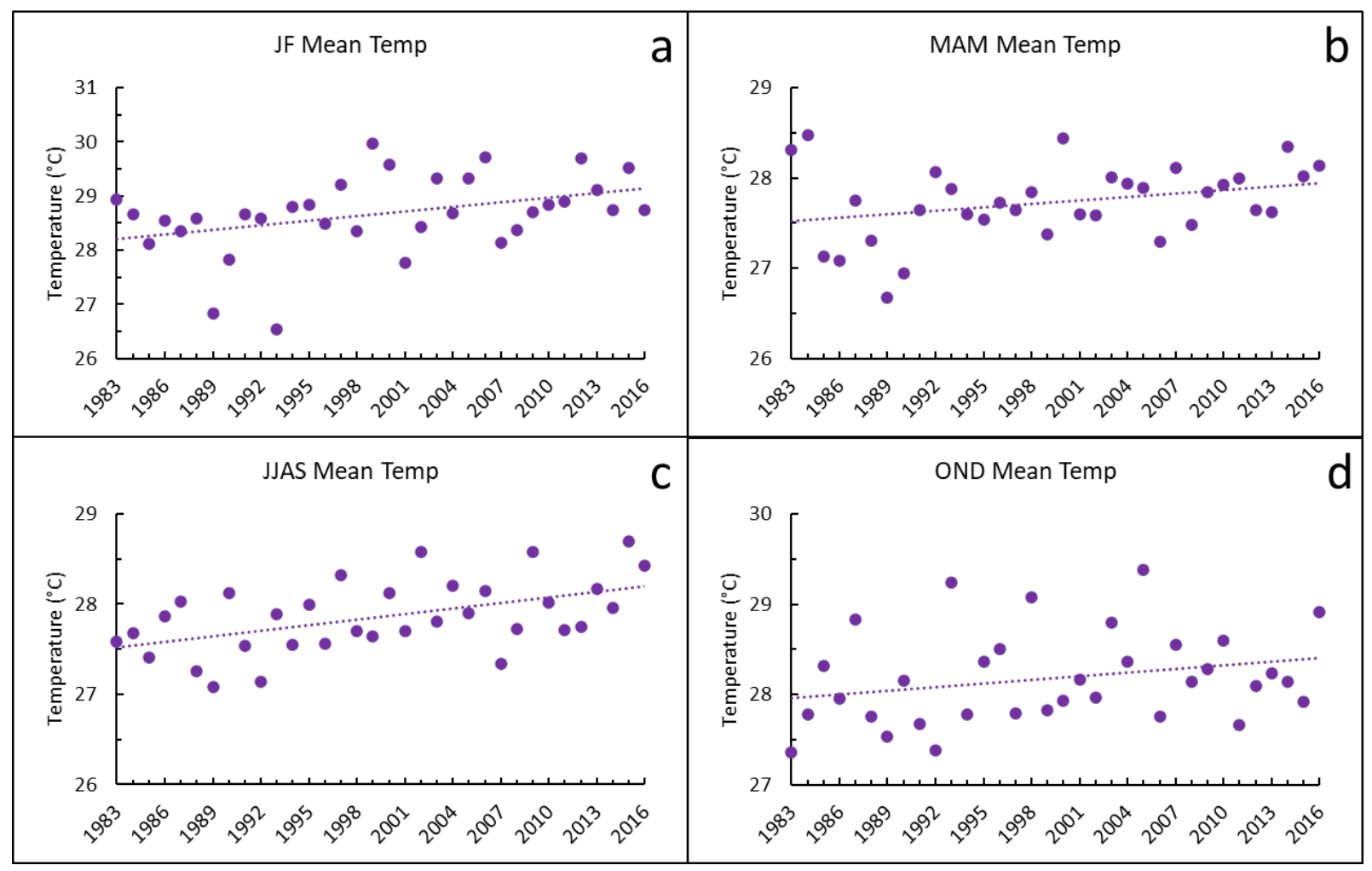

Figure 12. Mean seasonal variation in temperature for the LV subbasin.

\section{Spatial Temperature Trend Analysis}

Trend test was conducted on a monthly, seasonal, and annual time scale for temperature data using Mann-Kendall and Sen's slope tests. Figure 13 shows the annual and seasonal Sens's slope for the entire study region. This map illustrates if the temperature had increased or decreased and the magnitude at which they changed for one year out of the 34-year span, the high, violet, and low, yellow. The Sen's slope values are positive indicate that the overall 
temperature for the region increased over the 34 years span with statistically significant data (Figure 13b). The area that showed the highest increase in temperature is located near the BAJ and LALK subbasins as well as areas extending into the southern part of the Sudd (Figure 13a). The maximum temperature increase occurred around the BAJ and LALK subbasins borders, with a value around $0.03{ }^{\circ} \mathrm{C}$ per year, with an overall increase on around $1{ }^{\circ} \mathrm{C}$. The minimum, but increasing, temperature can be found predominately in the southern edge of the LVs and the northern section of the BAJ subbasin. Figure $13 \mathrm{~b}$ highlights the statistical significance of the data, otherwise known as the P-value. For the data to be considered significant, it must fall below a 0.05 (with 95\% confidence) point threshold. In this map, the areas shaded in yellow are below 0.05 and everything above is shown in purple. As shown in the map, the data is mostly statistically significant.

Considering the seasonal trends, Figures $13 \mathrm{c}-13 \mathrm{f}$ break down the Sen's slopes for each of the four seasons. As shown in these figures, overall increase in seasonal temperature observed for JF and MAM seasons in the study area while some areas experiencing decrease in temperature in JJAS and OND seasons, specifically the Sudd region in the BAJ. The highest increase in seasonal temperature occurred in JF season, which is about $2{ }^{\circ} \mathrm{C}$ in the 33 -year time period, specifically the BAJ subbasin experiences this increase is seasonal temperature.

The highest increase in temperature for the MAM seasons was around $1.2^{\circ} \mathrm{C}$, most of the largest increases occurred in most of the LALKs, most of the southern part of the Bahr al-Jabal, just south of the southern extent of the Sudd wetland, and into parts of northern LVs (Figure 
13d).

Figure 13e shows the Sen's slope for the JJAS season. The study site has experienced both an increase and decrease in temperature in this season. During this season, the highest increase in temperature is $\sim 1.1{ }^{\circ} \mathrm{C}$ and the lowest is a $-0.13{ }^{\circ} \mathrm{C}$ in 33 years of analysis. Except the northern parts of the Bahr al-Jabal and Sudd Wetland, the region experienced an overall increase in temperature.

Just like JJAS, OND season experienced both an increase and decrease in temperature, the highest increase is about rages out to $0.8^{\circ} \mathrm{C}$. The decrease in temperature is found in the southern part of the Bahr al-Jabal and Sudd Wetland with a value around $-0.3{ }^{\circ} \mathrm{C}$ over the studied period, while the increasing temperatures were found in the entire LVs and southwestern part of the LALKs. The northern part of the Bahr al-Jabal and Sudd saw little to no change in temperature during OND.

Figures 13a shows the long-term mean annual temperature for the study area. Looking at all parts of Figure 13, the highest average temperatures, shaded in purple, are found in the Bahr al-Jabal, which consists the Sudd, and parts of the LALKs. The Bahr al-Jabal and Sudd saw average temperatures between $34-40^{\circ} \mathrm{C}$. The lower average temperatures, shown in yellow, were seen in LVs on the western and eastern boundaries. Those mean temperatures ranged from 13-16 ${ }^{\circ} \mathrm{C}$. The cooler temperatures are found on both the western and eastern boundaries, while Lake Victoria, which is outlined in blue near the center of the basin, holds the warmer temperatures of 
the sub-basin. The p-values representing the monthly and seasonal temperature data, (Figure C2) show significant data for the entire region. 


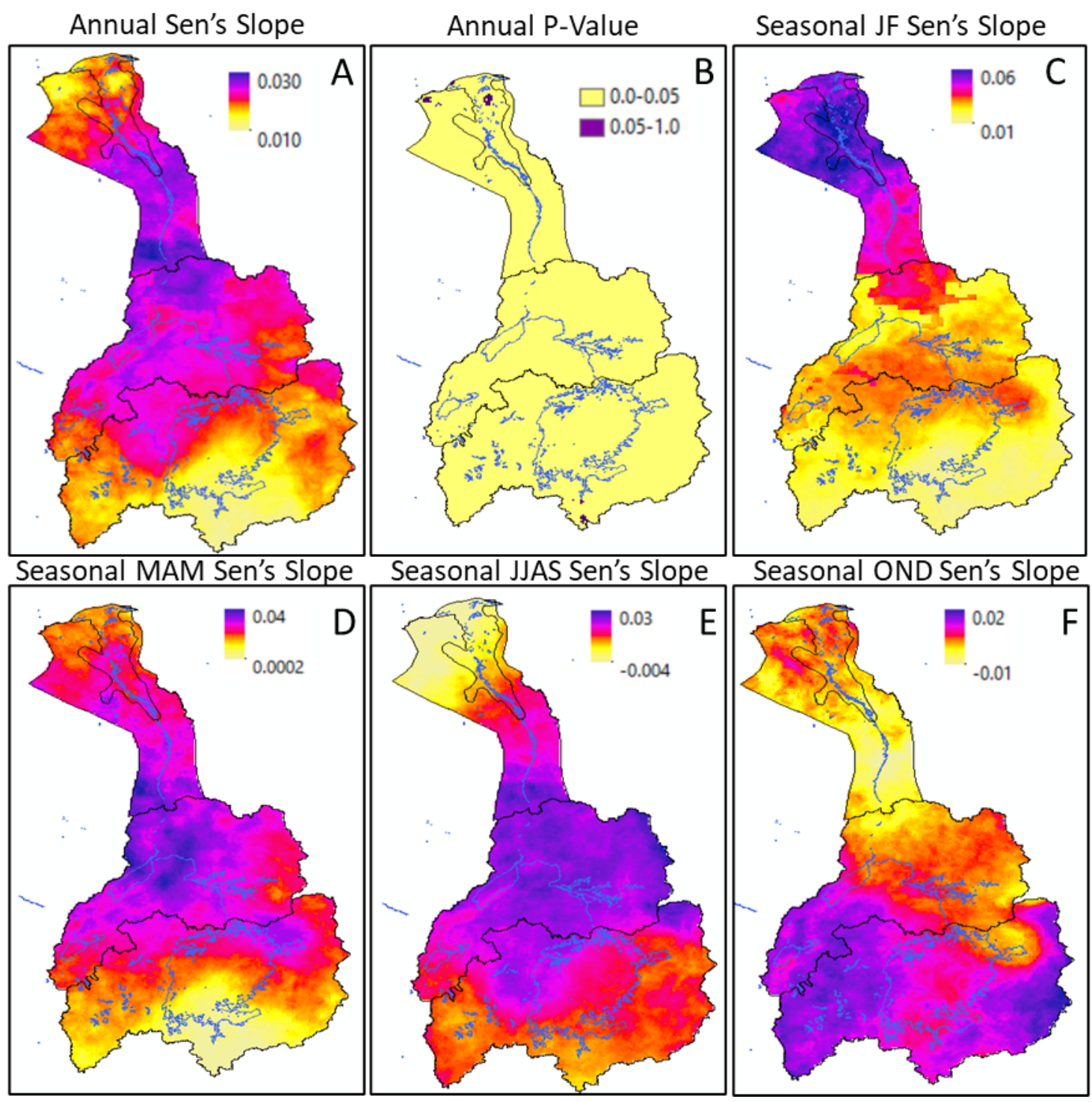

Figure 13. (a) Map of the entire study region showing the annual Sen's slope of the CHIRTS data. (b) Is the annual p-value map showing the areas and data that are significant. (c-f) Are the four seasonal Sen's slope maps. The Sudd is outlined in black located at the top (north) of the maps. Monthly Sen's slope and P-value maps are found in Figure 1-E. 


\section{Rainfall}

Figure 14a highlights the spatial and temporal variability of rainfall for the 39 years of data over the entire study area. As shown in Figure 14a, the Lake Victoria and southeastern part of the study area receives the highest rainfall. The southeastern and eastern tip of the study area received the lowest amounts of rainfall. The Sudd region shows a varying spatial pattern regarding average rainfall with values ranging from 519 to $2411 \mathrm{~mm}$ of total annual rainfall. Generally, the basin received relatively higher amount of rainfall in April, May, August, September, and October months, while the lowest rain received in January and February (Figure $14 d)$.

Figure 14b shows the overall increase in total annual rainfall for the entire study area. Based on Figure 14b, there is a consistent variability in rainfall within a 5-year period, but, overall, the amount is on a continuous increase. Considering total seasonal rainfall, the region received variable rainfalls (Figure 14c). The JF season is the driest season across the region, represented by the blue box (Figure 14d). The wettest season is the JJAS season for both BAJ and LALK subbasins while MAM for the LV subbasin. In terms of magnitude, the Bahr al-Jabal receives the highest seasonal rainfall during the JJAS compared to the other subbasins. However, the LALK and LV sub-basins received higher amount rainfall in the other seasons (e.g., MAM, OND) compared to the BAJ which is characterized by on peak rainfall season, i.e., the JJAS. 


\section{Long-term Annual Mean Rainfall (1981-2019) (mm)}

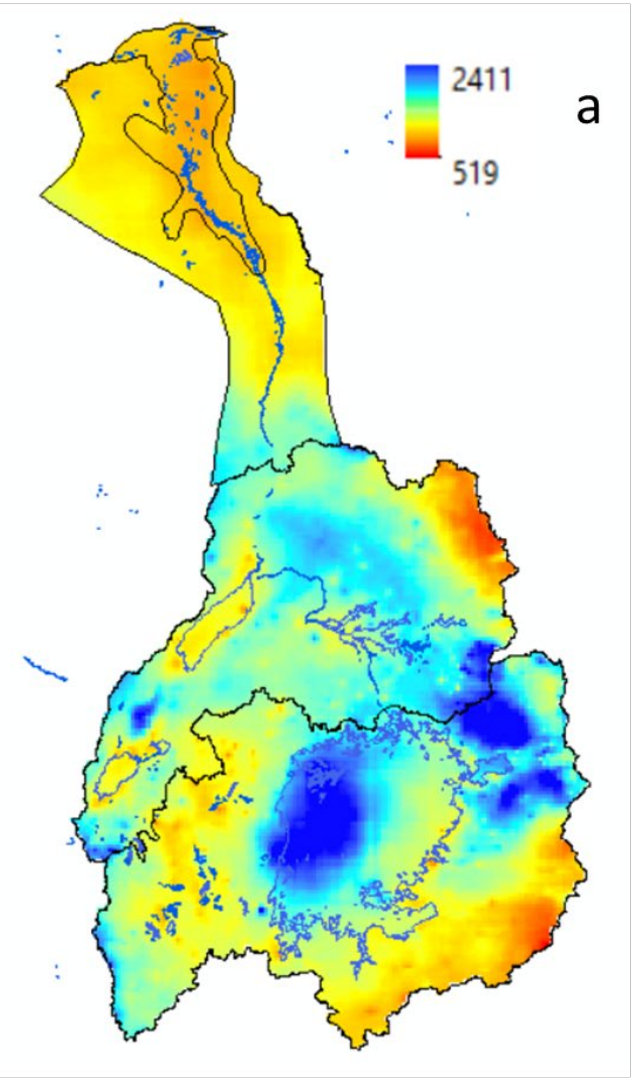

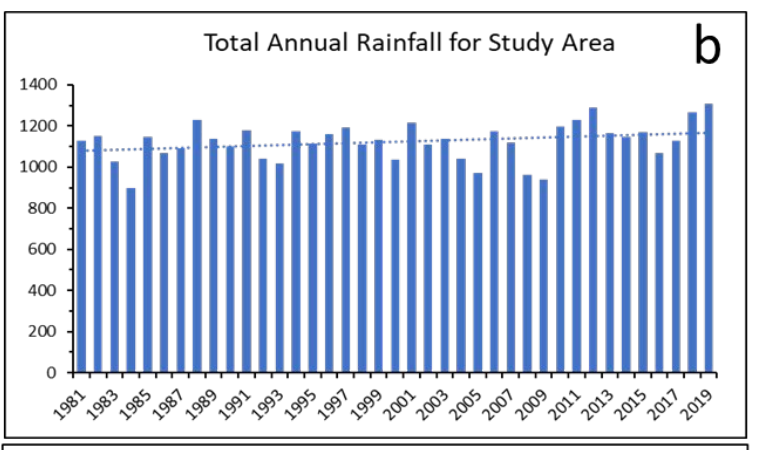
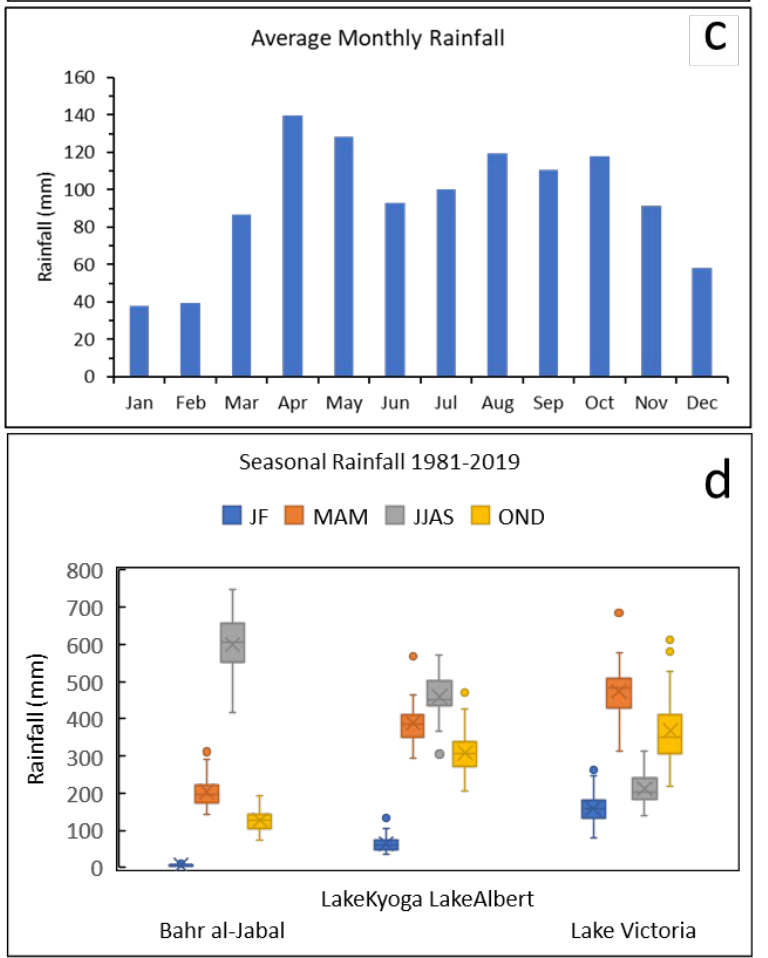

Figure 14. (a) A map that illustrates the average total annual rainfall distribution from the 39-

year data span for the study area. (b) Shows the long-term mean monthly rainfall measurements.

(c) A box-n-whisker graph showing average seasonal rainfall within each sub-basin.

\section{Bahr al-Jabal sub-basin}

The Bahr al-Jabal sub-basin, where the Sudd Wetland is located, has the least amount of rainfall recorded compared to LALKs and LVs for the studied time period. The mean monthly rainfall graph shows the low and high average values of rainfall recorded in each month 
throughout the study timespan (Figure 15 - top). The two seasons of OND and JF saw the lowest amount of average monthly rainfall. These seasons can also be depicted by looking at Figure 15 - center. The dry season of JF is depicted only by red boxes. Indicating there was no change in the amount of average rainfall, but JF was also the season with the lowest amount of average rainfall. Figure 16 - center shows no significant trends that could be generated by looking at this graph. However, the years of 1989, 2008, and 2009 saw the lowest amount of rainfall recorded. These years will be looked at later in the discussion.

The OND season showed more variation in amount of rainfall spanning from red to light blue colors. Figure 15 - center shows that the highest average rainfall that occurred in OND occurred in 1998 and 1999 with around 200mm. The two wet seasons of MAM and JJAS saw much higher average rainfalls. However, the month of March had the lowest amount of average monthly rainfall with little-to-no variation and amount. The highest average rainfalls observed during the timespan were seen in July and August (Figure 15 - top)

The seasonal rainfall data showed a slight decrease in total rainfall in JF with little-to-no change for MAM, JJAS, and OND seasons (Figure 16a-c). 


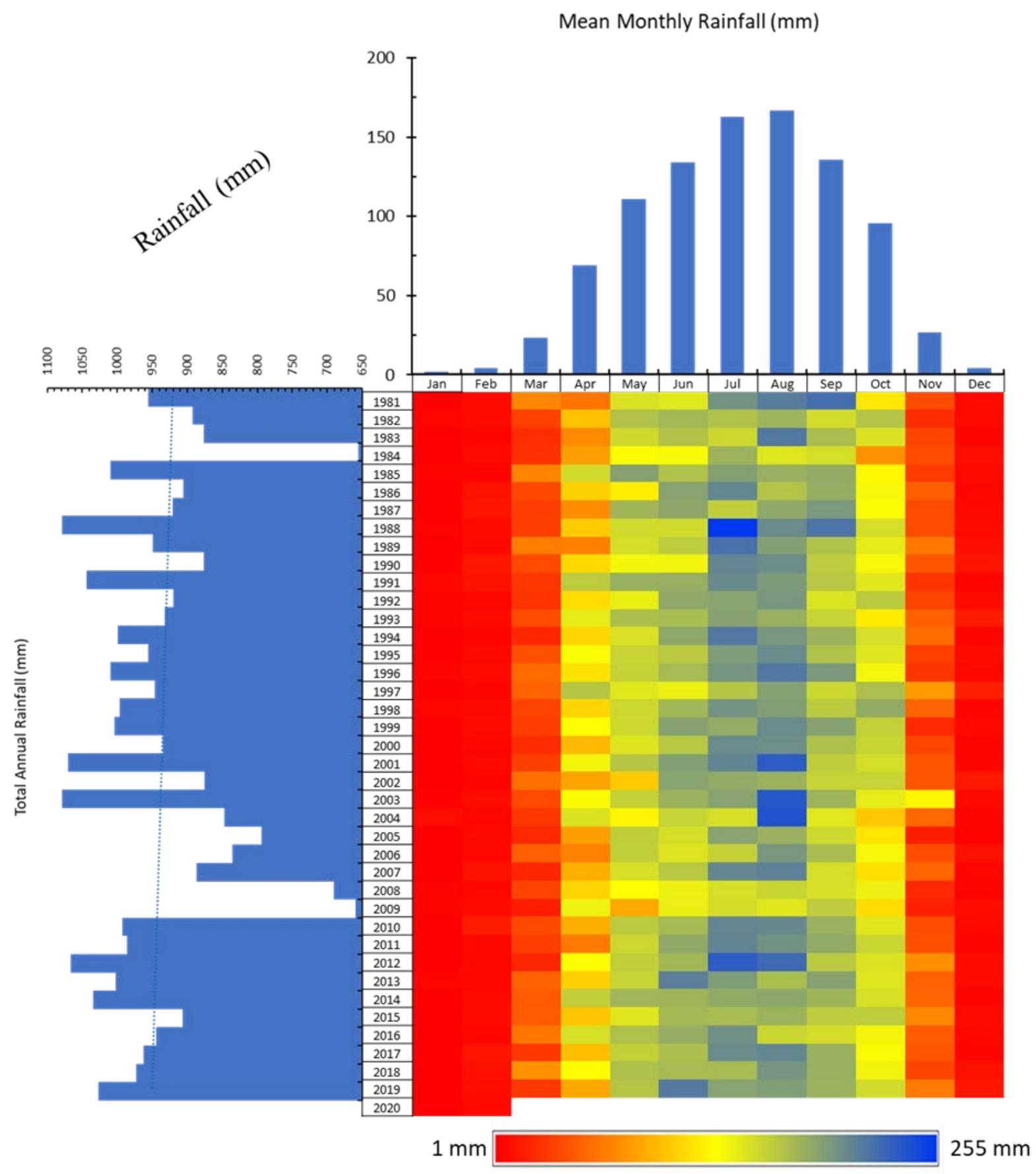

Figure 15. (Center) The heat map showing temporal variation of the average rainfall during each month of the 39 years of data, long-term mean monthly rainfall (top), and total annual rainfall (left side) for the BAJs. 


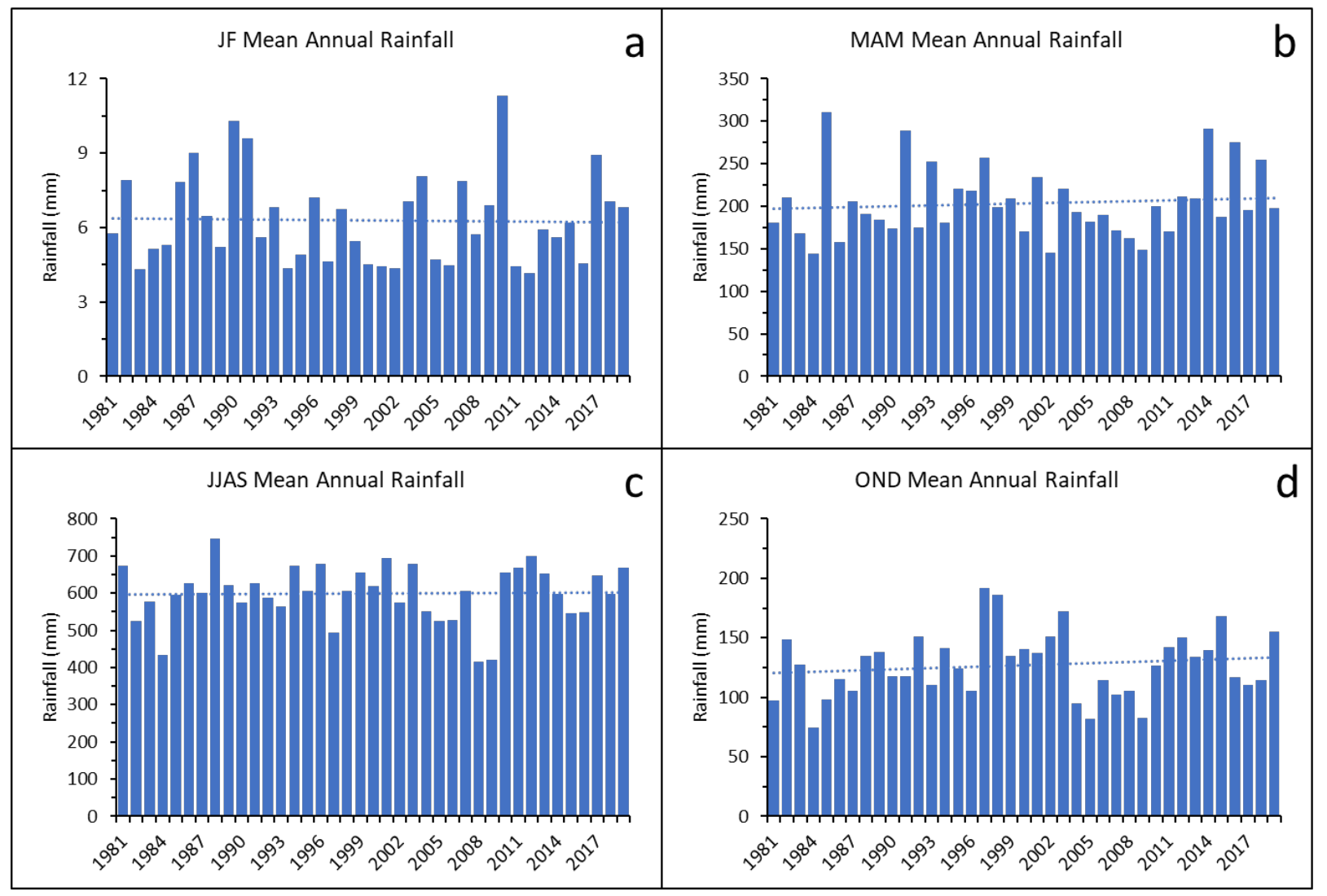

Figure 16. Graphs showing the total seasonal variation in rainfall (JF: January, February; MAM: March, April, May; JJAS: June, July, August, September; OND: October, November, December) in each subbasins.

\section{Lake Albert and Lake Kyoga sub-basin}

Figure 17 - center illustrates the average seasonal and monthly variation in rainfall over the 39-year timespan of data. The dry season of JF had the lowest amount of rainfall on record with very little variation in the average. The second dry season of OND had the second lowest amount of average rainfall of the four seasons. October and November saw a small increase in average rainfall during the data timespan. December saw no change in average rainfall as it received the lowest amount of the OND season. The months of April and October saw the highest amounts of monthly average rainfall recorded. 
Figure 17 - side shows the total annual rainfall within the LALKs. The lowest total rainfall years that were recorded were 1992/93 and 2009. Overall, the sub-basin saw an increasing trend in total annual rainfall. Of the mean monthly rainfall data, January, February, and December saw the lowest amounts of rainfall, while April, May, August, and October recorded the highest average monthly rainfalls (Figure 17 - top).

The only season that made a significant change, based on the trend line, in rainfall was the OND season, where it saw an increase in mean seasonal rainfall. The other three seasons, JF, MAM, and JJAS, showed little-to-no change in their mean seasonal rainfall (Figures 18 a-d). 


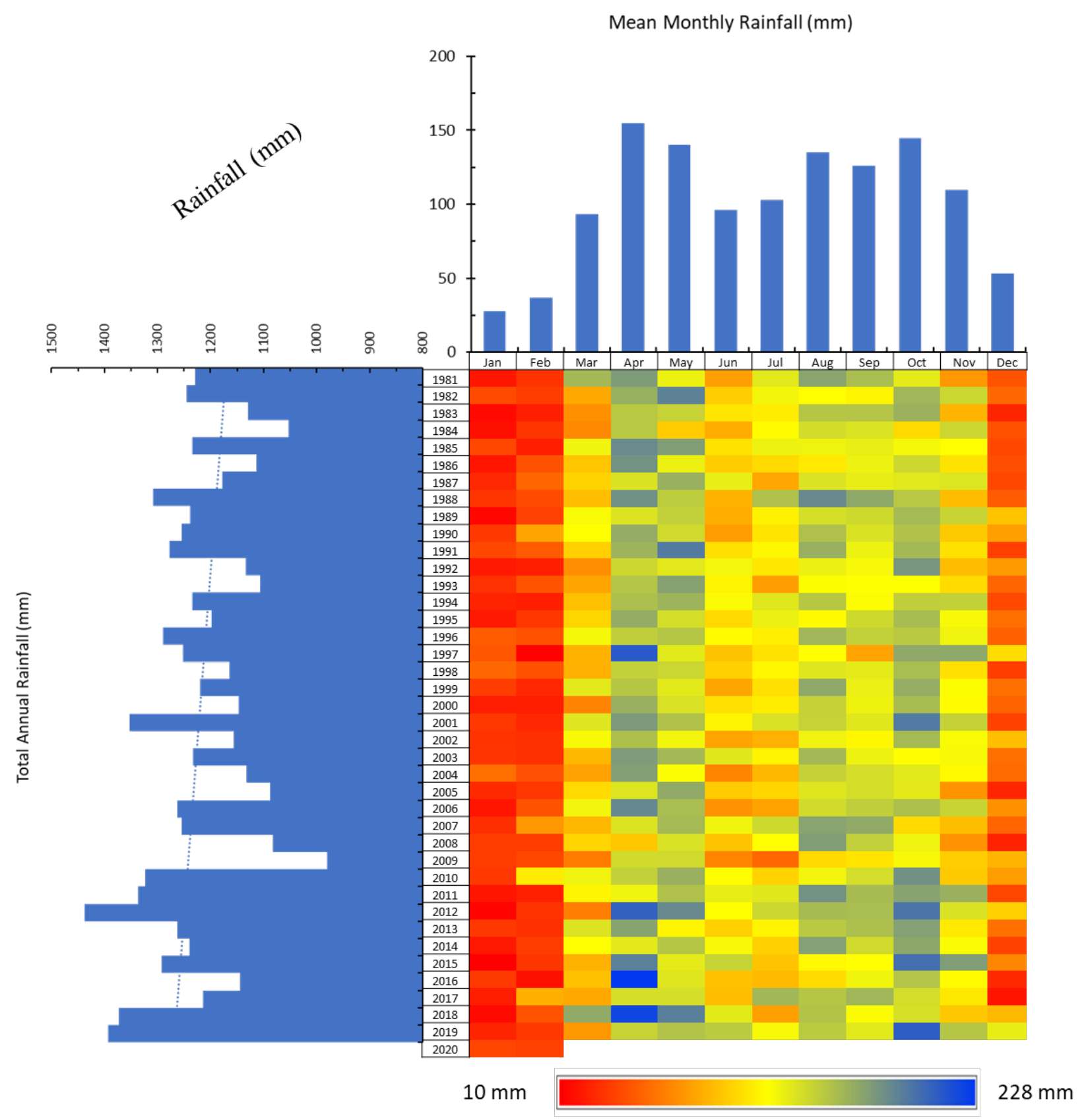

Figure 17. (Center) The heat map showing temporal variation of the average rainfall during each month of the 39 years of data, long-term mean monthly rainfall (top), and total annual rainfall (left side) for the LALKs. 


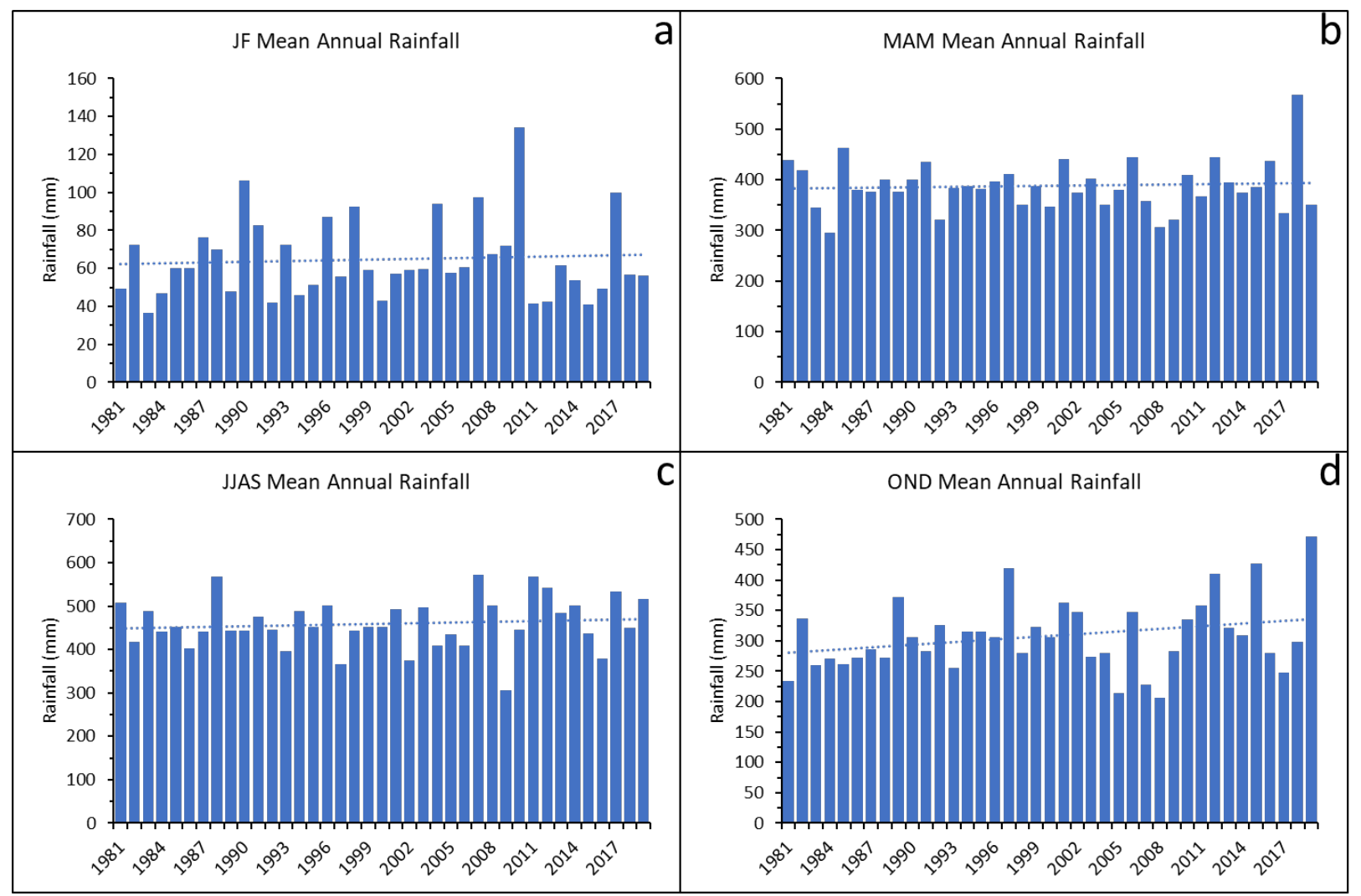

Figure 18. Graphs showing the total seasonal variation in rainfall (JF: January, February; MAM: March, April, May; JJAS: June, July, August, September; OND: October, November, December) in each subbasins.

\section{Lake Victoria sub-basin}

Figure 19 shows the monthly (heat map), mean monthly (bar graph - top), and total annual rainfall distribution for the LVs from 1981-2019. The mean monthly distribution showed that LV exhibit a bimodal rainfall receiving higher rainfall MAM and OND months (Figure 19 - top). The driest months are June, July, and August which is different from the other sub-basins. The season of MAM had the highest average rainfall. 
There is inter-annual variation in rainfall in the LV subbasin. Drought years occurred with a repeat cycle of 5 to 10 years. The LV subbasin received the lowest total annual rainfall in 1983/84, 1992/93, 2000, 2005, 2008, and 2016 years (Figure 19 - side). Generally, the total annual rainfall shows an increasing trend (Figure 19 - side graph) with more wet years occurring in the last decade. Figure 19 - center shows the heat map for the LVs. There appears to be an increase in rainfall from March to December. The two months that seem to show a decrease in rainfall are January and February as their colors shift to more oranges and reds.

Figure 19 - center helps show specific trends in the seasonal rainfall data. For the LVs, the seasons of MAM, JJAS, and OND all show increasing trends while JF shows a decrease in seasonal rainfall (Figure 20 a-d). 


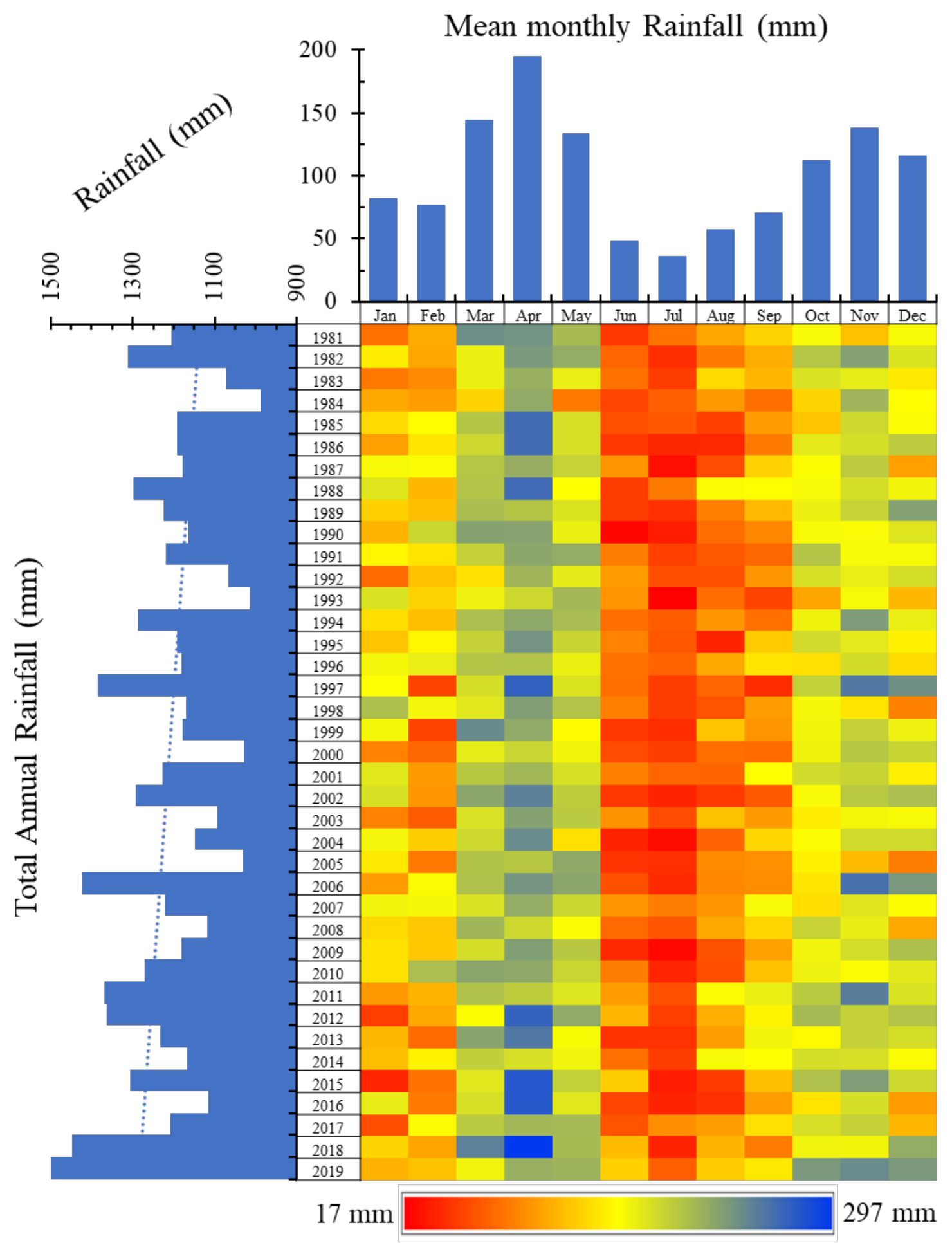


Figure 19. (Center) The heat map showing temporal variation of the average rainfall during each month of the 39 years of data, long-term mean monthly rainfall (top), and total annual rainfall (left side) for the LVs.

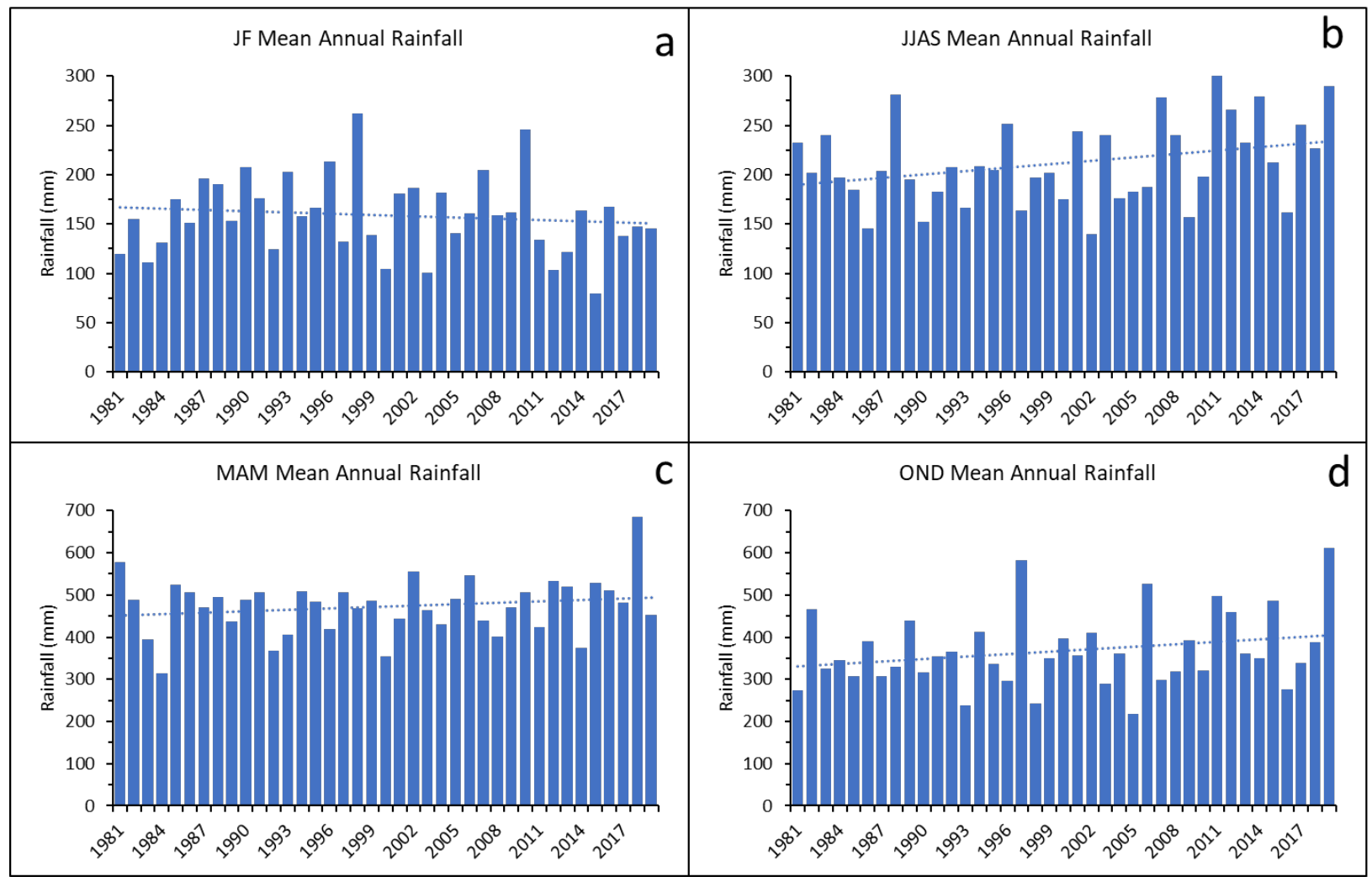

Figure 20. Graphs showing the total seasonal variation in rainfall (JF: January, February; MAM: March, April, May; JJAS: June, July, August, September; OND: October, November, December) in each subbasins.

\section{Spatial Rainfall Trend Analysis}

Sen's slope was used on the 39-year rainfall data to evaluate rainfall trends (increase or decrease) in the study area. Figure 21a is a map showing Sen's slope for annual rainfall in the basin, the blue color variation indicates an increase in rainfall while the orange-red variation 
indicates a decrease in rainfall. Generally, the central and northern section of the basin experienced a decrease or no change in total annual rainfall over the years. These changes are not statistically significant (Figure 21b). Figure 21b highlights the statistical significance of the data, otherwise known as the p-value. For the data to be considered significant, it must fall below a $0.05(5 \%)$ point threshold. In this map, the areas shaded in yellow are below 0.05 and everything above is shown in red. A small plot of yellow can be seen in the center of the Sudd in the Bahr al-Jabal sub-basin. However, statically significant ( $\mathrm{p}$-value $<0.05$ ) increases in total annual rainfall occurred in the southeast section of the studied basin up to an increase of $16.5 \mathrm{~mm}$ per year. Regions that saw high/increase in average rainfall were areas in, around, and to the east of Lake Victoria as well as the southeastern edge of the LALKs. While the lowest Sen's slope is $7.8 \mathrm{~mm}$ per year, which indicates anything shaded in red, and orange are considered areas that shows decrease in total annual rainfall. These areas include most of the Bahr al-Jabal, including the Sudd, northern and western parts of LALKs, and western areas of LVs.

Figure 21c shows seasonal Sen's slope results. The high value, 1.7, and low value, -2.6, show little variation between the two and are very low regarding any change in average rainfall. The areas that did see a small increase, indicated by the blue, were seen in the southwestern part of LALKs, south of Lake Albert, and in LVs west of Lake Victoria. The small decrease in average rainfall was seen in LVs, south and east of Lake Victoria. The green-shaded regions are areas of no change, which is most of the Bahr al-Jabal and northern parts of LALKs. Figure 21d illustrates the Sen's slope of the wet MAM season. Unlike the JF dry season, MAM saw a larger variation between the high and low Sen's slope values. With the maximum increase value at 10.5, if multiplied by 39 for the entire rainfall data then the average rainfall for regions in blue 
increased around $400 \mathrm{~mm}$. Those regions were to the west and southeast of Lake Victoria. The low value of -4.0 , which averages out to a decrease of $150 \mathrm{~mm}$ of average rainfall, was seen in the central part of LALKs and to the south of Lake Victoria. Figure 21e shows the Sen's slope of the JJAS season while Figure $21 \mathrm{f}$ illustrates the OND season. Although JJAS is a wet season and OND is a dry season, their Sen's slope maps compared similarly to each other. Both seasons show similar variation in their high and low values. The higher value is around 7.3-7.5 while their low values are both negative with JJAS having a -2.3 and OND a -3.9. The spatial variations are closely related by looking at the maps. The largest increase in in average rainfall for both seasons occurred in the southeastern portion of LALKs, the northeastern part of LVs, and eastern part of LVs occurring in and to the east of Lake Victoria. A decrease in average rainfall for OND occurred in the region just northwest of Lake Victoria with a small decrease/no change occurring in the Sudd and Bahr al-Jabal sub-basin. As for the JJAS, a decrease in average rainfall occurred at the northern edge of LALKs near the border of the Bahr al-Jabal with a smaller region of decrease just to the south of the Sudd Wetland in the Bahr al-Jabal.

Figure 1-E depicts the average amount of rainfall that was recorded annually and seasonally. The lowest amount of average rainfall that was observed was in the Bahr al-Jabal sub-basin and smaller portions of the LALKs and LVs located on their eastern boundaries. Figure 23b shows the dry JF season that left a huge deficit in rainfall for the Bahr al-Jabal, most of the LALKs, and northern parts of LVs. The red values for JF depict a value of zero. On the other hand, MAM displays the opposite regarding spatial variation of average rainfall for JJAS wet season. The variation between high, $967 \mathrm{~mm}$, and low values, $5.4 \mathrm{~mm}$, is much larger compared to JF. The Bahr al-Jabal saw a high influx of average rainfall that extended into 
LALKs and northeastern parts of LVs. The entire southern region of LVs saw a low average of about $5 \mathrm{~mm}$ of rainfall with a slightly increasing average moving into northern LVs. Similar spatial resolutions were seen even though MAM is a wet season and OND is a dry season. Both seasons showed the smallest average rainfall occurred in the Bahr al-Jabal with an average of around $92 \mathrm{~mm}$ in MAM and $64 \mathrm{~mm}$ in OND. The LALKs also recorded a similar rainfall average as the sub-basin is shaded in yellow for MAM and OND, except a small section in the southwestern part of the basin. The LVs saw the largest average rainfall for both MAM and OND with the western portion of Lake Victoria receiving the largest average. Just like the annual rainfall data, the seasonal averages will be discussed later when talking about the rainfall's role in understanding climate impacts on the Sudd. 
Annual Sen's Slope

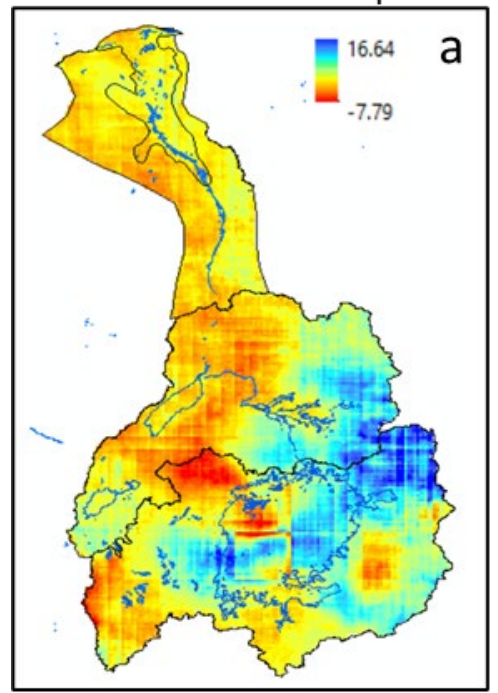

MAM Sen's Slope

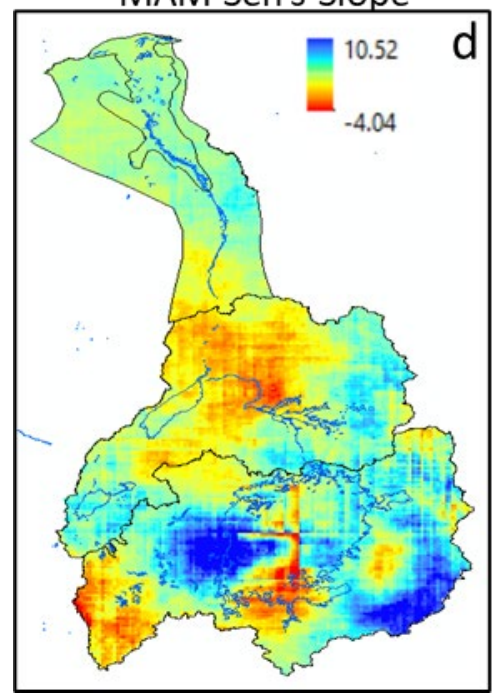

Annual P-Value

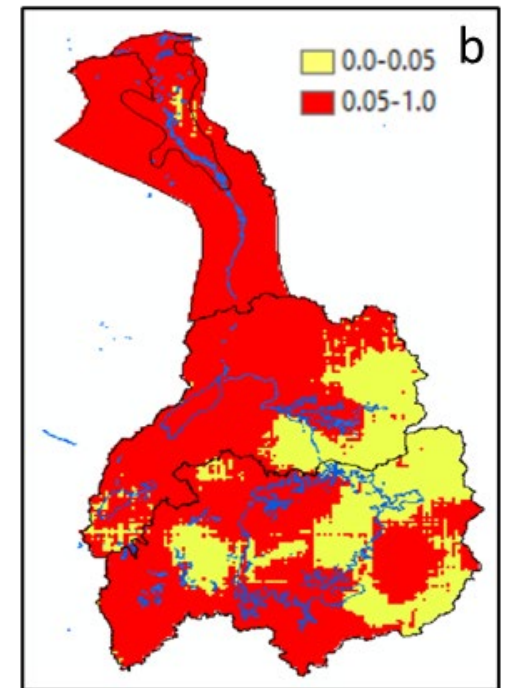

JJAS Sen's Slope

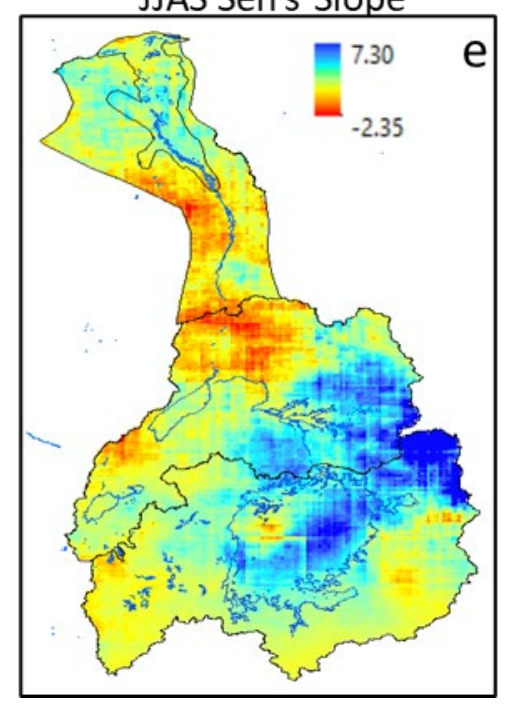

JF Sen's Slope

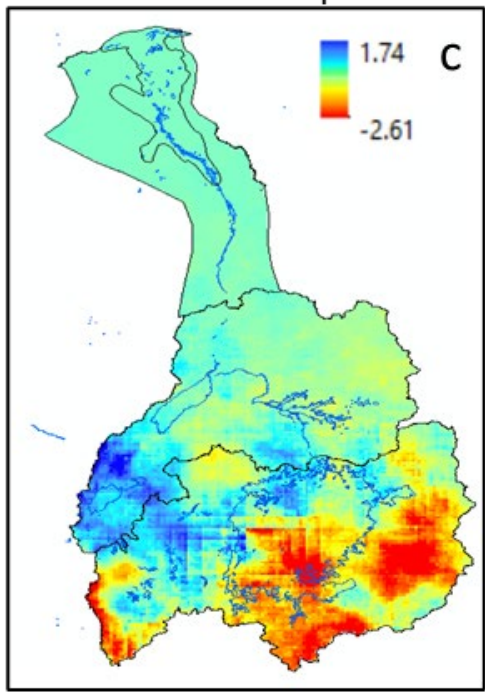

OND Sen's Slope

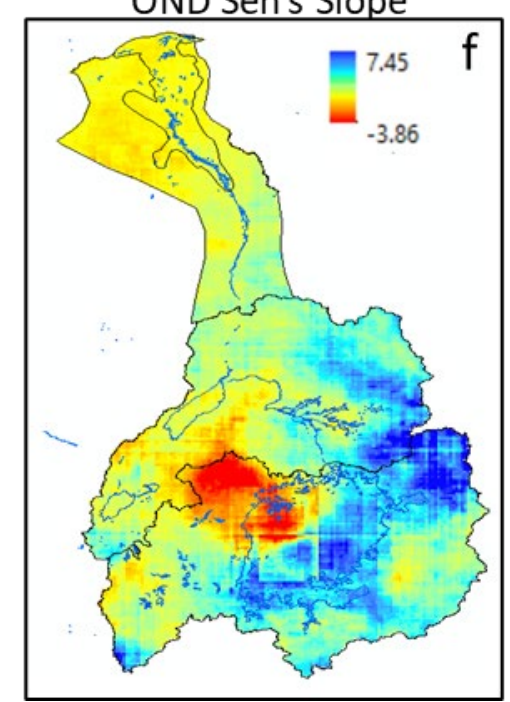

Figure 21. (a) Map of the entire study region showing the annual Sen's slope of the CHIRPS data. (b) Is the annual P-value map showing the areas and data that are significant.

(c-f) Are the four seasonal Sen's slope maps. The Sudd is outlined in black located at the top (north) of the maps. Monthly Sen's slope and P-value maps are found in Figure D-2. 


\section{Sudd Wetlands}

\section{The Normalized Difference Vegetation Index (NDVI)}

The Sudd Wetland, located in the Bahr al-Jabal sub-basin, contains a range of vegetation and water that provides as a resource to a vast biodiversity and indigenous people who occupy it. To understand the changes in the wetland vegetation due to climate, satellite-based greenness index (NDVI) was used. NDVI values range from 0 to 1,0 represents no green vegetation cover to 1 with $100 \%$ green vegetation cover in each pixel.

The first depiction of the data is illustrated in Figure 22 of a heat map generated to show variation in the greenness index. The overall trend of this heat map shows a lower amount of vegetation from January to April (dry season of JF and part of wet season of MAM) and a higher amount of vegetation from June November (wet season of JJAS and part of the dry season of OND). However, those lesser amounts of vegetation that are consistent from January through April begin to slowly decrease in the rate throughout the years. There were longer periods of less vegetation prior to the 2000's, but those red months transition to orange and even yellow colors indicating an increase from prior years. The months of June and December are key months to examine. December from 1981-2000 is consistently yellow and light orange, but the values shift into light green and green in more recent years. The same trend is seen in the months of July to November, the more common yellows and light green shift into green and dark greens in the last decade. The 1984 and 2009 droughts recorded in East Africa are seen in the NDVI data in the following years (1985 and 2010) which will be discussed later in how those dry years can be indicators as to how climate truly effects the wetland. 
Figure 23 shows the monthly mean distribution of NDVI. The mean monthly NDVI varies from month to month, with high vegetation coverage in the months of June, July, August, and September (with average NDVI of 0.6) and the lowest vegetation coverage occurs in the months of February, March, and April (with average NDVI value of 0.35).

Figures 24 a-b show the minimum and maximum annual NDVI data for the Sudd from 1981-2019. Both the minimum and maximum values show an overall increasing trend. The data can be directly linked to the heat map (Figure 22) with the greener and drier years. As mentioned above, the drier months of the year (January to May) move from a more consistent red to light, orange and yellow colors. The lowest value recorded is found in 1985. These values are translated in Figure 24b showing those drier/minimum values are increasing in recent decades. The same correlation can be made with the greener months (June to November), which represent Figure 23a. These values that were already yellow to green are more consistently green in the recent decades. The highest value recorded is seen in 2010.

Figures 25 a-d show an increasing trend of the Sudd Wetland vegetation in all four seasons. Figure 25c shows the dry season of JF and its average values for NDVI. Overall, it appears that the vegetation cover is increasing, but it can be seen if split into 5-year increments the values decrease. From 1983-1987 there is a sharp decrease in the dataset. Every year there is a maximum value, the following years show a downward trend (i.e., 1988-1990, 1993-1997, 1999-2003, 2014-2019). The trend that is seen in JF is seen in the rest of the seasons as shown in Figures 25 d-f. 


\begin{tabular}{|l|l|l|l|l|l|l|l|l|l|l|l|l|}
\hline & Jan & Feb & Mar & Apr & May & Jun & Jul & Aug & Sep & Oct & Nov & Dec \\
\hline 1981 & & & & & & & & & & & & \\
\hline 1982 & & & & & & & & & & & & \\
\hline 1983 & & & & & & & & & & & & \\
\hline 1984 & & & & & & & & & & & & \\
\hline 1985 & & & & & & & & & & & \\
\hline 1986 & & & & & & & & & & & \\
\hline 1987 & & & & & & & & & & & \\
\hline 1988 & & & & & & & & & & & \\
\hline 1989 & & & & & & & & & & & & \\
\hline 1990 & & & & & & & & & & & & \\
\hline 1991 & & & & & & & & & & & & \\
\hline 1992 & & & & & & & & & & & & \\
\hline 1993 & & & & & & & & & & & \\
\hline 1994 & & & & & & & & & & & \\
\hline 1995 & & & & & & & & & & & & \\
\hline 1996 & & & & & & & & & & & & \\
\hline 1997 & & & & & & & & & & & \\
\hline 1998 & & & & & & & & & & & \\
\hline 1999 & & & & & & & & & & & & \\
\hline 2000 & & & & & & & & & & & & \\
\hline 2001 & & & & & & & & & & & & \\
\hline 2002 & & & & & & & & & & & \\
\hline 2003 & & & & & & & & & & & \\
\hline 2004 & & & & & & & & & & & & \\
\hline 2005 & & & & & & & & & & & \\
\hline 2006 & & & & & & & & & & & \\
\hline 2007 & & & & & & & & & & & & \\
\hline 2008 & & & & & & & & & & & \\
\hline 2009 & & & & & & & & & & & \\
\hline 2010 & & & & & & & & & & & \\
\hline 2011 & & & & & & & & & & & & \\
\hline 2012 & & & & & & & & & & & \\
\hline 2013 & & & & & & & & & & & \\
\hline 2014 & & & & & & & & & & & & \\
\hline 2015 & & & & & & & & & & & & \\
\hline 2016 & & & & & & & & & & & \\
\hline 2017 & & & & & & & & & & & \\
\hline 2018 & & & & & & & & & & & & \\
\hline 2019 & & & & & & & & & & & & \\
\hline 2020 & & & & & & & & & & & & \\
\hline
\end{tabular}

Figure 22. Heat map generated combining the AVHRR and MODIS data to create a complete dataset showing annual, monthly, and season variation of NDVI. 


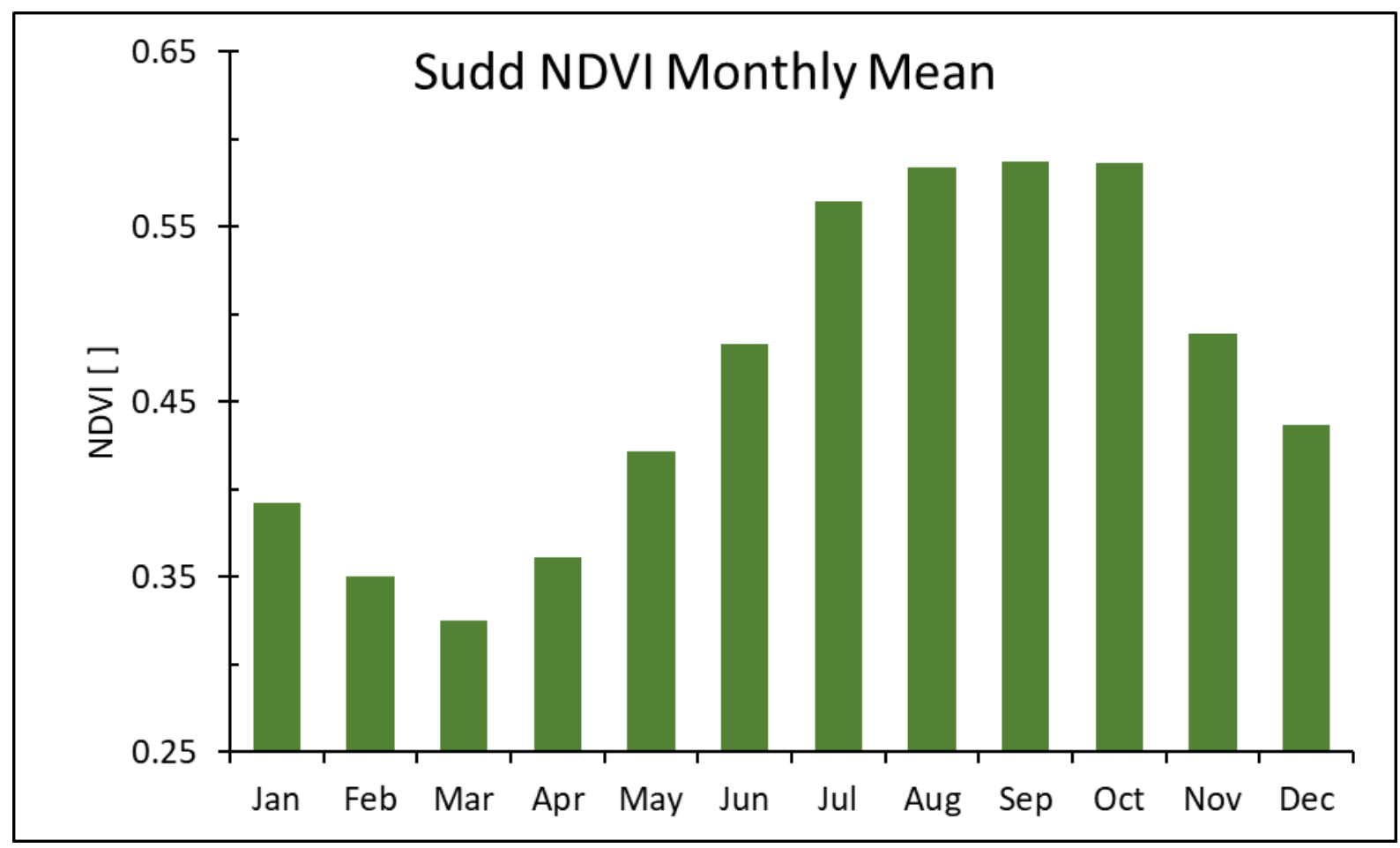

Figure 23. Mean monthly NDVI for the Sudd Wetland from 1981-2019. 


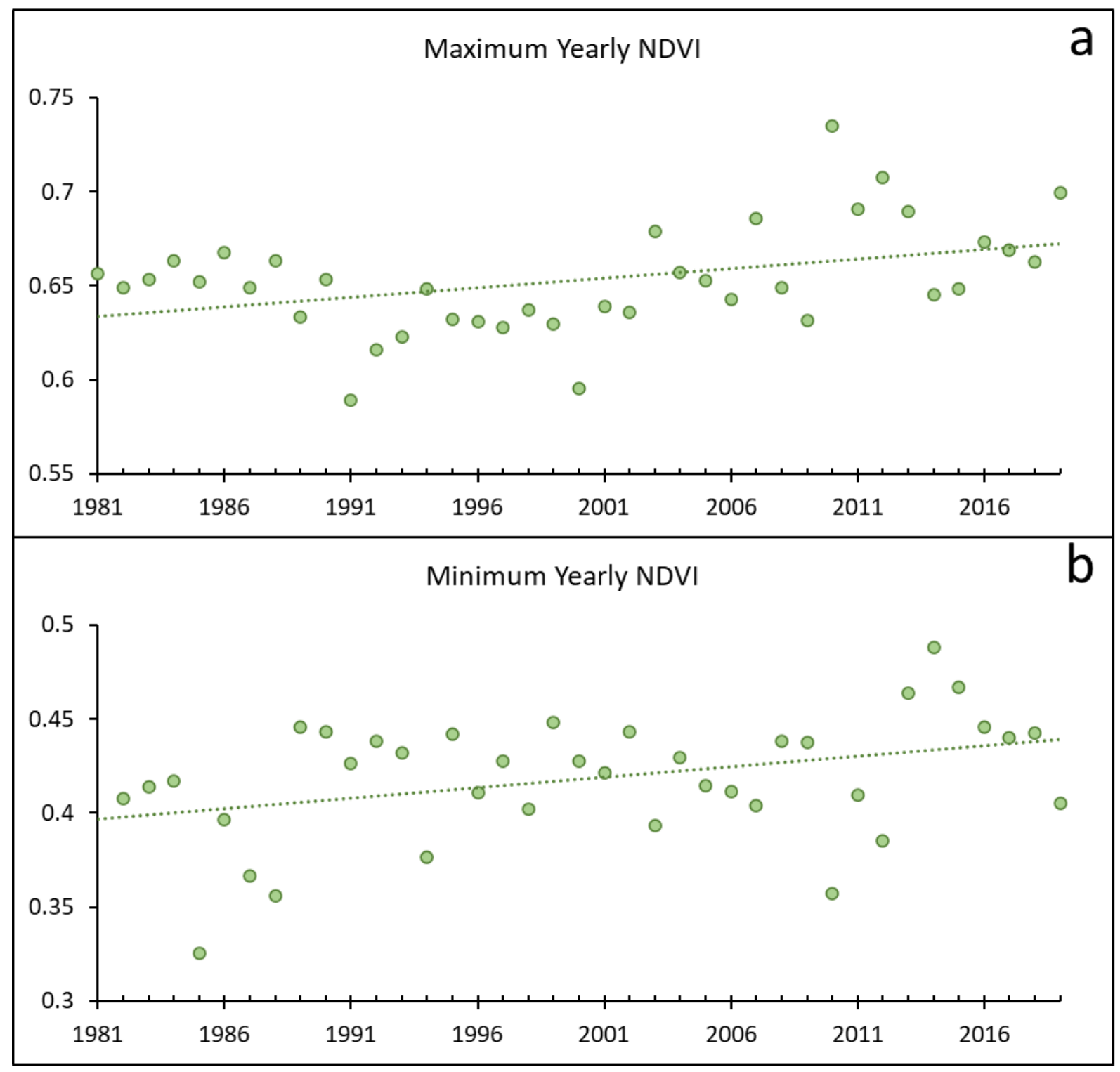

Figure 24. Minimum (a) and maximum (b) NDVI recorded in the year from 1981-2019. 


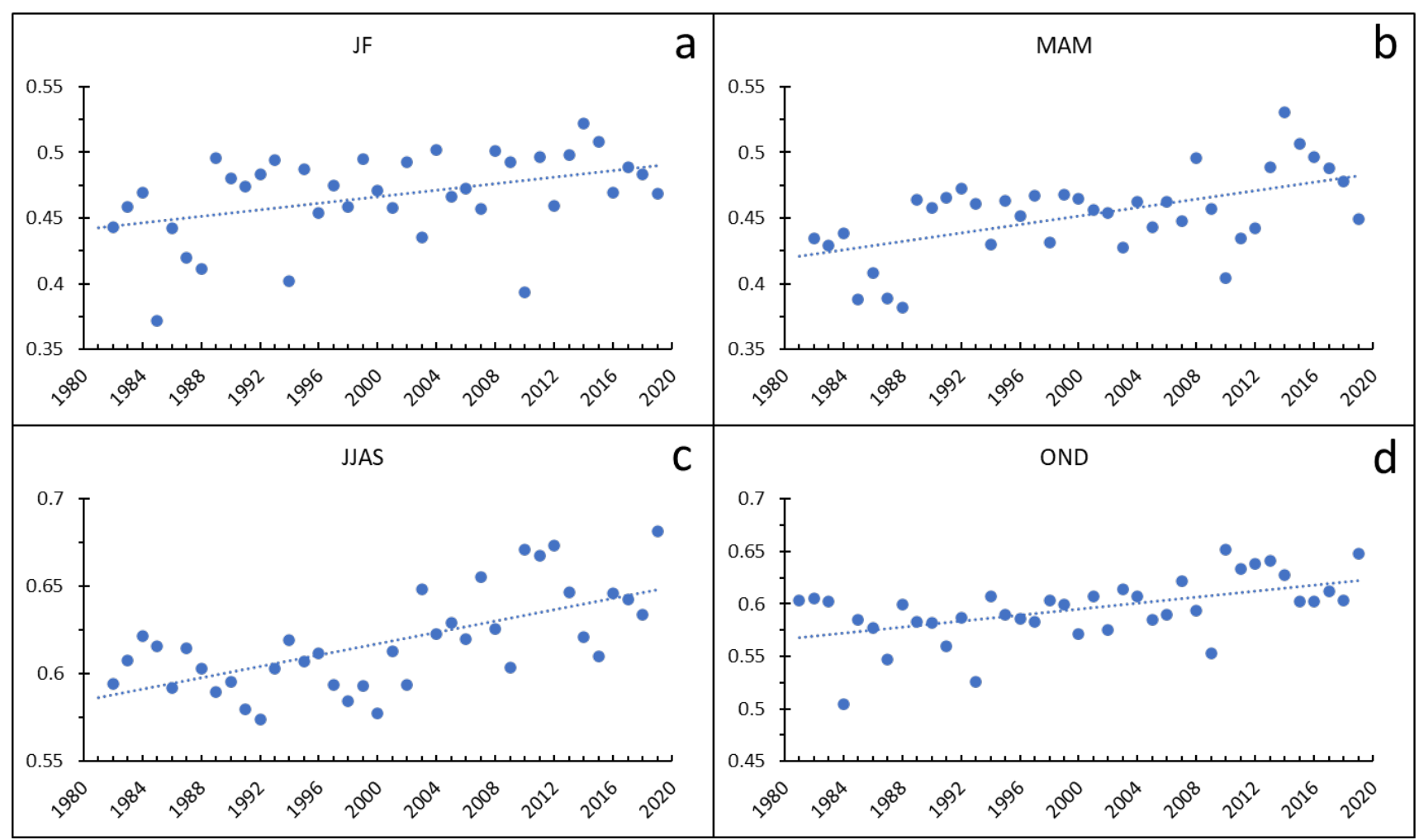

Figure 25 (a-d) Seasonal graphs created to show the change of the NDVI within the four seasons.

\section{Spatial NDVI Trend Analysis}

The AVHRR and MODIS sensors were the two datasets used to complete a full time span of this project (1981-2020). To keep the integrity of the data, the two different spatial resolution datasets were not merged. Figures 26a and 26c are the Sen's slopes monthly NDVI from AVHRR (Figure 26a) and MODIS satellite data (Figure 26c). The vegetation, based on the spatial maps, overall appears to be staying the same. However, there are areas that are showing more of an increase than areas showing a decrease. The P-Value graphs for both AVHRR (Figure 26b) and MODIS (Figure 26d) are represented to show the significance of the two NDVI datasets. Both datasets show that most of their data are insignificant (as shown in red) compared 
to the data that is significant (shown in green). There are two areas in the AVHRR data that are missing data (signified by white boxes found in the Sudd).

Figure 26e is the JF seasonal dataset for AVHRR. The areas in the Sudd that saw an increase in average vegetation was seen mostly at the southern tip where the White Nile River enters the wetland. The rest of the color values indicate no change or a decrease in vegetation, especially the areas north of the central region of the Sudd. Outside of the Sudd in the sub-basin, many areas also saw a decrease in vegetation. The southern boundary, where the Bahr al-Jabal borders the LALKs, saw the largest area of land that decreased in average vegetation.

Figure 26f shows the AVHRR dataset of the wet season of MAM. Compared to JF, it appears the Sudd is covered in greener, increasing, areas along its eastern and norther boundaries. Along the western and southern edge of the Sudd, there is a predominant rate of decrease in average vegetation. The rest of the Bahr al-Jabal saw largely a decrease or no change in the vegetation just like JF.

The JJAS AVHRR data showed even greater amount of decrease in vegetation within the wetland as most of the boxes are light orange to red (Figure 26g). Everything to the west and south of the Sudd showed signs of increase.

Figure 26h was the OND season, and it saw most of the Sudd showing signs of decreasing average vegetation. Not only did the Sudd see decrease, but the entire northern 
section of the Bahr al-Jabal saw a decrease in vegetation. At the southern edge of the Sudd and in that surrounding region was the only area of the sub-basin that saw an increase during OND.

Based on all four AVHRR figures, most of the Bahr al-Jabal and Sudd saw no change or decrease in average vegetation in the early analysis period, from 1981 to 2000.

The MODIS data with higher spatial resolution was used to represent NDVI from 20002019. Figure 26i illustrates the Sen's slope of the JF season. The areas that show signs of increase are seen in the northwest corner of the Sudd Wetland extending outside the wetland's boundary as well as a small patch of increasing average vegetation in the lower eastern portion of the Sudd. Most of the sub-basin is experiencing no change or a decrease in average vegetation for the season. A large swath of area that is showing signs of decrease is seen just outside of the southeastern wetland extent. A smaller area of red can be seen both inside and outside of the wetland extent located near the west-central area of the Sudd.

The MAM season analyzed by MODIS shows similar trends as the JF season (Figure 26j). Both regions of red, decreasing average vegetation can be seen in both JF and MAM. Most of the Sudd shows signatures of no change or a decrease in average vegetation. However, outside of the wetland extent, there is more regions of green are the Sudd compared to JF. Near the southern border of the sub-basin is a large region of decreasing vegetation much greater than what is seen in JF. 
The Sen's slopes created for the JJAS and OND (Figures 26k and 261) seasons show similar trends regarding the Sudd's vegetation values. Just like JF and MAM, the Sudd's overall vegetation value is showing no change or signs of decrease. Small pockets of the Sudd show increasing values in the northwestern, west central, and southern parts. Both JJAS and OND had large areas south of the central region and to the north in the Sudd experience decrease in average vegetation. 


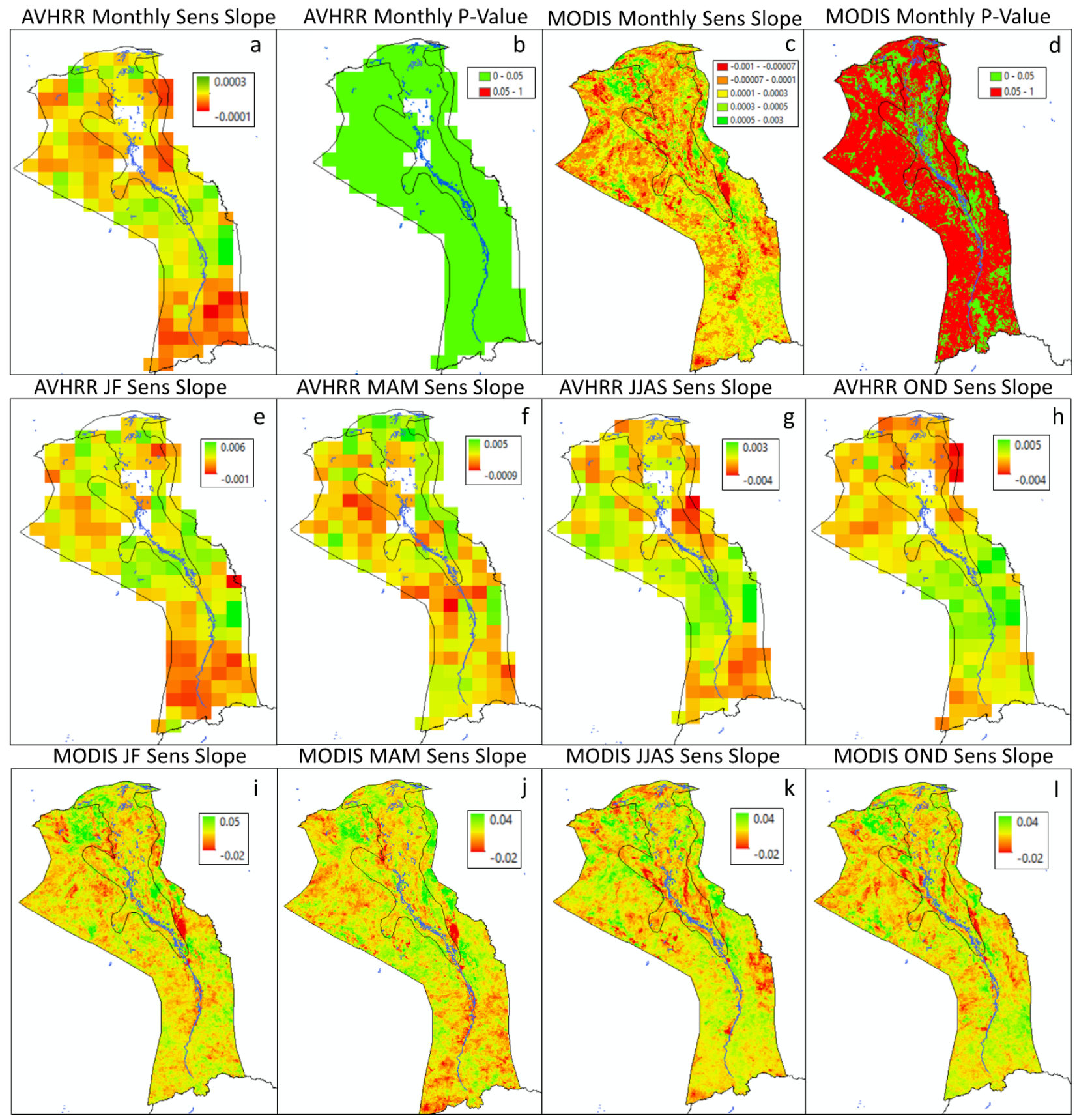

Figure 26. (a and c) are the monthly Sen's slopes for AVHRR and MODIS and their respected PValues (b and d). (e-h) show seasonal Sen's slope for NDVI data plotted on the Bahr al-Jabal sub-basin that was recorded by the AVHRR sensor from 1981-2000. (i-1) are seasonal Sen's slope for NDVI in the Bahr al-Jabal taken from the MODIS sensor that mapped from 2000-2020. 


\section{Water Level/Surface Area of Water Bodies}

Figure 27a depicts the annual sum of surface area of the water bodies in the Sudd Wetland. The total surface area of water bodies in the Sudd Wetland is on a decreasing trend from 1984-2020. The year of 1989 saw a sharp decrease in surface area, and then rebounds in the following two years.

Figure $27 \mathrm{~b}-27 \mathrm{~d}$ show lake water height for lakes in the basin. There is no overall trend of the lakes water height. There seem to be consistent fluctuations of lakes height. From 2007-2011, there is a consistent lower surface height. From late 2019 into 2020, there is a rise in water surface height by about 1-4 m.a.s.1. in the lakes. Lake Kyoga's surface height was the lowest in 1994. The water levels recovered and stabilized until they dropped again in late 2006 and stayed consistent at a lower height. The water levels continued to stay at a lower level until more recently (from 2018-2020) where there is an increase in height. A smaller variation in lake height of Lake Victoria about $\pm 1 \mathrm{~m}$ is seen from 1992 to the early 2000's. The year 2006 brings the lowest recorded water levels seen in Lake Victoria (Figure 27d), but then rebound quickly and continue to increase. The largest increase in water height is seen in late 2019 and into 2020 , where the highest water level point is recorded. 

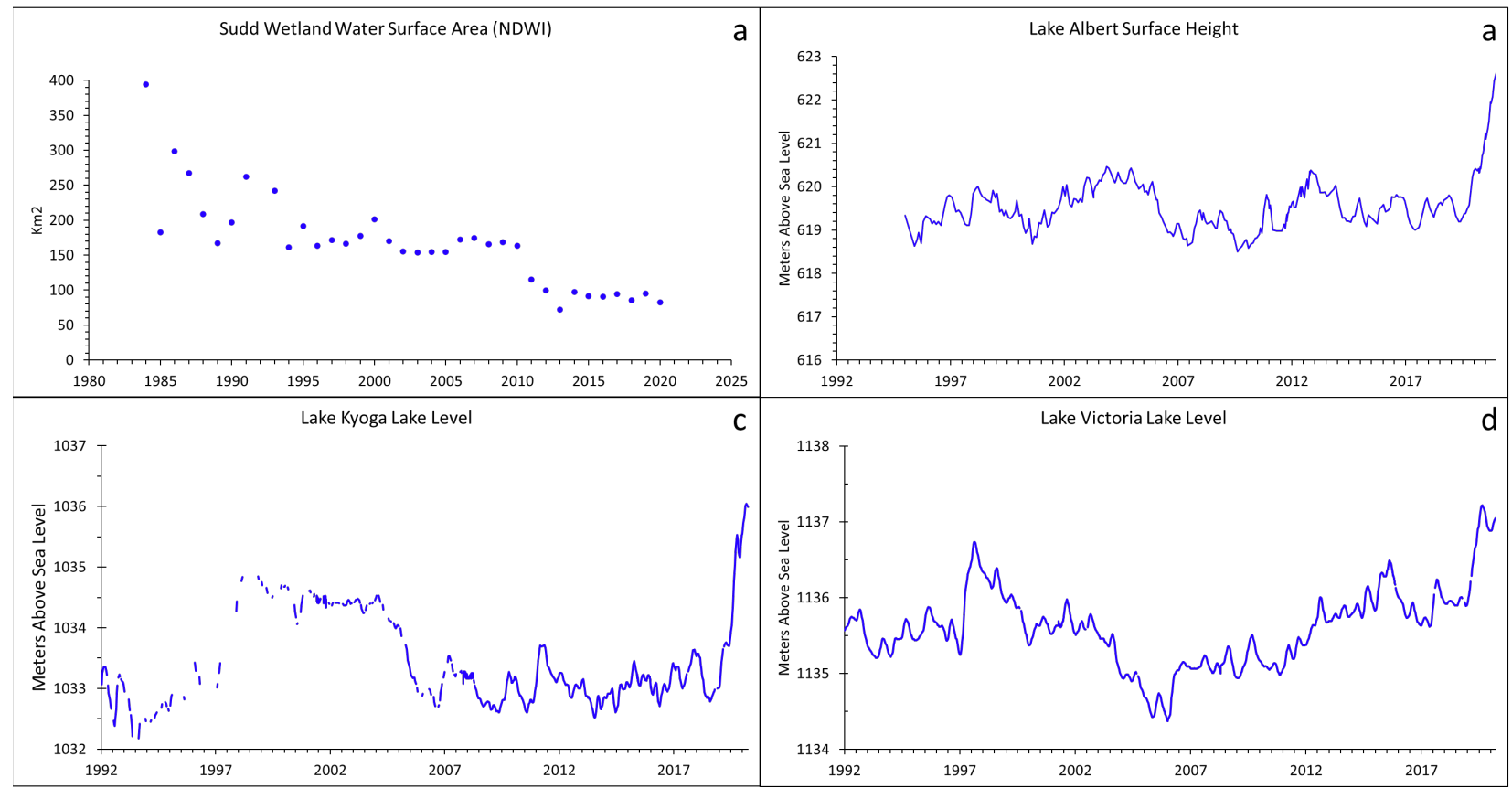

Figure 27. (a) Total surface water area of water bodies in the Sudd Wetland extracted from various Landsat satellites. (b) Lake Albert water height that was collected from ESA's Copernicus climate program. (c and d) Lake level data for Lake Kyoga and Lake Victoria plotted based on distance above sea level (in meters) from 1992-2020. Data was gathered from various satellite missions of TOPEX/Poseidon and Jason's 1-3. 


\section{CHAPTER VI: DISCUSSION}

The mean temperature data (1983-2016) showed an overall increasing rate in the basin as well as within each sub-basin. It is important to understand this piece of evidence as temperature directly impacts biome processes, like evapotranspiration, that relay on specific temperatures during various changing seasons. Similar increases in average temperature were seen across the continent of Africa (Hulme et al., 2001; Gebrechorkos et al. 2019). The rainfall data (1981-2019) also saw an overall increase through time and within each sub-basin. The LV subbasin had the highest rate of increasing average rainfall whereas decreasing or no change in rainfall trend was observed for the other two sub-basins. The NDVI data that characterize the spatial and temporal pattern in vegetation saw an increasing trend over time both monthly and seasonally. The NDVI illustrates that the upstream supply of surficial water flowing into the wetland is replenishing the vegetation enough to keep the Sudd from decreasing.

For sustainability of vegetation in the Sudd, there needs to be enough supply of water to nourish the wetland. That supply of water comes from direct rainfall, inflow of water from the surrounding Bahr al-Jabal sub-basin, and inflow from the two upstream sub-basins LALKs and LVs. The average rainfall that falls the LALK and LV sub-basins will eventually make its way into the Sudd through the White Nile River. Figures 28a shows cross-correlation between NDVI and rainfall for each sub-basin, rainfall was plotted as the "leading data" against the "lagging data" of the monthly NDVI. Figures $28 \mathrm{~b}$-d highlight the highest correlation (r) between rainfall and NDVI for each of the three sub-basins. The Bahr al-Jabal $(\mathrm{r}=0.87)$ and LALKs $(\mathrm{r}=0.62)$ both resulted in a 2-month lag correlation, while LVs highest correlation $(\mathrm{r}=0.47)$ had a 7-month lag 
correlation. The entire data set had a correlation significant of $\mathrm{r}=0.1$. A 2-month lag for the Bahr al-Jabal and LALKs is signifying that it takes short period for the rainfall that fell in those two sub-basins to take effect on the Sudd wetland. The rainfall might have a more immediate effect than two months, but the main distribution of rainfall has the greatest impact at a 2-month length with a higher $r$ value. The two main sources of water for the Sudd come from Lake Albert and Lake Kyoga that supplies water into the White Nile River that runs north into the Sudd. The LALKs and LVs show similar distribution of rainfall vs. NDVI data in Figures $28 \mathrm{c}-\mathrm{d}$. However, the lag time for LVs is 7 months. This is most likely due to that fact that it is the farthest subbasin from the Sudd. The main source of water supplies for the Sudd from the LVs is Lake Victoria water flowing into the White Nile River, which then travels roughly $700 \mathrm{~km}$ to reach the Sudd. Any impact on rainfall and/or lake levels of Lake Victoria will take time to trickle through the system into the Sudd. 


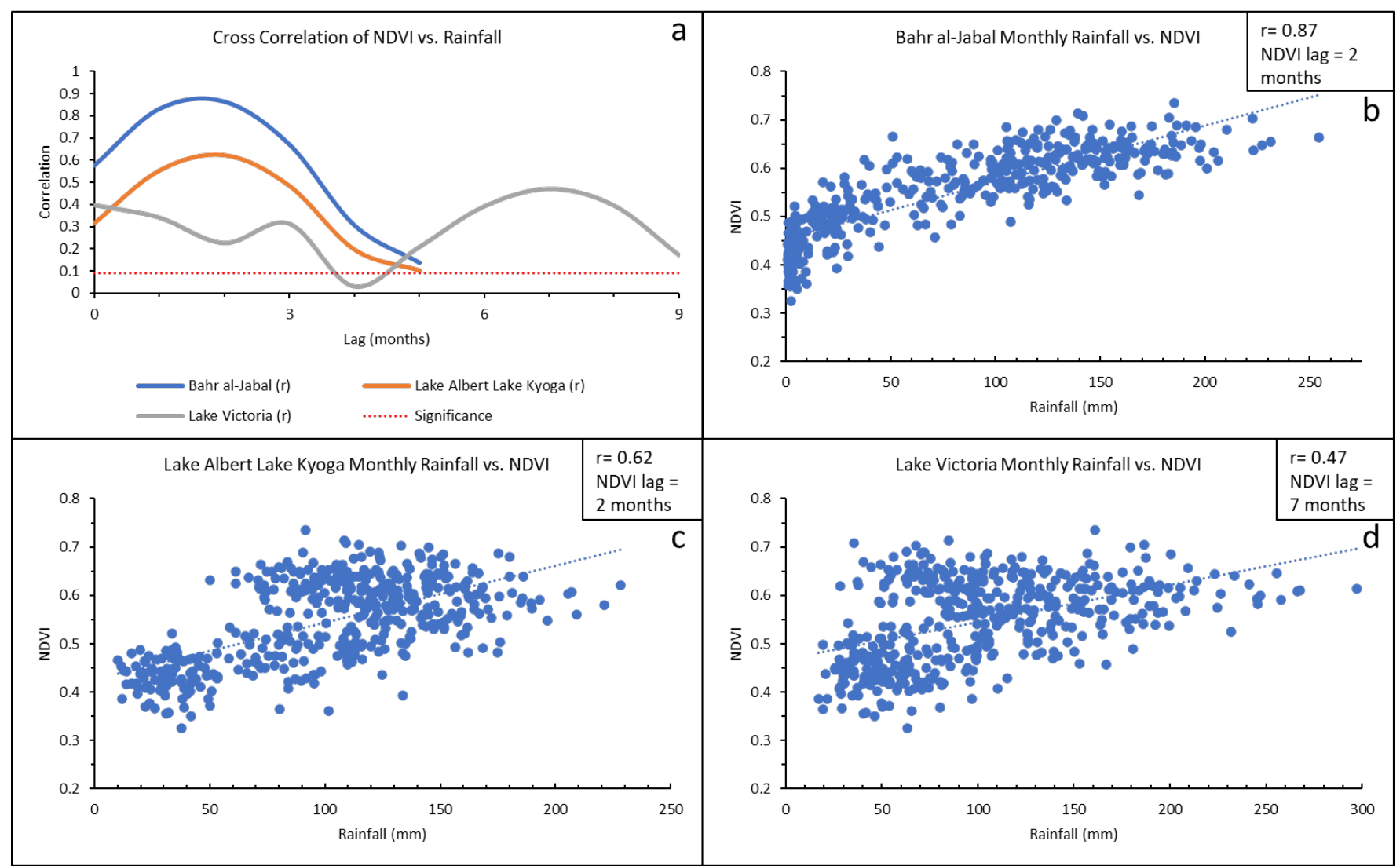

Figure 28. (a) Cross-correlation between NDVI and rainfall in each of the three sub-basins. (b-d) are the graphs representing the highest correlation for each sub-basin's monthly average rainfall plotted against the Sudd's monthly NDVI data.

\section{Climate}

Overall, the entire study basin saw an increase in average temperature. The greatest increase of temperature from $1983-2016$ is $1.02{ }^{\circ} \mathrm{C}$, which is seen in small areas in the Sudd Wetland, the southern portion of the Bahr al-Jabal, and the northern part of the LALKs at the Bahr al Jabal border. The smallest increase of temperature during the 34 -year is $0.32{ }^{\circ} \mathrm{C}$ which occurred in the upper portion of the Bahr al-Jabal and south-central part of LVs. 
The seasonal trends also showed that every season saw an overall increase in average temperatures, except OND in the Bahr al-Jabal. The Bahr al-Jabal, and the upstream areas of LALKs and LVs are increasing at a rate roughly between $0.5^{\circ} \mathrm{C}-1.0^{\circ} \mathrm{C}$.

These trends observed in the East African region hold true and are greater in some portions of the study area. Hulme et al., (2001) studied the entire continent of Africa and observed an increased in temperature during the $20^{\text {th }}$ century by at least $0.5^{\circ} \mathrm{C}$. Temporal and spatial temperature data from 1951-2010 was examined by Ongoma and Chen (2017) in East Africa's, specifically Uganda, Kenya, and Tanzania, found that on average the regional temperature has increased by $1.5^{\circ} \mathrm{C}$. Mohamed and Savenije (2006) conducted research on the Sudd Wetland trying to understand climate impact from 1900-2000. They found that the maximum temperature (T-max) increased $0.6{ }^{\circ} \mathrm{C}$ while the minimum temperature (T-min) increased by $1.5^{\circ} \mathrm{C}$ during the $20^{\text {th }}$ century. The evidence is clear from the macroscale of the entire continent of Africa down to the microclimate of East Africa and even studies from the Sudd that the temperature is increasing at a significant rate.

Rainfall in the East African region is highly dependent on the changing air circulations of various biannual process. These air circulations advertently affect the seasons that impact the upper Nile River basin. As described earlier, the Intertropical Convergence Zone (ITCZ) migrates between $25^{\circ} \mathrm{N}$ and $25^{\circ} \mathrm{S}$ of the equator throughout the year and is affected by the IOD. The negative phase of the system brings colder sea surface temperatures to the east coast of Africa, which reduces the amount of rainfall in East Africa and is responsible for the two dry seasons (JF, OND) (Johnson, 2020). Warmer waters are driven to the east coast of Africa during 
the positive phase of the IOD that truly generates the rainfall in the region and study area that is seen during the wet seasons of MAM and JJAS (Gebrechorkos et al. 2019). Due to changes in elevation and location, the seasonal climate of LVs is slightly shifted in terms of dry and wet seasons. With the positive phase of the IOD increasing rainfall in East Africa already, climate change would theoretically cause those current, warm waters to increase in temperature. Increasing the sea surface temperature would also increase average rainfall events. The same scenario may occur when looking at the negative phase of the IOD. The 2019 positive phase of IOD showed increases in sea surface temperatures when compared to data from 1981-2010 (Johnson, 2020. In the future if climate change continues and increase the overall surface temperatures of the oceans, the cold water during the negative phase could be increased to slightly warmer waters. The warming of the once colder sea temperatures could increase the chances of more rainfall events to occur in the East Africa region.

From the data observed temporally and spatially of rainfall from 1981-2019 there is an overall increase in average rainfall. Looking at both the wet seasons of MAM and JJAS (which are affected by the positive phase of the IOD) and dry seasons JF and OND (which are affected by the negative phase of the IOD), all but the season of JF show signs of increasing average rainfall from 1981-2019. Spatially, the LV subbasin experiencing significant increase while no or small increase observed in the remaining subbasins-LALK and BAJ.

Regarding seasonal rainfall, each of the four seasons, two wet and dry, during the year all saw various trends of average rainfall in each sub-basin. The dry season of JF was the only trend of the seasonal rainfall data that saw an overall decline in average rainfall. For JF, Bahr al-Jabal 
and LVs saw a decline in rainfall, while LALKs saw little-to-no change. The wet season of MAM within each sub-basin recorded little-to-no change in the Bahr al-Jabal and LALKS, and LVs saw an increase in average rainfall. The second wet season of JJAS brought no change of average rainfall in the Bahr al-Jabal but increasing trends in LALKs and LVs. Lastly, the dry season of OND saw an increasing trend for average rainfall in LALKs and LVs and little-to-no change in the Bahr al-Jabal. The Bahr al-Jabal was the only sub-basin that saw a fractional change or no change at all throughout the four seasons.

Within the study area, the elevation differences between the three sub-basins are a big factor of their average temperatures annually and seasonally. At higher elevations, a decrease in temperature occurs making it cooler. At or near sea level, the amount of air and air pressure is greater allowing for temperatures to be greater than temperatures at higher elevations. The Bahr al-Jabal, which contains the Sudd Wetland, sits at $400 \mathrm{~m}$ above sea level (Figure 3), and it is the closest to sea level compared to LALKs and LVs. Lake Victoria, in the LVs, sits at around 1,100 $\mathrm{m}$ above sea level (Lehman, 1998). Therefore, average temperatures decline as the elevation increases from the Bahr al-Jabal into LALKs and LVs. As the LVs is the headwater region of the White Nile River, the elevation is at its highest for the study area (Figure 3). Higher elevation in LVs causes average temperatures to be only $1-2{ }^{\circ} \mathrm{C}$ cooler than the LALKs and about $5-7{ }^{\circ} \mathrm{C}$ cooler than the Bahr al-Jabal.

An increasing temperature in all aspects of the Sudd basin can be directly tied to climate change - due the increase in GHG emissions. Further, climate projections and models generated for the rest of the $21^{\text {st }}$ century shows an increasing trend. For example, Hulme et al. (2001) 
analyzed projected climate data for the $21^{\text {st }}$ century data for Africa using multiple climate models. Based on their predictions, they projected that East Africa could see a $0.5^{\circ} \mathrm{C}-1.0{ }^{\circ} \mathrm{C}$ and $15 \mathrm{~mm}-50 \mathrm{~mm}$ increase in temperature and rainfall, respectively, for DJF seasons and $10 \mathrm{~mm}-20$ $\mathrm{mm}$ rainfall increase for JJA between 2020-2080. The second model simulation projects a 1.0 ${ }^{\circ} \mathrm{C}-3.0^{\circ} \mathrm{C}$ and $30 \mathrm{~mm}-130 \mathrm{~mm}$ increase in temperature and rainfall, respectively, for DJF and 20 mm-70 mm rainfall increase for JJA between 2020-2080.

\section{Sudd Wetland in Relation to Climate}

Based on the results shown above, there is conclusive evidence of increase in both average rainfall and temperature over the past four decades for the three sub-basins located in the Nile River basin, and projections made by published journals support the idea these constituents of climate will continue to increase in East Africa.

It is speculated that the rainfall from the upstream basins influence the wetland vegetation. The rainfall supplies the sub-basins with fresh water that will then flow from the White Nile River into the Sudd Wetland. However, this does not happen instantly due to a lag. Between the correlations of NDVI and average rainfall in each sub-basin and the average rainfall of each of the 12 months, there is a consistent relationship between the Sudd and rainfall. The NDVI data shows an increase in vegetation from the annual, monthly, and seasonal data listed above. The increase in vegetation helps support the speculation, which is examined more in depth in the following section, that a rise in rainfall upstream, which then feeds into the Sudd over time, helps sustain the wetland. To understand the full water balance of the upstream 
portion of the White Nile River, more recent discharge rates would need to be recorded and addressed to compare with historic data to see if there is a change in water flowing into the Sudd.

The seasonal average NDVI for the Sudd showed that the JJAS and OND seasons have the more green values with JF and MAM showing less green values. The wet seasons are the MAM and JJAS months. Because of the lag the NDVI is "delayed" because it takes time for that rainfall to take effect on vegetation. The surface water from the upstream sub-basins plays a crucial role in supplying water to the Sudd. However, it is hard to determine if the drastic change (decrease) in water entering LVs and LALKs leaves a measurable impact on the Sudd's extent due to the consistent supply of water flowing from the White Nile into the Sudd. What is apparent though is the upstream sub-basins affect the maximum average NDVI values recorded by looking at Figure 24 and rainfall data for LALKs and LVs. As the annual rainfall has increased for both LVs and LALKs, the maximum average NDVI values also increase.

Not only is there a relationship between annual rainfall and the seasonal NDVI, but that relationship is increasing into the more recent years of the study. The average amount of rainfall is increasing at a steady rate in each sub-basin (Figure A), while the NDVI values in each season show an increase. While the averaged seasonal NDVI data is useful, it does not tell the full story about the wetland extent. The spatial NDVI data (Figures 26) not only indicate the specific areas that are seeing loss or gain but their magnitudes. Based on Figures 26, the Sudd seems to undergo no change with more parts showing a decrease in vegetation versus an increase. The spatial data helps capture the full impact the climate has on the Sudd. The relationship between 
temperature and the Sudd Wetland is likely to be between local temperature within the Sudd and surrounding parts of the Bahr al-Jabal.

Looking at the surface water data gathered for the Sudd, the data shows a steady decline from 1984-2020. The surface water (Figure 27a; Figure B-1) is found in the floodplains of the White Nile River that diverges into two streams in the Sudd. With no change in rainfall, with an increase in temperature and NDVI, the decrease in water surface area of water bodies in the wetland is likely due to an increase in evapotranspiration that is occurring within the wetland. As mentioned before, the Sudd sits within a semi-arid climate (versus the tropical climate seen in the upstream LALKs and LVs) that sees drier air conditions all year round. With a drier environment, the process of evaporation will occur much quicker and frequently than a tropical environment. With the addition of an array of vegetation and the Sudd Wetland, evapotranspiration occurs between the plants and the surface water. As average temperatures increase in the Bahr al-Jabal and Sudd, the air will continue to become drier, and evapotranspiration will occur at a faster rate. The water surface area recorded in the Sudd in 1984 was around $400 \mathrm{~km}^{2}$ and in 2020 around $85 \mathrm{~km}^{2}$. At the decreasing rate that is observed in the surface water in the Sudd, the consequences for the biota could start to emerge. The rate of loss of surface water can also lead to consequences for the groundwater such as lowering of the water table. Although it was not focused on in this study, the groundwater systems beneath the Sudd might aid in the sustainability of the wetland, specifically during dry seasons.

Another speculation that could lead to further study of the Sudd is dealing with the analysis of vegetation and the surface area water bodies. Since the data showed an increase in vegetation throughout the wetland, it is possible that the increase in vegetation could cause 
surface water to be blocked out by the vegetation. If vegetation is covering surface water, the NDVI sensors aboard satellites could read that area as vegetated verse being a water body. The increasing trend of vegetation from 1981-2020 could also cause the decrease in visible surface water bodies in the Sudd, which is showing a declining trend from 1984-2020.

\section{Interannual Variability (fluctuations) of the Climate}

Recognizing low water height levels in the three lakes upstream from the Sudd in correlation with below-average rainfall years and/or seasons and then analyzing the NDVI of the Sudd will help assess the effect of interannual climate variability in the Sudd. Extreme drought occurred across the region in the year 1984, 1993, 2005, and 2009. Assessing these droutht conditions and comparing them to how the Sudd Wetland responds to them over time was essential to understanding how the climate can really impact the Sudd. This approach was done with another paper that focused on East African climate (Seyoum, 2018). As discussed in the previous section, water supplies from the lakes (shown by lake level data) upstream, the White Nile River, and rainfall from the upstream basins have a lasting impact on the vegetation in the Sudd, while the temperature within the Sudd has more of an affect compared to the temperature in LALKs and LVs. That is why a culmination of the lake level data, upstream rainfall data, and temperature data from within the Sudd need to be correlated to see if the Sudd is being impacted by the regional climate. Low values of vegetation were assessed during the dry months (JanuaryMay) in the heat map (Figure 22) to address potential drought conditions. 2009 showed signs of lower vegetation throughout the year; it also showed lower lake levels (Figures 27) within the same year as well as lower average rainfall data recorded that year (Figure 17 and $19-$ left). Due 
to the lag of vegetation in the Sudd in response to the upstream rainfall, the dry sesons of January-March in 2010 on the NDVI heat map were recorded as the lowest (more red) values throughout the study period. In 2010, average rainfall in the upstream basins recorded much higher values than in 2009, all three lakes showed increase in lake level that same year. As a result of drier conditions in 2009 followed by wetter conditions in 2010, the vegetation in the Sudd for 2010 and 2011 are seen in Figure 29. February of 2011 showed much greater amounts of vegetation within the Sudd compared to February of 2010. The effect of upstream water supplies as well as regional climate by targeting these drought conditions help show the correlation between regional climate and the Sudd's vegetation.

Feb. 2010

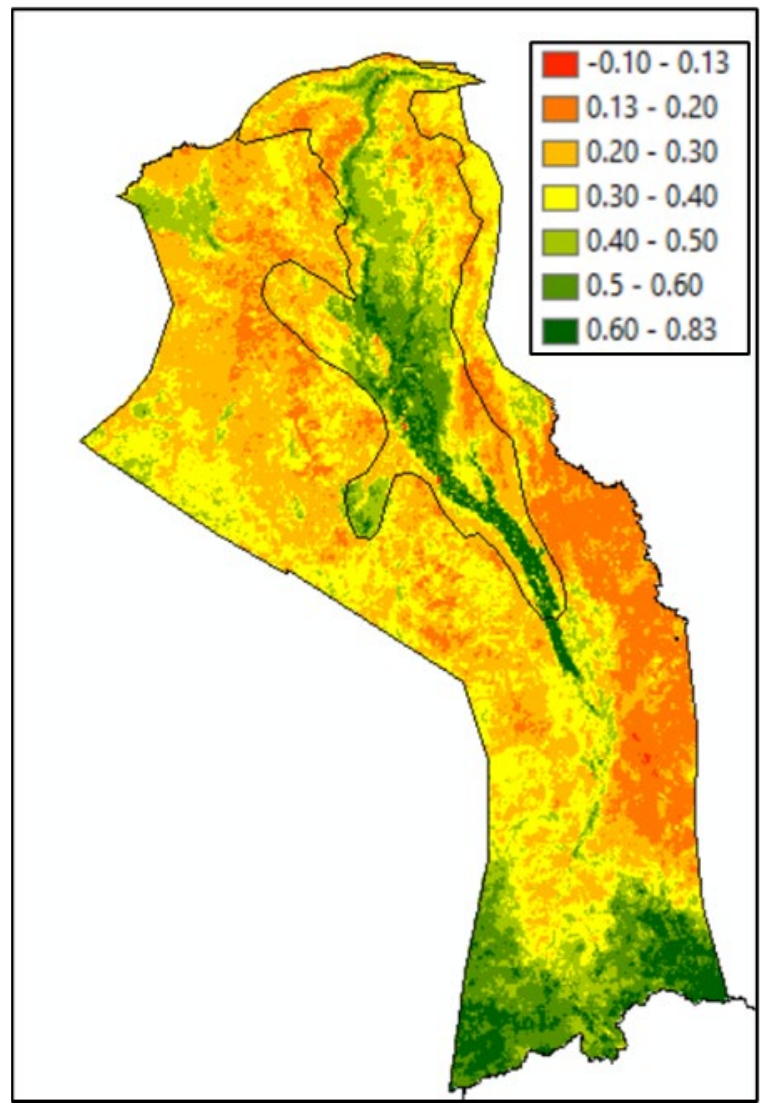

Feb. 2011

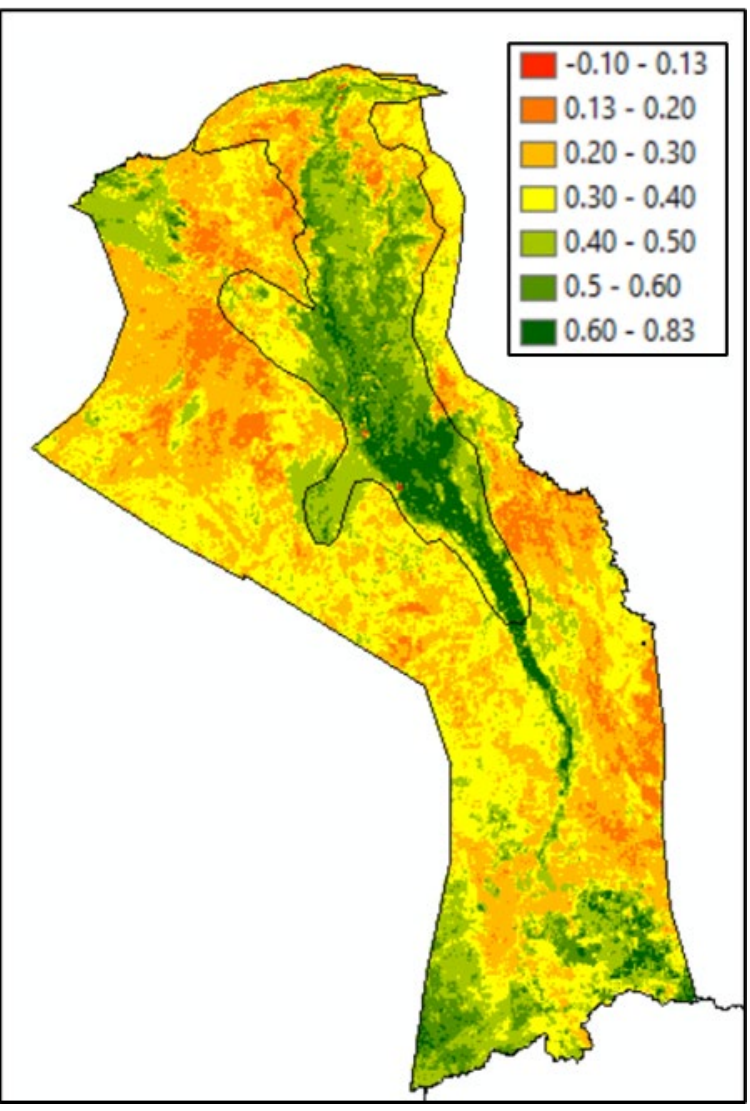

Figure 29. Maps illustrating NDVI for the Sudd and surrounding areas. 


\section{CHAPTER VII: CONCLUSION}

The Sudd Wetland, the largest wetland in Africa, in East Africa is a consistent source of water for the lower Nile River basin and is home to various indigenous people and a vast biota. The Sudd Wetland, although considered a wetland of importance by the Ramsar Convention, has had very few studies conducted on overall and only a handful of in-situ testing. The wetland is under threat of climatic changes that not only effect its inhabitants but the region that rely on its water resources. The Sudd Wetland's climate and vegetation indices and the upstream White Nile River basin's climate were investigated to understand the impact the regional climate may have on the wetland. Publicly available data were used to conduct this study and to understand the role of climate on the hydrologic system.

The studies that were conducted remotely, like this one, relied on satellite imagery and remote sensing. Three questions were devised for this project with the aim at understanding the Sudd's wetland extent and climate change's impact on it.

- The temperature data from 1983-2016 showed an overall increase in average annual and seasonal temperature for the Bahr al-Jabal, LALKs, and LVs. The average increasing rate of temperature shown in this study matches with similar results from other works (Ongoma and Chen, 2017), (Mohamed and Savenije, 2006), (Hulme et al., 2001), and (Gebrechorkos et al., 2019) in the East African region.

- Within each of the sub-basins, there is an overall increase in temperature. Within each of the four seasons, all except OND show an overall increase in temperature. OND shows little-to-no change throughout the study period. 
- The largest increase in temperature in the study basin was seen in the southern portion of the BAJs, the northern part of LALKs, and near the border of BAJs and LALKs (Figure 13). The smallest increase in temperature was seen in the south-central part of LVs - just south of Lake Victoria. There was also a small increase in the northern part of BAJs and the Sudd.

- The rainfall data from 1981-2019 showed an increase in average rainfall annually for LALKs and LVs with little-to-no change of average rainfall in the Bahr al-Jabal.

- The wet seasons of MAM and JJAS saw an increase in LALKs and LVs but no change in the Bahr al-Jabal.

- The dry season of OND showed increasing averages in all three sub-basins, but the dry season of JF saw a decrease in the Bahr al-Jabal and LVs and no change in LALKs.

- The timeseries NDVI for the Sudd Wetland showed increasing trends monthly and seasonally.

- Spatial resolution of NDVI for the Sudd Wetland showed increasing trends monthly and seasonally associated with rainfall.

- The spatial NDVI maps show the average trend for each pixel, while the temporal averages out all those pixel resolutions into one ratio for each year, month, and season.

- The influences of the sub-basins on the Sudd are unique. The entire upstream region from the Sudd supplies constant freshwater into the White Nile River, which then flows into the Sudd. Rainfall upstream impacts the Sudd over time, while temperature within the BAJs and Sudd effect the Sudd almost immediately. Each component this study looked at is important to the overall structure of the Sudd. 
- The average surface water area in the Sudd Wetland has been decreasing from 19842020. Lake Albert (1995-2020) and Lake Victoria (1992-2020) water heights have been increasing most recently, but Lake Kyoga data from 1992-2020 has shown decreasing water heights. However, significant lake height fluctuations were observed in the lake data, which is associated with interannual climate variability and extreme drought occurred in the region.

- Specific recommendations going forward following this study would be to investigate the specific vegetation that is found within the Sudd. Aquatic versus land-based vegetation is affected differently. Understanding the specific classification of plants found in the Sudd could help map out the change in NDVI over time when looking at climate factors. Another component to the White Nile River regime would be to gather and analyze the discharge rates flowing into the Sudd from 1980-2020. Taking into account how the change in water flowing to the wetland could be compared to rainfall rates in the upstream basins as well as surface area water bodies found within the Sudd.

This study helped provide further enlightenment that climate change is and will affect key components of the hydrologic system. The findings of this study will help set aside political and ideological boundaries in order to provide clear and concise water management and policies that will positively affect the East African region. Understanding what the driving forces of climate change are and how present and future natural processes will be affected in specific regions will lead to a promising future.

A key component that could provide more promising answers is the groundwater system in the Sudd. It is believed that the groundwater in the wetland is providing enough freshwater to 
the vegetation to stabilize the wetland extent during dry periods. It was observed that the surface water area in the Sudd was decreasing from 1984 to the present, but the average NDVI from 1981-2019 was increasing. While the average rainfall and temperature showed an increasing trend annually and seasonally for both LALKs and LVs, the average rainfall data for the Bahr alJabal remained the same from 1981-2019. The use of Gravity Recovery and Climate Experiment (GRACE) data would provide information about the groundwater as well as soil moisture content. A future study is recommended to use GRACE data. This would then provide better assistance with understanding the impact climate change has in the East African region, but this could also be extrapolated to other dynamic and important hydrologic systems that require proactive analysis on to help shape water management and policy. 


\section{WORKS CITED}

1. Angel, J. R. \& Kunkel, K. E. The response of Great Lakes water levels to future climate scenarios with an emphasis on Lake Michigan-Huron. J. Great Lakes Res. 36, 51-58 (2010).

2. Barnett, T. P. \& Pierce, D. W. Sustainable water deliveries from the Colorado River in a changing climate. Proc. Natl. Acad. Sci. U. S. A. 106, 7334-7338 (2009).

3. Council on Foreign Relations. Civil War in South Sudan. (2019).

4. DeAngelis, D. L. et al. Landscape modeling for Everglades ecosystem restoration. Ecosystems 1, 64-75 (1998).

5. Gosain, A. K., Rao, S. \& Basuray, D. Climate change impact assessment on hydrology of Indian river basins. Curr. Sci. 90, 346-353 (2006).

6. Gebrechorkos, S. H., Hülsmann, S. \& Bernhofer, C. Long-term trends in rainfall and temperature using high-resolution climate datasets in East Africa. Sci. Rep. 9, 1-9 (2019).

7. Graham, S. Tropical Rainfall Measuring Mission. Earth Observatory: NASA. (1999).

8. Hassan, A., Jin, S., Lake level change and total water discharge in East Africa Rift Valley from satellite-based observations. Global and Planetary Change 117, 79-90. (2019).

9. Hirsch, R. M., Slack, J. R., and Smith, R. A. Techniques of trend analysis for monthly water quality data. Water Resour. Res. 18, 107-121. (1982).

10. Howell, P., M. Lock, and S. Cobb. The Jonglei Canal: Impact and Opportunity. Cambridge Studies in Applied Ecology and Resource Management. Cambridge, UK: Cambridge University Press. (1988) 
11. Hulme, M., R. Doherty, T. Ngara, M. New, D. Lister. African climate change: $1900-2100$. Climate Research 17: 145-168. (2001).

12. Johnson, Nat. Meet ENSO's neighbor, the Indian Ocean Dipole. NOAA: Climate.gov. (2020).

13. Kendall, M. G. Rank Correlation Methods. New York, NY: Oxford University Press. (1975).

14. Koetse, M. J. \& Rietveld, P. The impact of climate change and weather on transport: An overview of empirical findings. Transp. Res. Part D Transp. Environ. 14, 205-221 (2009).

15. Lehman, J. T. Role of climate in the modern condition of Lake Victoria. Theoretical and Applied Climatology, 61(1-2), 29-37. (1998).

16. Mann, H. B. Nonparametric tests against trend. Econometrica 13, 245-259. (1945).

17. Matthews, G. V. T. The Ramsar Convention on Wetlands: its History and Development Ramsar Convention. The Ramsar Convention on Wetlands: history and development (1993).

18. Mohamed, Y. A., Savenije, H. H. G., Bastiaanssen, W. G. M., \& van den Hurk, B. J. J. M. New lessons on the Sudd hydrology learned from remote sensing and climate modeling. Hydrology and Earth System Sciences, 10, 507e518. (2006).

19. Mohamed, Y. A., Van Den Hurk, B. J. J. M., Savenije, H. H. G. \& Bastiaanssen, W. G. M. Impact of the Sudd wetland on the Nile hydroclimatology. Water Resour. Res. 41, 1-14 (2005). 
20. Mortsch, L., Hengeveld, H., Lister, M., Lofgren, B., Quinn, F., Slivitzky, M., Wenger, L. Climate change impacts on the hydrology of the great lakes-st. Lawrence system. Can. Water Resour. J. 25, 153-179 (2000).

21. NASA.gov, Global Climate Change: Vital Signs of the Planet. (2020).

22. Palacios-Orueta, A., Khanna, S., Litago, J., Whiting, M. L. \& Ustin, S. L. Assessment of NDVI and NDWI spectral indices using MODIS time series analysis and development of a new spectral index based on MODIS shortwave infrared bands. Proc. 1st Int. Conf. Remote Sens. Geoinf. Process. 1-8. (2006).

23. Parmesan, C. \& Yohe, G. A globally coherent fingerprint of climate change. Nature 421, $37-$ 42 (2003).

24. Petersen, G. The Hydrology of the Sudd Hydrologic Investigation and Evaluation of Water Balances in the Sudd Swamps of Southern Sudan. Thesis 107 (2008).

25. Nguvava, M., Abiodun, B. J. \& Otieno, F. Projecting drought characteristics over East African basins at specific global warming levels. Atmos. Res. 228, 41-54 (2019).

26. Rebelo, L.-M. \& El-Moghraby, A. I. The Sudd (South Sudan). Wetl. B. 1-8 (2016).

27. Seyoum, W. M. Characterizing water storage trends and regional climate influence using GRACE observation and satellite altimetry data in the Upper Blue Nile River Basin. Journal of Hydrology, 566 (September), 274-284. (2018).

28. Seyoum, W. M., Milewski, A. M. \& Durham, M. C. Understanding the relative impacts of natural processes and human activities on the hydrology of the Central Rift Valley lakes, East Africa. Hydrol. Process. 29, 4312-4324 (2015). 
29. Serdeczny, O., Adams, S., Baarsch, F., Coumou, D., Robinson, A., Hare, W., Schaeffer, M., Perrette, M., Reinhardt, J. Climate change impacts in Sub-Saharan Africa: from physical changes to their social repercussions. Reg. Environ. Chang. 17, 1585-1600 (2017).

30. Sharma, S., Blagrave, K., Magnuson, J.J., O’Reilly, C., Oliver, S., Batt, R. D., Magee, M. R., Straile, D., Weyhenmeyer, G. A., Winslow, L., Woolway, R. I. Widespread loss of lake ice around the Northern Hemisphere in a warming world. Nat. Clim. Chang. 9, 227-231 (2019).

31. Smith, R. \& Berry, P. Contribution to wetland monitoring of multi-mission satellite radar altimetry. North 3-7. (2007).

32. Sutcliffe, J. V. \& Parks, Y. P. The hydrology of the Nile. Hydrol. Nile. IAHS Spec. Publ. No.5. 5, (1999).

33. Thome, K. MODIS: TERRA The EOS Flagship. NASA. (2020).

34. USGS.gov, USGS EROS Archive - Advanced Very High Resolution Radiometer (AVHRR) - Sensor Characteristics. (2020).

35. Yu, Y. S., Zou, S., \& Whittemore, D. Non-parametric trend analysis of water quality data of rivers in Kansas. Journal of Hydrology, 150(1), 61-80. (1993).

36. Wang, C., Jia, M., Chen, N., \& Wang, W. Long-term surface water dynamics analysis based on landsat imagery and the Google Earth Engine Platform: A case study in the middle Yangtze River Basin. Remote Sensing, 10(10). (2018).

37. Williams, K., Chamberlain, J., Buontempo, C., \& Bain, C. Regional climate model performance in the Lake Victoria basin. Climate Dynamics, 44(5-6), 1699-1713. (2015). 
38. Wolff, C., Haug, G. H., Timmermann, A., Sinninghe Damste, J. S., Brauer, A., Sigman, D. M., Cane, M. A., \& Verschuren, D. Reduced Interannual Rainfall Variability in East Africa During the Last Ice Age. Science, 333(August), 743-748. (2011). 


\section{APPENDIX A: RAINFALL GRAPHS}

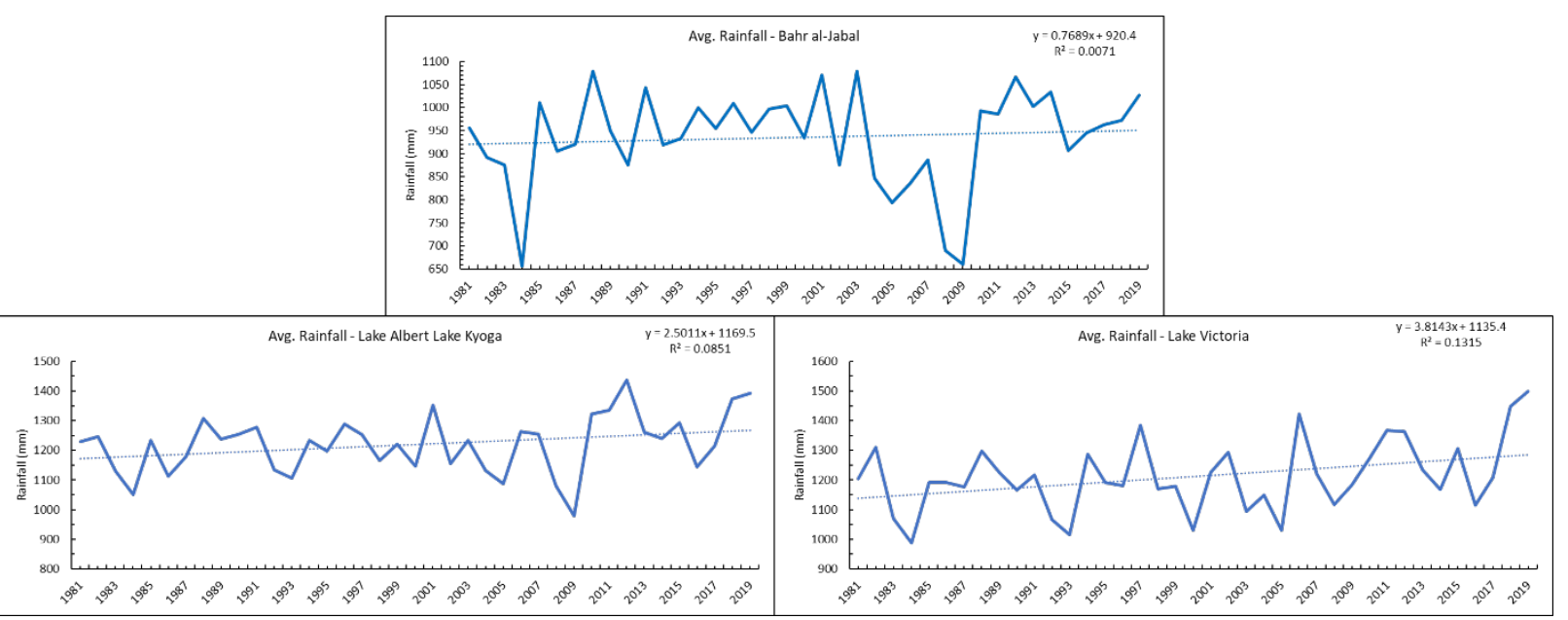

Figure A-1. Annual average rainfall data for each sub-basin.

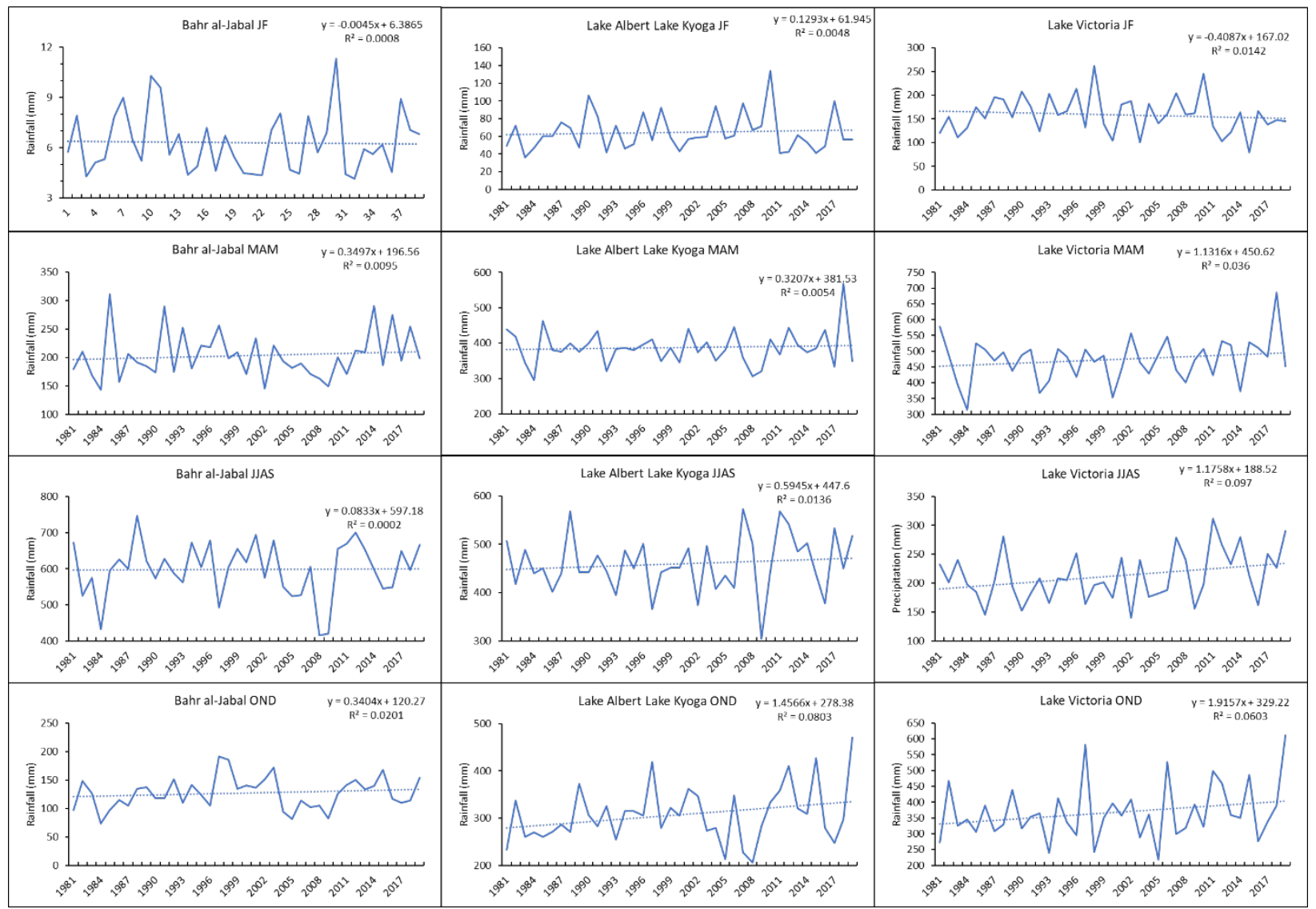

Figure A-2. Seasonal average rainfall data for each sub-basin. 
APPENDIX B: NDWI DATA

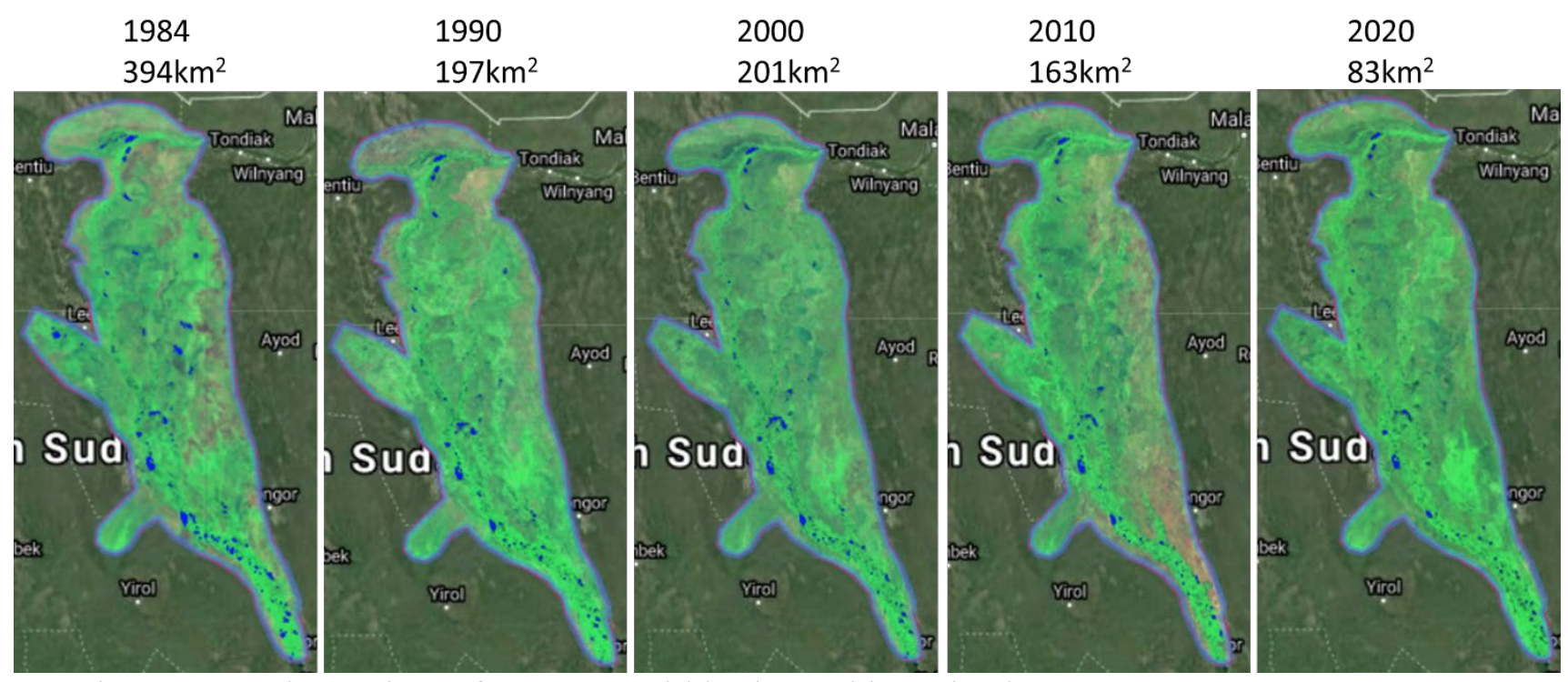

Figure B-1. Change in surface water within the Sudd Wetland. 


\section{APPENDIX C: NDVI P-VALUE DATA}

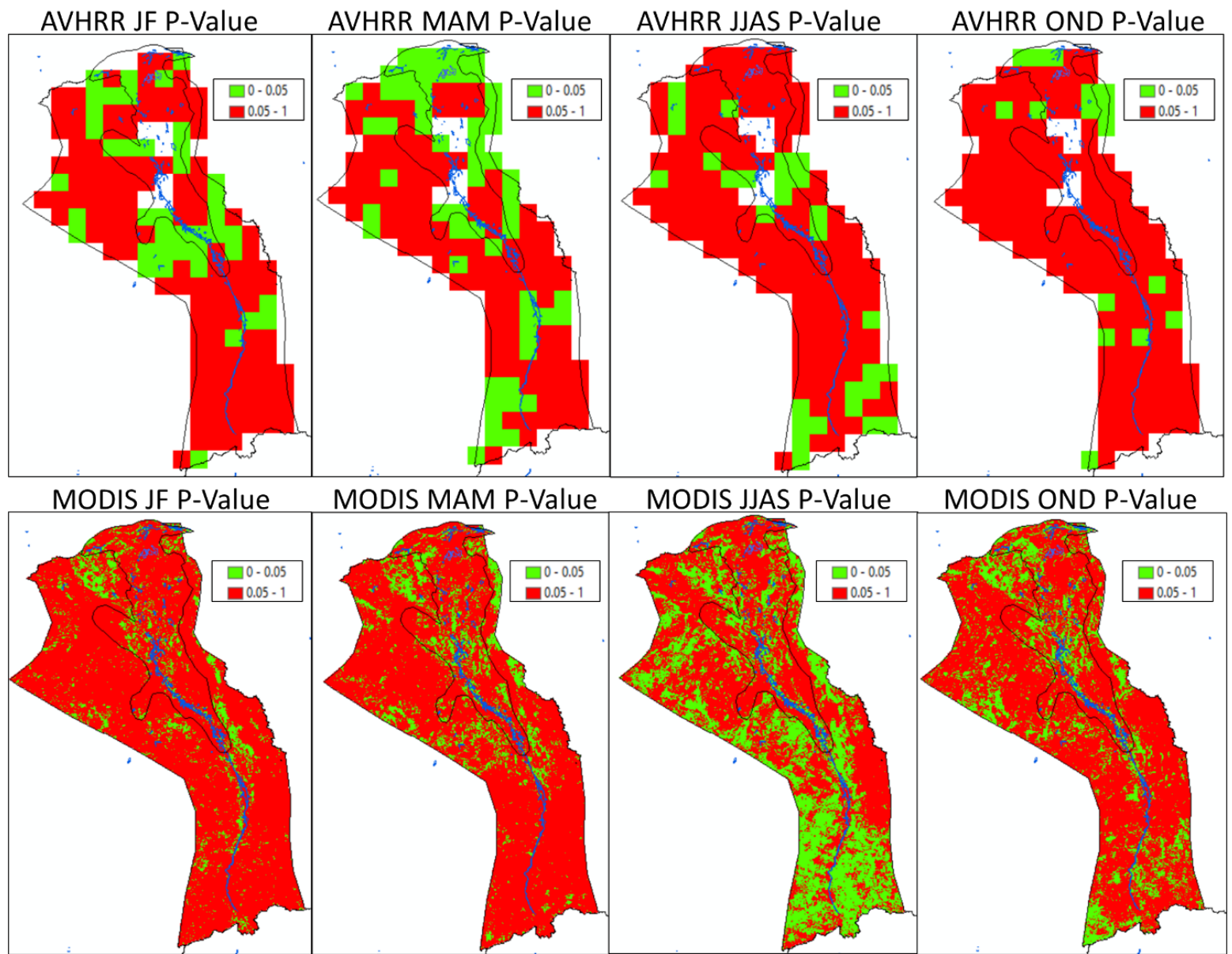

Figure C-1. Significance maps for the NDVI data. (White boxes found in the Sudd in AVHRR indicate missing values). 


\section{APPENDIX D: TEMPERATURE AND RAINFALL P-VALUE DATA}

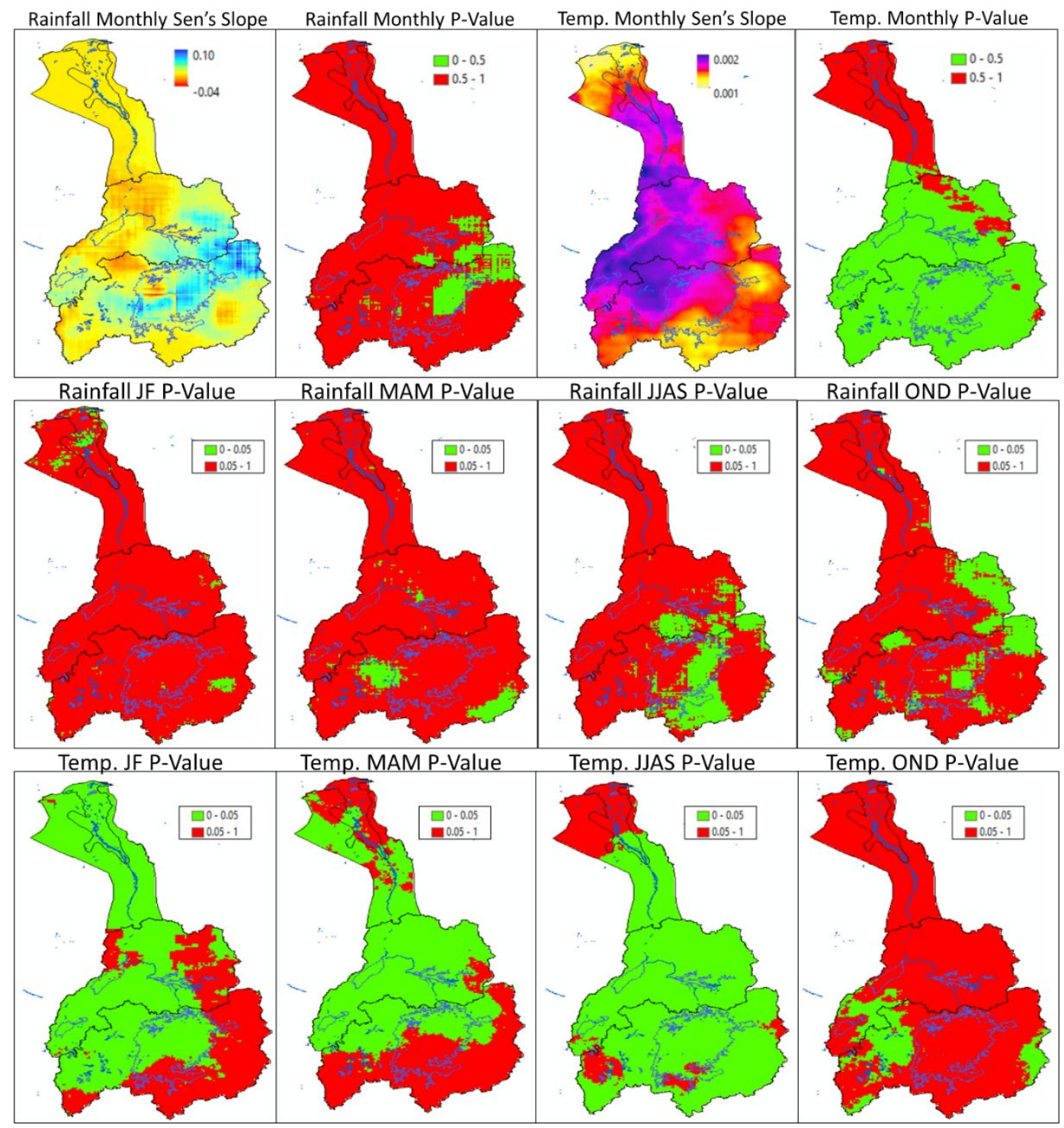

Figure D-2. Significance maps for rainfall and temperature monthly and seasonal data and monthly Sen's slope. 


\section{APPENDIX E: RAINFALL DATA}
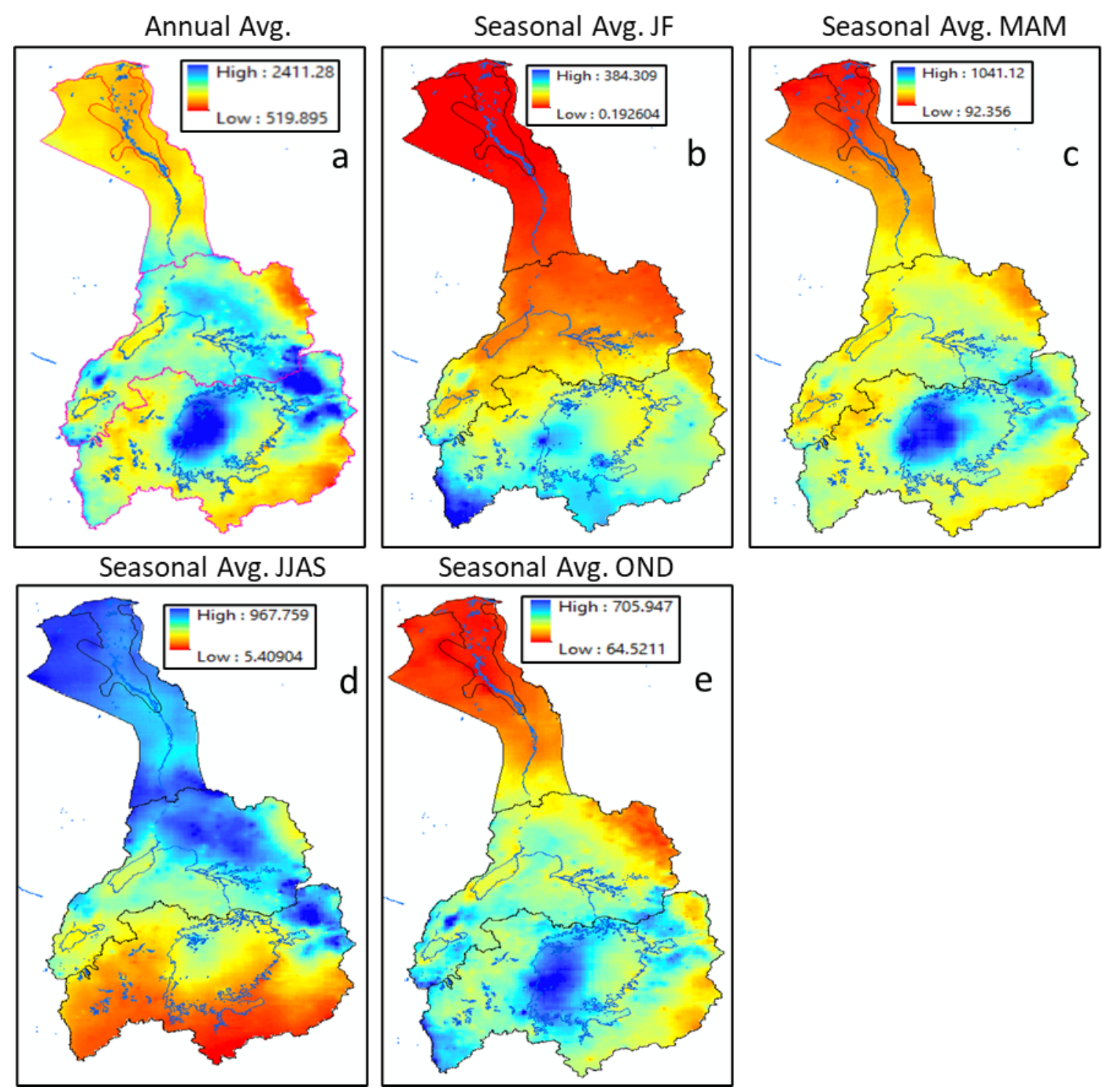

Seasonal Avg. OND

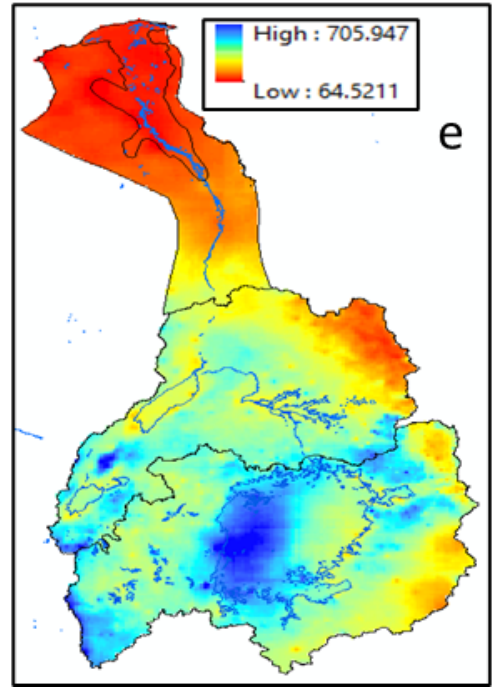

Figure 1-E. Annual and seasonal average rainfall data of the study area. 


\section{APPENDIX F: TEMPERATURE DATA}

Annual Avg.

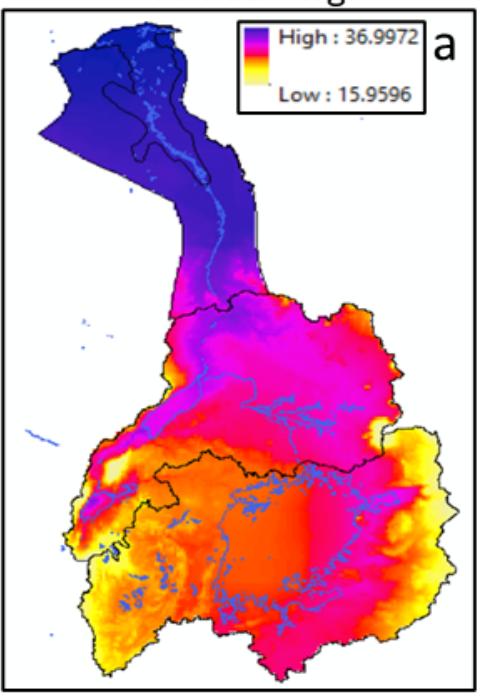

Seasonal Avg. MAM
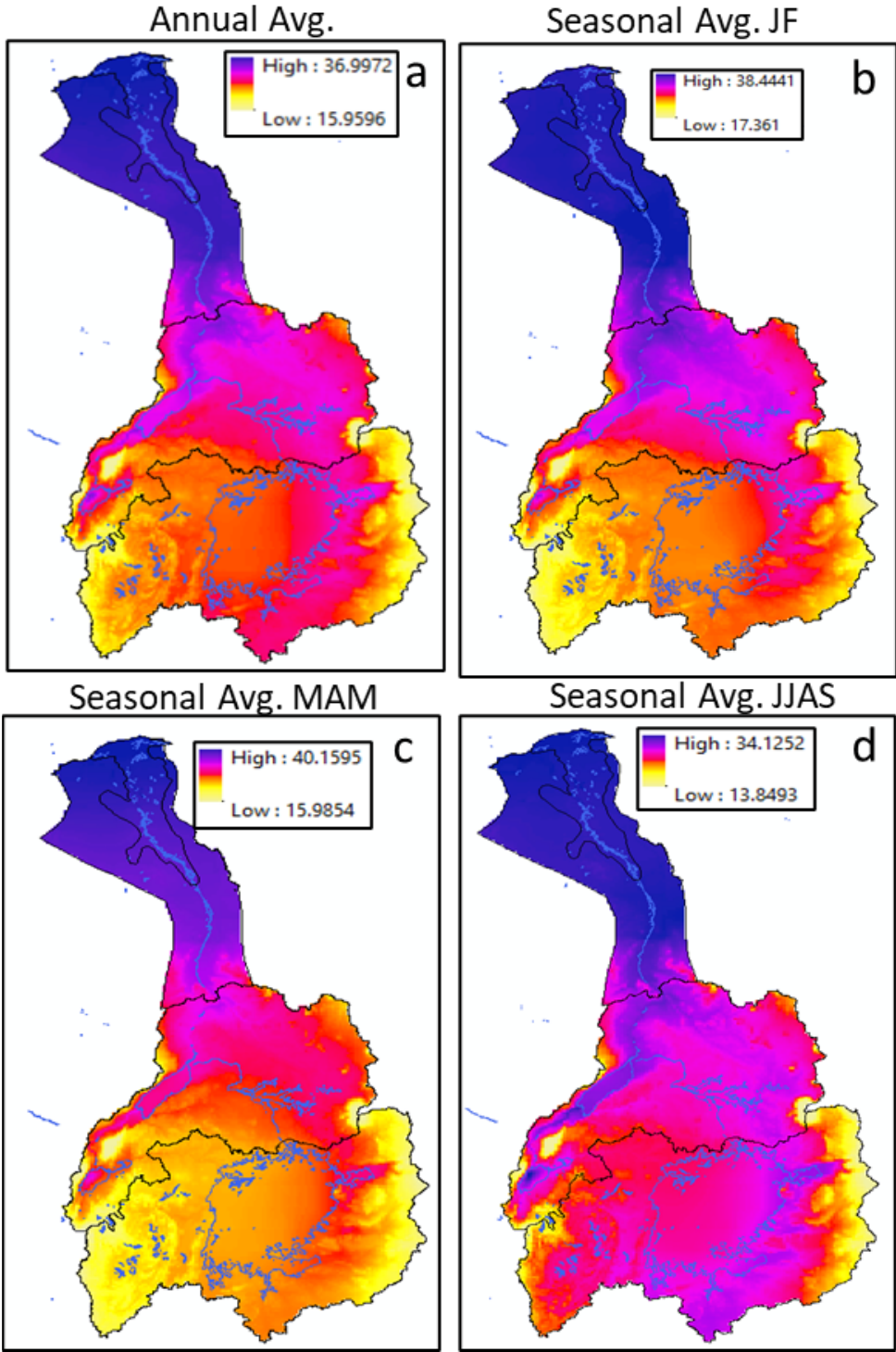

Seasonal Avg. JJAS

Seasonal Avg. OND
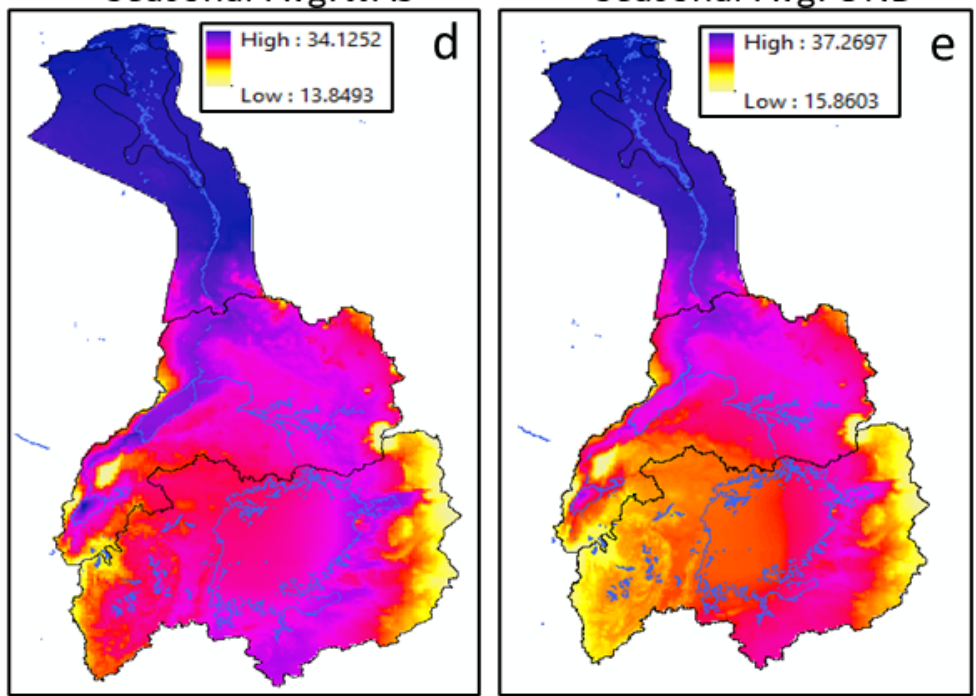

Figure 1-F. Annual and seasonal average temperature data of the study area. 